Too See and Be Seen: Indigenous Theories of Knowledge of Racism and its Mediation - The Experience of Nehiyaw/Cree Youth and Their Community

by

\title{
Davina Rousell
}

A thesis submitted to the Faculty of Graduate and Postdoctoral Affairs in partial fulfillment of the requirements for the degree of

\section{Doctor of Philosophy}

in

Sociology

\section{Carleton University \\ Ottawa, Ontario}

(C) 2018

Meskanahk Ka Nipa Wit School, Maskwacis, Alberta \& Davina Rousell ${ }^{1}$

\footnotetext{
${ }^{1}$ I included the Meskanahk Ka Nipa Wit School to honour and respect that this thesis emerged from a collaborative effort and to challenge the notion that knowledge can be owned. However, this does not negate that any errors or omissions are my responsibility.
} 


\begin{abstract}
Racism is a social construct that has had significant and negative impacts on Indigenous peoples across Canada. These effects are evident in the Indigenous and nonIndigenous health, education, and income gaps (Bourassa, McKay-McNabb \& Hampton, 2004; King \& Gracey, 2009; King, Smith, \& Gracey, 2009; Royal Commission on Aboriginal Peoples, 1996). The study of racial prejudice and its mediation are informed by Western theories of knowledge so strongly that other ways of knowing such as Indigenous theories of knowledge are marginalized. How might the inclusion of Indigenous theories and knowledge impact experiences of racism? This research study examines this question. It interweaves a theoretical framework of decolonization and Indigenous knowledge with Grounded Theory Methodologies and Indigenous Methodologies to examine a cohort of 21 Indigenous students' lived experience with a school program, the Photography Class, designed to mediate students' experience of racism. This program was of particular interest because it utilized a combination of oral teachings and photography to provide students with a more accurate, positive, and more complete understanding of what it means to be Nehiyaw/Cree and to mediate racist narratives circulated through mainstream media. This study documents how the Nehiyaw/Cree practice termed Kisewatotatowin/awakening Kiskisohkemowin/remembering was mobilized through the Photography Class. Specifically, the research findings illustrate how Canada's colonial legacy of racism and its learned practice of hate can be redressed by: (1) awakening and reminding the students of their inherent love for themselves, their family, community, and all beings (human and non-human) and (2) fostering space for the students to create a more accurate, positive,
\end{abstract}


and complete narrative about who they are. The data analysis presented from those findings contribute to the study of racial prejudice through the documentation of a mediation process for racism grounded in Indigenous theories of knowledge, Nehiyaw/Cree in particular. More important, it provides insight into what constitutes racism from an Nehiyaw/Cree worldview and how an integration of Indigenous knowledge and practices extend Western theories of racial prejudice and its mediation. Keywords: Indigenous theories of knowledge, racial prejudice, mediation, storytelling, decolonization 


\section{Acknowledgements}

Over the 6 years that it took to complete this thesis I have come to appreciate how incredibly important the people around me are in my ability to stay grounded in what matters and do things in a good way. With this in mind I would like to take this opportunity to thank the people who helped to keep me moving forward with a good heart and mind and acknowledge that this research study took place on Treaty 6 Territory.

I would like to thank the love of my life, my wife Maddalena, for your love, encouragement, and patience that was tested many times and in many ways. I can now get started on that 6-year long honey-to-do-list! I would like to thank my mom for your never ending support and belief in me and this project. I would like to thank Elder D. M. who I had the honour of being adopted by during this project. I cannot overstate how grateful I am for your support, wisdom, love, and kindness. Without it, this project simply would not have been possible. I would also like to thank S. H., Elder E. B., and all of the students, school personnel, and community members that contributed to this project. As with Elder D. M., without all of you this project would not have been possible. I would like to thank my supervisor, Dr. Katharine Kelly, for her continued support and ability to help me find a path forward. You were pivotal in helping me to find a way to express concepts and ideas that are not easily communicated within an academia space that continues to be dominated by Western theories of knowledge. Finally, but not least, thank you to Dr. Karen March, Dr. Sean Lessard, Dr. Tullio Caputo, and Dr. Michael Wohl for your time, invaluable feedback and insights, and support at different points throughout this project. 
A project like this is truly relational and is not possible with any one individual but rather is the result of the effort, time, and wisdom of many people, hai hai. All my relations. 


\section{Table of Contents}

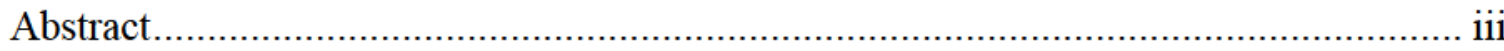

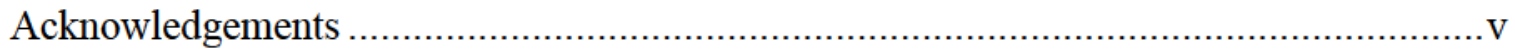

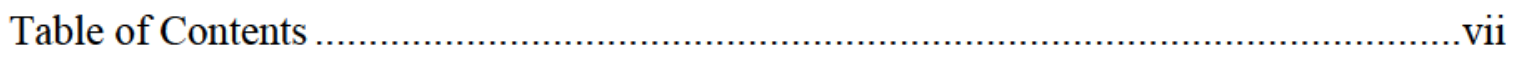

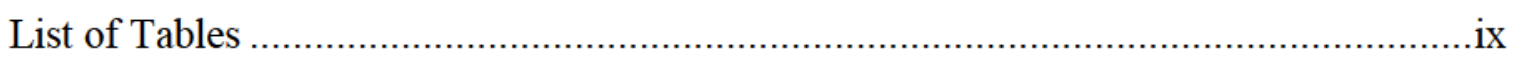

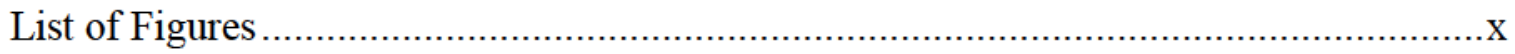

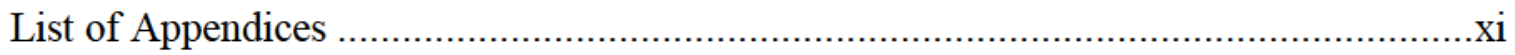

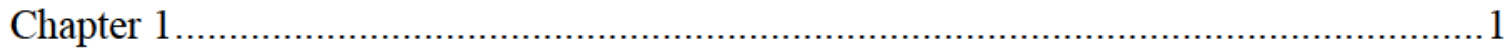

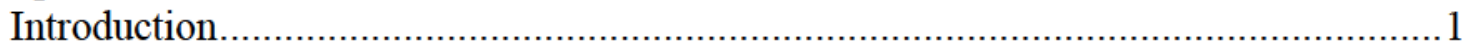

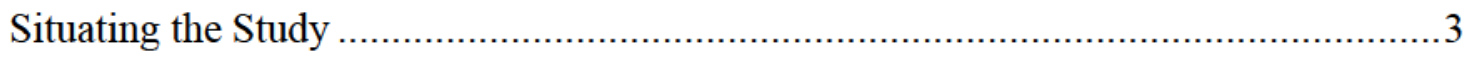

From entering the field to working in relationship............................................6

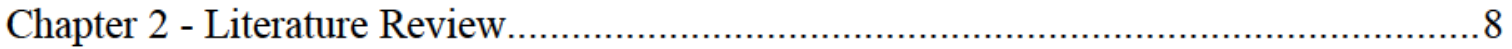

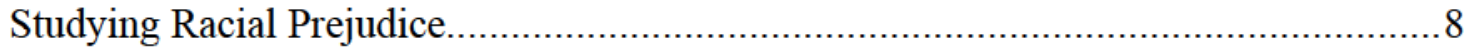

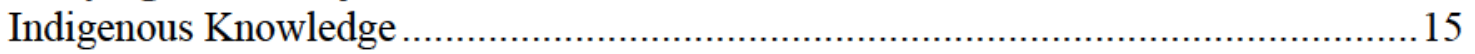

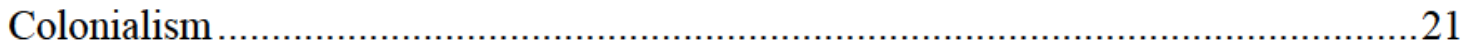

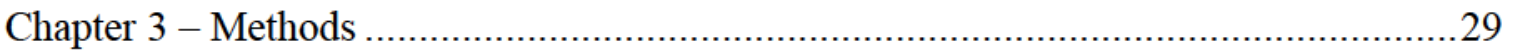

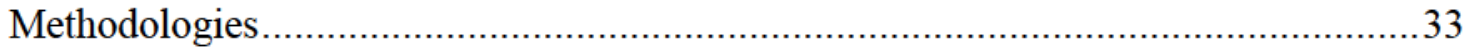

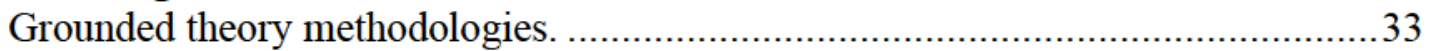

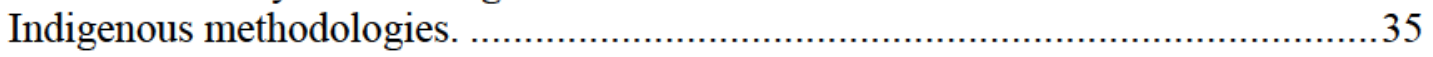

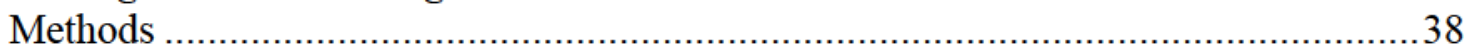

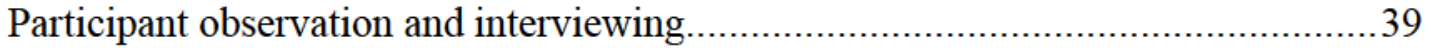

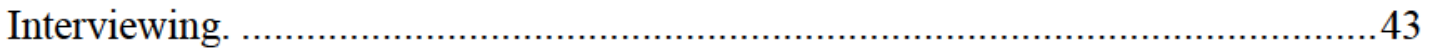

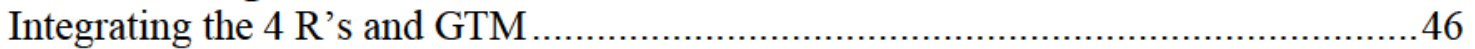

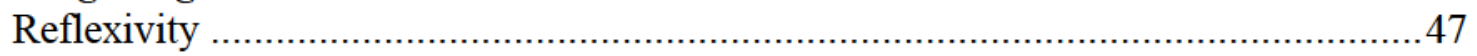

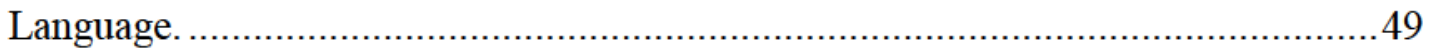

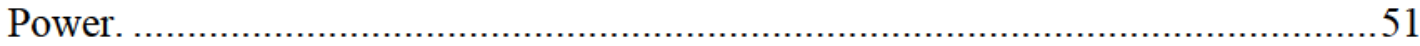

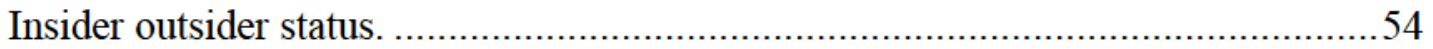

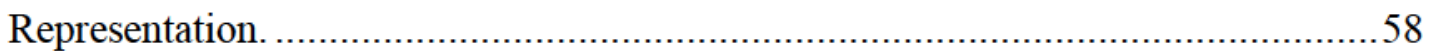

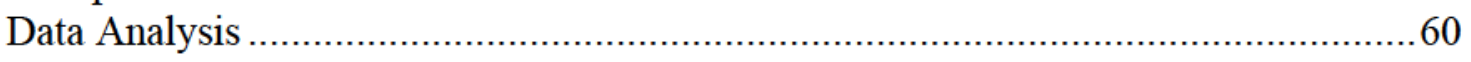

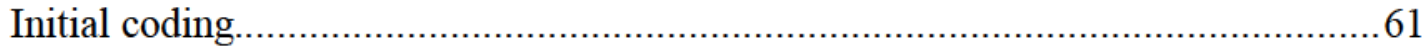

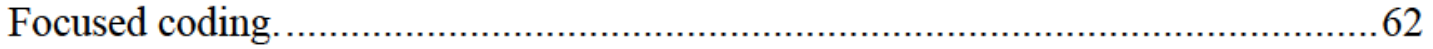

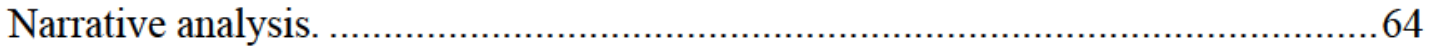

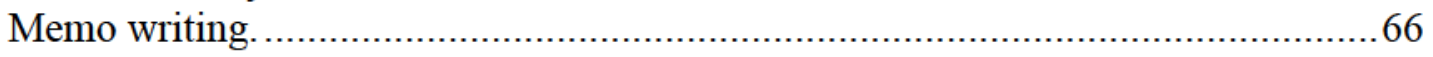

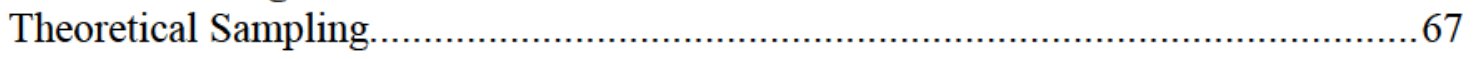

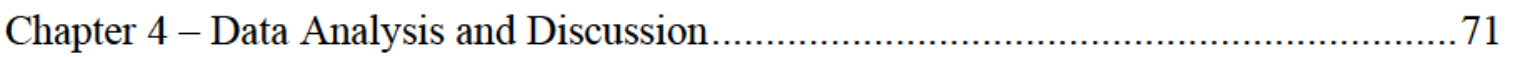

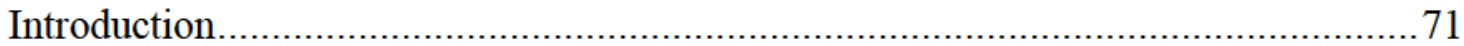

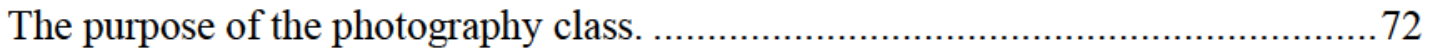

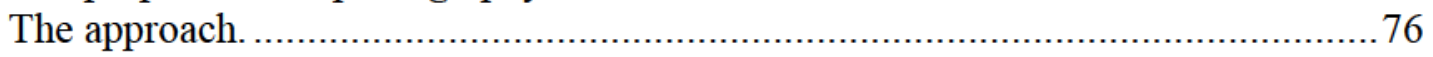

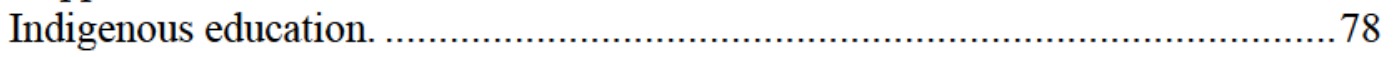

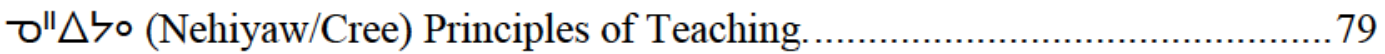

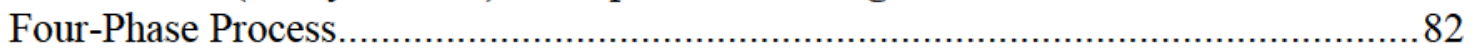




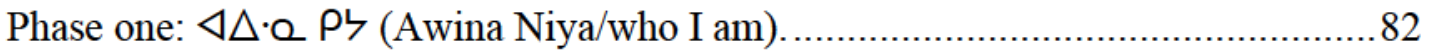

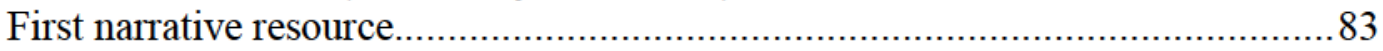

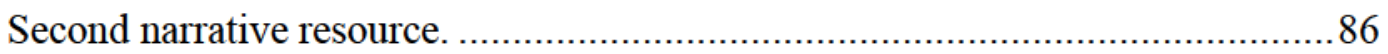

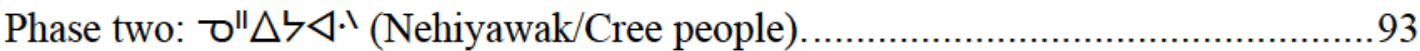

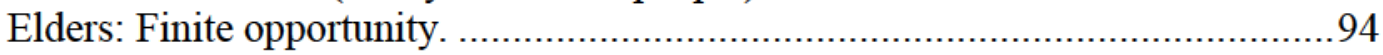

Third narrative resource . ..................................................................... 96

Fourth narrative resource. ................................................................... 99

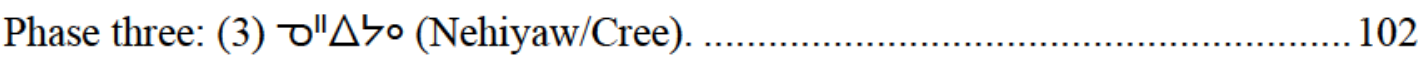

Practicing: First activity..................................................................... 104

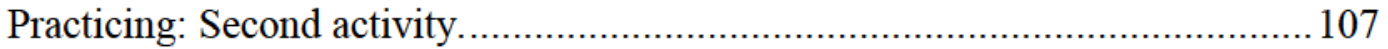

Identifying the over arching narrative ....................................................... 110

Developing individual narratives....................................................... 114

Phase four: $\nmid \rho^{\|} \Delta \supset \Delta^{. \supset}$ (Sakihitowin/love and kindness). ................................ 123

Practicing $\nmid \rho \| \Delta \supset \Delta^{\circ} \cdot$ (Sakihitowin/love and kindness) and courage. ................. 123

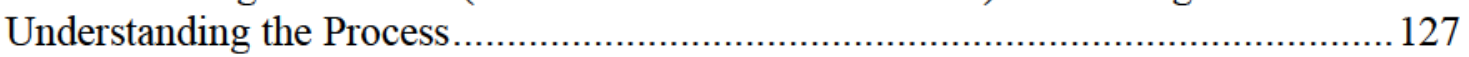

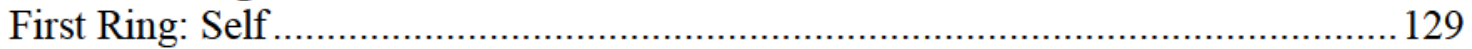

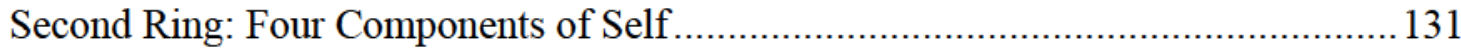

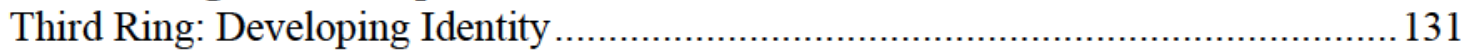

Fourth Ring: Widening the Circle of Practice ............................................. 134

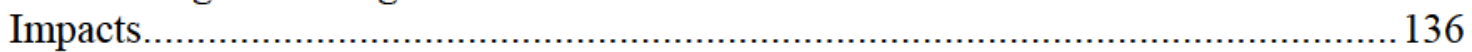

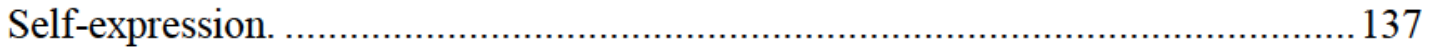

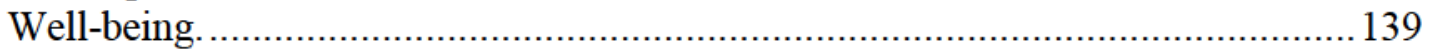

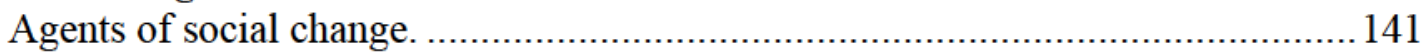

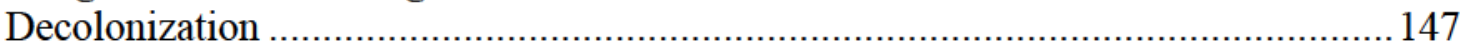

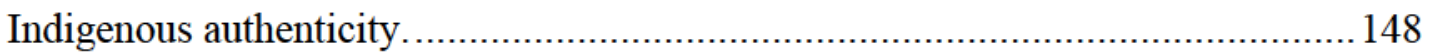

Impact in immediate past, present and future. ............................................. 148

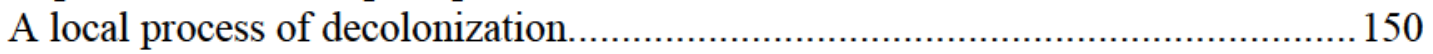

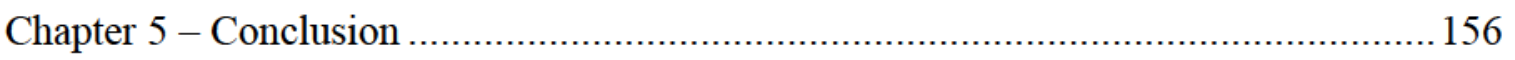

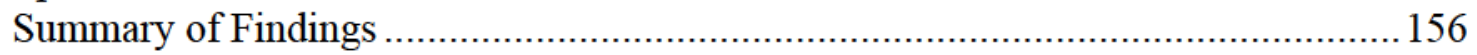

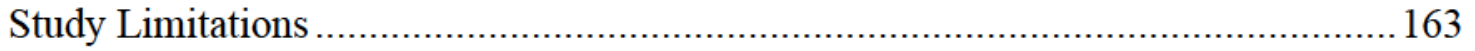

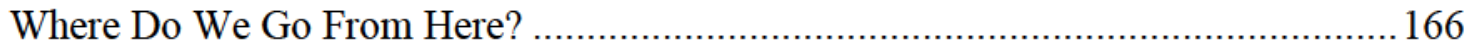

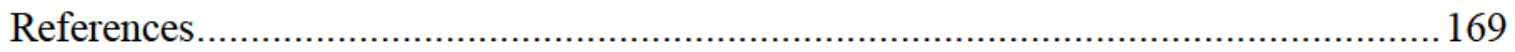




\section{List of Tables}

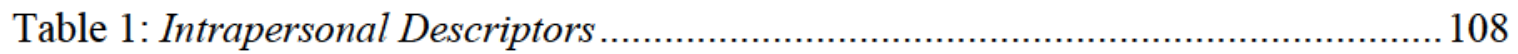

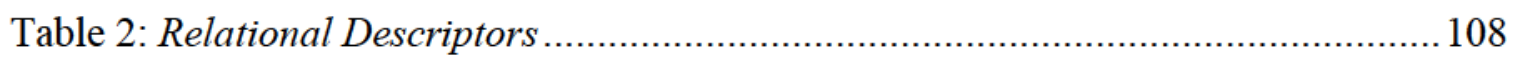

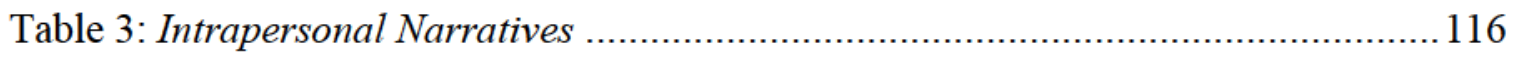

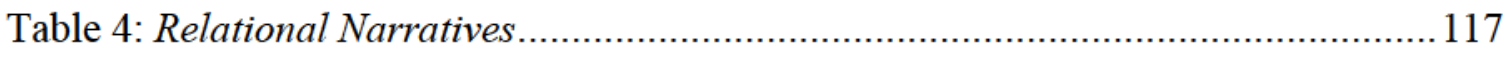




\section{List of Figures}

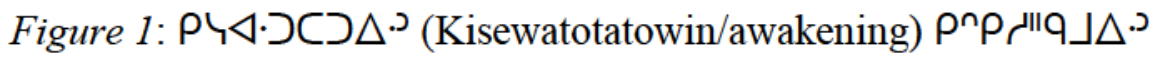

(Kiskisohkemowin/reminding)

Figure 2: Lebret Residential Petroglyphs exhibit ..................................................... 143

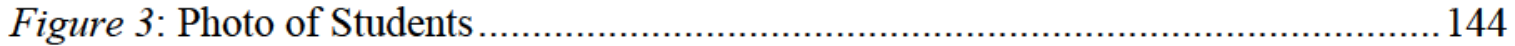




\section{List of Appendices}

Appendix A STUDENT INFORMATION LETTER \& WRITTEN ASSENT 187

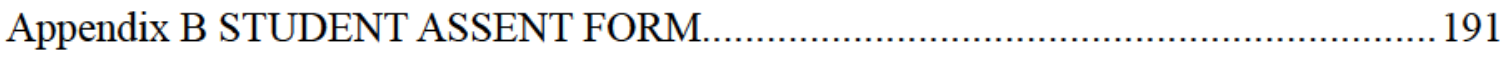

Appendix C STUDENT INFORMATION LETTER \& ASSENT SCRIPT ................... 193

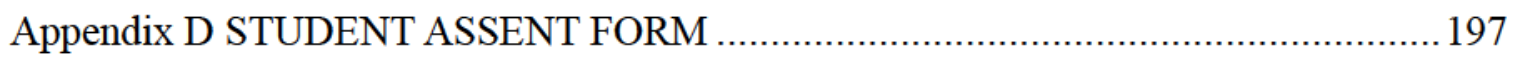

Appendix E PARENT/CAREGIVER INFORMATION \& WRITTEN CONSENT FORM

Appendix F PARENT/CAREGIVER CONSENT FORM …..................................203

Appendix G PARENT/CAREGIVER INFORMATION \& WRITTEN CONSENT

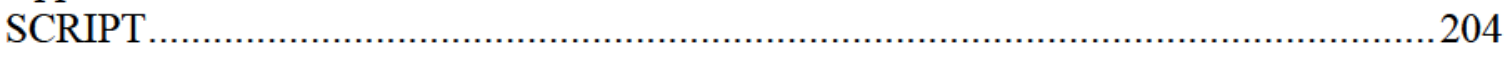

Appendix H PARENT/CAREGIVER CONSENT FORM........................................2208

Appendix I SCHOOL STAFF INFORMATION LETTER \& WRITTEN CONSENT .210

Appendix J SCHOOL STAFF WRITTEN CONSENT FORM …………....................213

Appendix K SCHOOL STAFF INFORMATION LETTER \& VERBAL CONSENT.. 214

Appendix L SCHOOL STAFF VERBAL CONSENT FORM ………........................217

Appendix M Research Assistant and Confidentiality Agreement ................................219

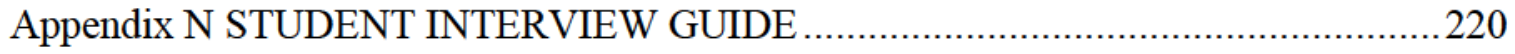

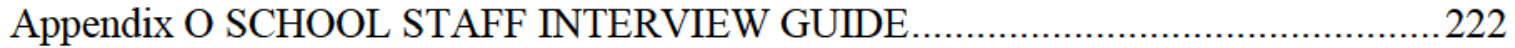

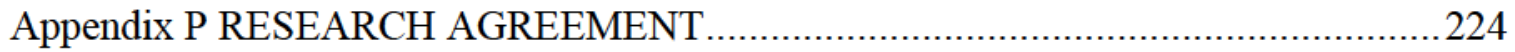




\section{Chapter 1}

\section{Introduction}

Canada has had a long history of racism at both individual and state levels. Recognition of the country's participation in racist activities led the Government of Canada to develop a national framework aimed at addressing racism in 2005. This initiative was outlined in a document entitled Canada's Action Plan Against Racism (Government of Canada, 2005). That document described how Canada would implement an anti-racism strategy that acknowledged the need to address racial prejudice targeting minority groups including Indigenous peoples ${ }^{2}$. The election of the Conservative Government of Canada in 2006 led to a refocus on the development of social inclusion and economic opportunities for minorities instead of anti-racism initiatives (Government of Canada, 2011). As a result, Canada's first and only attempt to address racism ${ }^{3}$ on a national scale was replaced with an initiative that aimed at fostering employability. It was not until 9 years later, with the conclusion of Canada's Truth and Reconciliation Commission, that the issue of racism again caught the nation's and Government's attention.

The Truth and Reconciliation Commission examined Canada's colonial legacy with a particular focus on the Indian Residential School System; the Commission's work culminated in the release of a final report entitled Honouring the Truth, Reconciling for the Future (Truth and Reconciliation Commission of Canada, 2015). A common thread

\footnotetext{
${ }^{2}$ Indigenous peoples is utilized throughout the remainder of the paper to recognize that Indigenous peoples were the first stewards of Turtle Island, otherwise known as Canada, and to recognize that this term respectfully reflects the diversity amongst the First Nations, Inuit, and Metis peoples who continue to live across Turtle Island. However, in some sections of the paper the terms Indian and Aboriginal are used in quotes or titles of documents to refer to Indigenous peoples.

${ }^{3}$ According to the American Psychological Association (2015) the terms racism and racial prejudice refer to the same phenomenon and as such as used interchangeably through this paper.
} 
that runs throughout this six-volume report is the need to address systemic racism at all levels (micro, meso, and marco) of Canadian society (Truth and Reconciliation Commission of Canada, 2015). Moving this initiative forward means avoiding the mistakes of the nation's colonial past, especially the failure of mainstream individuals and agencies to recognize and value Indigenous theories of knowledge and worldviews which are critical for eliminating systemic racism. I use the terms "worldview" and "theories of knowledge" throughout the thesis because both terms refer to assumptions that a culture uses to understand the world and to make sense of day-to-day experiences (Little Bear, 2000). I believe it is only by examining and understanding Indigenous theories of knowledge and practices culturally and appropriately that we can redress racism between Canada's Indigenous and non-Indigenous peoples effectively.

With the above objectives in mind, this study (1) identifies and examines the meaning of racism from an Indigenous and, in particular, Nehiyaw ${ }^{4} / \mathrm{Cree}$ worldview, (2) identifies and examines how Western and Nehiyaw/Cree worldviews of racism are similar and unique from one another, and (3) identifies and examines how the mediation of racism from an Nehiyaw/Cree worldview offers a valuable/essential and culturally appropriate tool for mediating racism and the impact of racism on Indigenous peoples. To achieve these goals, I describe an ethnographic study of a cohort of 21 First Nation students and their lived experience with a community-based and community-driven school program designed to redress racism. The program was delivered through a course,

\footnotetext{
${ }^{4}$ Nehiyaw is the Cree word for Cree and will be used throughout the remainder of this paper in order to recognize, value, and respect the language of the First Nation community.
} 
the Photography Class, offered at a First Nation's community school ${ }^{5}$ in central Alberta. Critical to this study was my ability to learn from and with the community, their experiences, perspectives, and understandings. This meant decentering my preconceived western theories of knowledge and centering and privileging the community's theories of knowledge and lived experience.

\section{Situating the Study}

The 2015-2016 Photography Class was offered at a Nehiyaw/Cree First Nation ${ }^{6}$ community school. The community was geographically located in Treaty 6 territory and approximately 90 kilometers south of Edmonton, Alberta. According to the Government of Alberta (2017), this Nehiyaw/Cree First Nation had a population of 1,021 with 689 members (68\%) living on reserve and 332 members (32\%) residing off reserve. The Photography Class was offered through the community's local school which was operated and overseen by the Chief and Council. Each year the school provided education to approximately 150 students enrolled in kindergarten to Grade 9. The Photography Class was a unique program. The program was developed in response to the negative media coverage that the community received. In particular, the media had and continued to portray the community and its residents as violent gang members engaged in continual turf wars. For example, the dominant narrative in mainstream media depicts the students' community as being "plagued by violence and trigger-happy gang members, much has been done in an attempt to pull the community out of its

\footnotetext{
${ }^{5}$ In order to protect the anonymity and confidentiality of research participants I have used a generic term (Photography $\mathrm{Club}$ ) to refer to the school program and not specified the name of the community or the school where the Photography $C l u b$ was being offered.

${ }^{6}$ In order to protect and anonymity and confidentiality of the research participants I do not identify the specific Nehiyaw/Cree First Nation that this research study was conducted with and instead refer to the community as a Nehiyaw/Cree First Nation.
} 
persisting downward spiral" (September 6, 2011, Toronto Sun, para. 1). Gangs had been present in the community since oil and gas revenues started to flow in the $1970 \mathrm{~s}$ and 1980s. However, as is common in most communities with gang activity, the majority of community members were not involved with gangs or gang-related activities. Yet, this image continued to take precedence in the media. Additionally, while the media provided this narrow and negative understanding of the community, little, if any, understanding was present in their accounts of how colonial policies/practices had and continued to affect the people and their community. Specifically, the media conveyed nothing about who the community members were as First Nation and Nehiyaw/Cree people.

In 2010, 21 students decided to take action to challenge this negative and simplistic portrayal of their community. With the help of the school counselor and community Elders, they began to take photos of themselves, their families, and community and use these images to create their own narrative through the publication of a book. The book resulted in a visual story about the students, their families, and their community from their own perspective. In subsequent years, new cohorts of students continued this process through the Photography Class.

Since 2010, with the exception of the 2014-2015 school year ${ }^{7}$, the Photography Class published a book that challenged the mainstream media's dominant and negative narrative about who they are. Implementation of this goal required the following steps: (1) identify a narrative in the mainstream media about their community that is inaccurate, (2) independently take photos that they wanted to use to compose a more accurate

\footnotetext{
${ }^{7}$ There was a loss in the community that impeded the Photography Class from taking place during the 2014-2015 school year.
} 
narrative, (3) meet as a group to decide which of their photos would be used to compile a more accurate narrative, and (4) assemble the photos with written statements to present a narrative that is published and made available to a wider audience through a book launch held in a nearby urban center ${ }^{8}$. Although these four steps were consistent over the duration of the Photography Class, what was unique about the 2015-2016 book was how each of the four steps were predominantly guided by one of the school Elders, D. M. ${ }^{9}$

In previous years, the Photography Class had Elders involved in different aspects of the class, especially as honorary guests at the book launches. In 2015-2016, the extent of Elders' involvement took on a more participatory role. For example, once students agreed that their 2015-2016 book would provide a counter narrative to racist narratives perpetuated in mainstream media, the coordinator, S. H., consulted with Elder D. M. to ask for guidance regarding how the class should unfold in relation to the chosen topic. In response, Elder D. M. advised that the students interview different community Elders to learn about the seven Sacred Teachings. These teachings are discussed in more detail in a later section of this thesis. For now, it is important to note that by seeking out and following the guidance of Elder D. M., the Photography Class unfolded in a way that was community-based and driven by and for the community. In support of this community approach, Elder D. M. attended all the classes except one in order to provide continual guidance and encouragement to the students and the coordinator.

In 2016, keeping the Truth and Reconciliation Commission's goal of addressing racism in mind, the youth sought to use their photos to weave together a visual story

\footnotetext{
${ }^{8}$ To ensure confidentiality and anonymity of research participants I do not identify the city where students have and continue to hold their book launch. Instead I refer to this city as an urban center.

9 To ensure the confidentiality and anonymity of research participants I use initials to refer to Elders and all research participants.
} 
about racism and how it might be mediated from a Nehiyaw/Cree worldview perspective. Racism is of particular importance in this community because, collectively, the community and its neighboring First Nation communities have one of the largest populations of Indian Residential School survivors in Canada. As a result, many residents are living with the consequences of Canada's colonial legacy, including systemic poverty, intergenerational trauma, and lateral violence. Yet despite these negative impacts and their colonizers' attempts to systematically assimilate their community to Western culture, many of the Elders, adult, and youth in this community have continued to be knowledge holders of Nehiyaw/Cree ways of knowing, being, and doing.

From entering the field to working in relationship. From 2008 to 2012, I worked as a Program Evaluator at the University of Alberta. During this time period I supervised the evaluation of a youth program ${ }^{10}$ in seven schools across the four First Nation communities and I had the opportunity to develop meaningful relationships with different school personnel and community members (youth, parents/caregivers, Elders). One of these four communities is the one that I worked in partnership with during this research study. In addition, building upon the relationships that I developed while evaluating the program, in 2014, I was asked by the school to evaluate a program that teaches students about post-secondary opportunities. Upon completing this project in the spring of 2015, I was speaking with the school counselor, who was also the coordinator of the Photography Class, about $\mathrm{my} \mathrm{PhD}$ and research interest in examining racism

\footnotetext{
${ }^{10}$ In order to protect the anonymity and confidentiality of research participants I have used the generic term "youth program" to refer to this program.
} 
between Indigenous and non-Indigenous peoples and its mediation. I also shared that I was looking for an agency or community partnership so I could conduct a study on this topic. The school counselor began to tell me about the Photography Class and how the next book would probably focus on racism. She then asked if I would like to study and document the students' experience with the class. I was interested, but I knew that first I needed to follow protocol and respectfully present my research proposal to the Chief and Council, the School, and the school Elders. The school counselor and I parted ways and agreed to revisit the idea when students returned to school in the fall. As agreed, we met in the fall and within 2 weeks, with the support of the school counselor, I received the support of Chief and Council, the School, and the School Elders to study the Photography Class. In the following section I provide a literature review on the study of racial prejudice, Indigenous knowledge, and colonialism as a guide for understanding the grounded theory approach I experienced in gathering and analyzing the data collected through my study of the Photography Class. 


\section{Chapter 2 - Literature Review}

\section{Studying Racial Prejudice}

In 1954, Gordon Allport, an American social psychologist, published his seminal work entitled The Nature of Prejudice. In this text, Allport compiled and examined studies from various fields (psychology, anthropology, sociology) that had explored prejudice. Using this extent data, he proposed a framework for reducing what he termed ethnic prejudice. It is important to note that his work focused on the American context and the relations between in-groups identified as Caucasian Americans and out-groups identified as African Americans. He also discussed possible causes and solutions for reducing prejudice and problematized in-group attitudes towards out-group members as a key issue in prejudice (Allport, 1954; Katz, 1991).

Allport (1954) defined prejudice as:

an antipathy based upon a faulty and inflexible generalization. It may be felt or expressed. It may be directed toward a group as a whole, or toward an individual because he[/she] is a member of that group. (p. 9)

Importantly, Allport argued that prejudice was acquired at an early age through observation. The acquisition of prejudice was then reinforced as an individual's selfidentity emerged and as they developed membership(s) with certain groups (in-groups). In turn, group memberships fostered an individual's feeling of affiliation and loyalty to the in-group and feelings of separation in relation to out-groups. Allport (1954) argued that group memberships limited opportunities for intergroup contact and hence opportunities to challenge prejudice.

Although Allport (1954) perceived prejudice as involving in-groups and outgroups, he focused his work on in-groups because he hypothesized that prejudice 
emerged when in-group members develop and noted differences between themselves and out-group members. Allport also argued that prejudice is not inevitable, but once it develops it becomes inflexible in attitude, expression, and response. He hypothesized that in-group members simultaneously hold positive and negative prejudice towards outgroups. Which prejudice (negative or positive) is expressed or acted upon depends on the social context surrounding an individual including social norms and social demands. Thus, he concluded that levels of prejudice are shaped by intergroup contact.

Allport is commonly credited with introducing a human relations approach to the study of prejudice in his observations that researchers should study the role and impact of intergroup contact on the mitigation of in-group prejudice. For example, Allport argued that:

Prejudice (unless deeply rooted in the character structure of the individual) may be reduced by equal status contact between majority and minority groups in the pursuit of common goals. The effect is greatly enhanced if this contact is sanctioned by institutional supports (i.e., by law, custom or local atmosphere), and provided it is of a sort that leads to the perception of common interests and common humanity between members of the two groups. (p. 281)

More specifically, Allport's Intergroup Contact theory (1954) hypothesized that the prejudice held by members of an in-group could be reduced when in-group and outgroup members came together to interact with one another under the following four conditions: (1) equal group status, (2) common goal, (3) intergroup cooperation, (4) and support from authority, law, or custom. Collectively these conditions foster the optimal circumstances to reduce the prejudice held by in-group members towards out-group members (Allport, 1954).

Allport's (1954) theory hypothesized that when members of an in-group and outgroup come into contact with one another, the in-group's negative prejudices can be 
reduced and replaced with more favourable attitudes towards out-groups if the four conditions of equal group status, common goal, intergroup cooperation, and support from authority are met. Notably, Allport's theoretical contribution did not result in any particular finding or new method of measurement; but, his conceptual and theoretical contributions had a major impact because his work is widely credited with establishing the study of prejudice (Katz, 1991). Furthermore, the fundamental assumptions that Allport proposed continue to underpin this field of study. For example, Allport's conceptualization of prejudice as an in-group issue and his targeted examination of ingroups and the four conditions outlined in his Intergroup Contact theory continue to inform the study of prejudice.

Allport's work was first published in 1954 and researchers have developed a more nuanced definition of prejudice in the context of race relations. For example, VandenBos (2015) notes:

A form of prejudice that assumes that the members of racial categories have distinctive characteristics and that these differences result in some racial groups being inferior to others. Racism generally includes negative emotional reactions to members of the group, acceptance of negative stereotypes, and racial discrimination against individuals; in some cases it leads to violence. (p. 585)

While VandenBos (2015) focuses on racial prejudice as consisting of negative stereotypes, the phenomenon is much more complex. Racial prejudice can take the form of negative and positive attitudes and can be directed towards non-dominant and dominant group members. Because negative prejudice is associated with adverse impacts, it is of particular concern for my study of the Photography Class. So this literature review focuses on negative prejudice directed towards non-dominant groups by dominant groups. The distinction between in-group and out-group membership is critical 
because which group an individual belongs to and identifies with will impact their experiences with, and expression of, prejudice. We need to be cautious, however, in conceptualizing in-groups and out-groups as fixed entities. Studies have found that ingroup and out-group memberships are social constructs that are flexible, pliable, and develop as part of an individual's social identities (Tajfel \& Turner, 1986) and their external/social context (Haslam, Turner, Oakes, McGarty, \& Hayes, 1992; Turner \& Crisp, 2010). This acknowledgement of identity fluidity is critical because it demonstrates that although resistant, prejudice is susceptible to change if an individual's sense of self-understanding is also altered in particular ways.

Research in the field of racial prejudice focuses on two questions: (1) what is racial prejudice and (2) how can it be mediated. The latter question is of importance for this thesis. Building upon the conceptual and theoretical framework provided by Allport's (1954) Intergroup Contact Theory, studies have focused on identifying and examining processes that lead to reductions in dominant group prejudice. For example, self-disclosure, friendship, empathy (Turner, Hewstone, \& Voci, 2007), perceived importance of contact (Van Dick et al., 2004), perception of out-group attitude and variability (Islam \& Hewstone, 1993; Oaker \& Brown, 1986), and intergroup threats (Tausch, Hewstone, Kenworthy, Cairns, \& Christ, 2007; Wagner, Christ, \& Pettigrew, 2008; Wagner, Christ, Pettigrew, Stellmacher, \& Wolf, 2006) have all been identified as mediators in reducing dominant group racial prejudice towards non-dominant groups. These mediators are important to note; however, three mediators have been found to have the strongest relationship with the reduction of dominant group racial prejudice (Pettigrew \& Tropp, 2006, 2008): 
(1) enhancing in-group members knowledge about the other (Aboud, 1988; Aboud, Tredoux, Tropp, Brown, Niens, \& Noor; Bigler, 2012; Bigler \& Liben, 1992; Brown \& Hewstone, 2005; Cameron, Rutland, \& Brown, 2007; Cameron, Rutland, Brown, \& Douch, 2006; Liebkind \& McAllister, 1999; Livesley \& Bromley, 1973; Pettigrew \& Tropp, 2008; Turner et al., 2008),

(2) reducing in-group members anxiety (Crisp, Husnu, Meleady, Stathi, \& Turner, 2010; Crisp, Stathi, Turner, \& Husnu, 2008; Crisp \& Turner, 2009; Goff, Steele, \& Davies, 2008; Husnu \& Crisp, 2010; Johnson, Jasper, Griffin, \& Huffman, 2013; Mahonen, Jasinskaja-Lahti, \& Liebkind, 2011; Paolini, Hewstone, Cairns, \& Voci, 2004; Plant, 2004; Plant \& Butz, 2006; Shelton \& Richeson, 2005; Stephan \& Stephan, 2000; Turner \& Crisp, 2010; Turner, Crisp, \& Lambert, 2007; West \& Dovidio, 2013; Voci \& Pagotto, 2010),

and

(3) increasing in-group members empathy/perspective taking and giving (Bruneau \& Saxe, 2012; Kteily, Saguy, Sidanius, \& Taylor, 2013; Saguy, Dovidio, \& Pratto, 2008; Saguy \& Kteily, 2014; Shnabel \& Nadler, 2008; Shnabel, Nadler, Ullrich, Dovidio, \& Carmi, 2009; Vorauer, Main, \& O'Connell, 1998; Vorauer \& Sasaki, 2009, 2012).

The body of research on racial prejudice, referenced above, focuses on reducing negative attitudes, feelings, and behaviours of dominant group members towards members of non-dominant groups and tends to highlight some level of interaction between members of the dominant and non-dominant group as having potential for attitudinal/behavioural change. There are two particular weaknesses in this research. First, the majority of studies focus on the dominant group as the group requiring change thereby excluding consideration of the out-group and their role in the processes. The second limitation is that most of the studies were developed from the perspective of the dominant group and use a Western theoretical and conceptual lens.

In response to this bias, research has expanded to include both dominant and nondominant groups (Shnabel \& Nadler, 2008; Vorauer \& Sasaki, 2009, 2012). But, it continues to use a Western theoretical and conceptual lens which limits examination of 
the factors to be considered in mediating prejudice. Non-Western theories of knowledge, such as Indigenous theories of knowledge, provide different understandings of how to mediate the impact of racism, particularly from the perspective of target groups. These ways of knowing are critical to comprehending how the processes of mediation work. Recent research has found that using Western-based mediation processes can not only be ineffective but they can also have negative impacts on non-dominant groups. For example, Shnabel and Nadler's (2008) work found that the approach of perspective taking, an approach that focuses on actively engaging in-group and out-group members in reconciliation, inadvertently marginalizes out-group members and leaves them feeling voiceless, disempowered, and objectified. These findings are also supported by two studies conducted by Vorauer and Sasaki $(2009,2012)$ that examined the impact of perspective taking on in-group members.

One of the studies conducted by Vorauer and Sasaki (2009) analyzed empathy and perspective taking using a technique termed the ostensible interaction paradigm. Ostensible interaction is a research technique that is characterized by in-group participants communicating with an ostensible/pretend out-group member through audiotape or written exchanges. This technique is viewed as fostering the closest experience to intergroup contact without actual contact occurring. Because the in-group member never sees the out-group member and only sees the written communications, it is argued that they are unaware that the out-group member is fictitious.

Vorauer and Sasaki (2009) employed the ostensible interaction paradigm (using written exchanges) in the relational context of Aboriginal ${ }^{11}$ Canadians and non-

\footnotetext{
${ }^{11}$ Aboriginal is used as a constitutional term to describe persons and groups identifying as First Nations, Inuit, or Métis (Brittain \& Blackstock, 2015). This term is used here to reflect the language that was used in this study.
} 
Aboriginal Canadians. Their findings raise serious concerns about other key studies that have used Allport's (1954) Intergroup Contact theory and report that positive intergroup contact decreases in-group prejudice. In particular, Vorauer and Sasaki $(2009,2012)$ found that when empathy and perspective taking were employed under the condition of an ostensible interaction, in-group prejudice was not reduced. Also, favourable attitudes or intentions towards out-group members did not increase either. Instead, empathy and perspective taking triggered "meta-stereotypes".

Vorauer et al. (1998) define a meta-stereotype as “a person's [in-group member's] beliefs regarding the stereotype that out-group members hold about his or her own group. Meta-stereotypes vary according to which particular out-group is considered" (p. 917). For example, when a non-Aboriginal and Aboriginal Canadian are brought together to engage in empathy and perspective taking, the meta-stereotype that could be triggered for a non-Aboriginal person (in-group member) might be the belief that the Aboriginal person (out-group member) thinks that they are rich and do not care about Aboriginal peoples. Furthermore, when a meta-stereotype is activated, the in-group member becomes preoccupied with assessing the out-group member's evaluation of them and experiences an egocentric state instead of an empathetic state that is characterized by an engagement in empathy and perspective taking (Vorauer et al.). As a result, when a meta-stereotype is activated in-group members are unable to engage in empathy and perspective taking which, in turn, impedes reductions in in-group prejudice (Vorauer et al., 1998; Vorauer \& Sasaki, 2009, 2012). Both studies (Vorauer et al., 1998; Vorauer \& Sasaki, 2009, 2012) examined the impact of perspective taking on non-dominant participants (Indigenous peoples). For the purpose of my research study, the preliminary 
findings from Vorauer and Sasaki's $(2009,2012)$ study are of particular importance because they illustrate that the mediation process of empathy and perspective taking can increase racial prejudice through the activation of mega-stereotypes. These findings raise questions about this process of mediation and the theories of knowledge underpinning this field of study.

To date the study of prejudice has been designed by and for members of dominant groups using the dominant group's (Western) theories of knowledge. However, racial prejudice involves at least two actors/groups that have unique experiences with racial prejudice. Each of these groups (dominant or target group) experience racial prejudice differently and these experiences are informed by unique worldviews (e.g., Western or Indigenous) leading to different mega-stereotypes that can either exacerbate or ease conflict. Yet the processes of mediation that are examined and discussed in the current literature are based upon a Western worldview that has been found to negatively impact Indigenous participants (Vorauer \& Sasaki, 2009, 2012). Therefore, I argue that it is necessary to broaden this field of study by documenting and analyzing processes of mediation that are developed for and by Indigenous peoples. Doing so enhances the relevancy and effectiveness of the studies and findings emerging from the study of racial prejudice. Next, I discuss fields of study that have begun to take Indigenous theories of knowledge seriously, outline why I believe to do so is an important step, and what distinguishes Indigenous theories of knowledge from Western theories of Knowledge.

\section{Indigenous Knowledge}

The incorporation of other worldviews, particularly Indigenous knowledge, has been found to provide critical insights in a wide range of fields including environmental 
studies (Kim \& Dionne, 2014; McGregor, 2004; Menzies \& Butler, 2007), health studies (Downey \& Sweetwater, 2003; Lowell, Kildea, Liddle, Cox, \& Paterson, 2015; Milbur, 2004), educational studies (Ball, 2004; Battiste \& Henderson, 2009; Villegas, Neugebauer, \& Venegas, 2008), and research methodologies (Kovach, 2009; Smith, 1999, 2012; Wilson, 2008). This body of work illustrates how Indigenous knowledge provides a unique contribution to examining and understanding the world around us. For example, and as previously referenced, Kim and Dionne (2014), Menzies and Butler (2007), and McGregor's (2004) work have made unique contributions to environmental studies through the inclusion of Indigenous theories of knowledge about traditional ecological knowledge.

Although there is no one description of Indigenous knowledge, the tenet of relationality is widely accepted as a core characteristic of any definition. As Battiste and Henderson (2002, p. 42) note:

Perhaps the closest one can get to describing unity in Indigenous knowledge is that knowledge is the expression of the vibrant relationships between people, their ecosystems, and other living beings and spirits that share their lands.... All aspects of knowledge are interrelated and cannot be separated from the traditional territories of the people concerned.

The tenet of relationality is not a foundational element of Western-based theories of knowledge and is one of the distinguishing differences between Western and Indigenous theories of knowledge. This difference illustrates one way in which Western approaches to knowledge construction creates challenges for First Nations communities and scholars because of differing presumptions about the world around us.

The eminent Indigenous scholar, Leroy Little Bear (2000) goes further and explains that worldviews are based upon cultures that provide distinct assumptions about 
the world that are then used to make sense of the world and everyday experience. For example, Little Bear (2000) describes how a Western worldview assumes that the world is linear/chronological, static, product-oriented, and offers a singular perspective of the world that is grounded in an individual's relationship with objectivity. In contrast, an Indigenous worldview assumes that the world is cyclical/repetitive, process-oriented, and offers a perspective of the world that is grounded in one's relationships to all beings and to land/place. Furthermore, experiencing health and well-being requires attention to one's physical, cognitive, emotional, and spiritual aspects of self and others. In contrast, the Western worldview predominantly focuses on an individual's physical, cognitive, and emotional health and well-being to the exclusion of one's spiritual health and well-being (Rountree \& Smith, 2016; Stangeland \& Walsh, 2013; Young et al., 2015).

Another critical element of an Indigenous worldview is the assumption that all beings (humans and non-humans) are part of a process of continual renewal where everything is interconnected and interdependent. Because all beings are interconnected and interdependent, when the cycles of renewal are disrupted so too is the balance and well-being of all beings (human and non-human) (Little Bear, 2000). As an extension of this philosophy, all beings, including human, beings have roles and responsibilities to contribute to the maintenance of balance through a continual process of renewal. For example, since time immemorial ${ }^{12}$ Indigenous peoples have learned about their roles and responsibilities in relation to the land/place, family, and community through teachings and ceremonies that have been passed from one generation to the next through renewal ceremonies such as storytelling.

\footnotetext{
12 Online Oxford English (2017) dictionary defines immemorial as "a time in the past that was so long ago that people have no knowledge or memory of it".
} 
Henderson explains that an Indigenous worldview is "not an act of imagination, but a series of teachings about a particular place and about the proper way to relate to a whole and irrevocable ecosystem" (2002, p. 45). For many Indigenous communities these teachings are commonly referred to as the natural laws, customary laws, or sacred laws and are fundamental to understanding an Indigenous worldview. The First Nation community that this study was conducted with used the term sacred teachings to refer to these teachings/laws. Irrespective of the term used, each of these interchangeable terms refers to:

The traditional concepts of respect and sharing that form the foundation of the Aboriginal way of life are built around the seven natural laws, or sacred teachings. Each teaching [love, respect, courage, honesty, wisdom, humility, truth] honours one of the basic virtues intrinsic to a full and healthy life. Each law is embodied by an animal [love is embodied by the eagle, respect by the buffalo, courage by the bear, honesty by the sabe/big foot, wisdom by the beaver, humility by the wolf, truth by the turtle], to underscore the point that all actions and decisions made by man are manifest on a physical plain. The animal world taught man[/person] how to live close to the earth, and the connection that has been established between the animal world and that of man[/person] has instilled a respect for all life in those who follow the traditional Aboriginal way. (Sharing Circle, 2017)

It is important to note that each community has their own stories that are shared to pass sacred laws, such as the ones summarized above, from one generation to the next. It is generally agreed that although the stories that are used to pass these sacred teachings to the next generation may differ from nation to nation, the norms and values communicated through the sacred teachings are consistent.

Another consideration is that there are also core differences in how knowledge is passed on. Brundige's (2004), Little Bear's (2000), and Weber-Pilwax's (2001) work illustrates how storytelling was and continues to be a key pedagogical tool for passing on knowledge about specific customs and values that have a critical role in guiding the 
development of one's understanding of their identity as an individual and as a member of an Indigenous community. For example, while conducting research with the Swampy Cree, Brundige (2004) found that through stories:

We learn how to respect our human relatives, our animal relatives, our animal cousins and our plant kin. We learn about our responsibilities to our sacred Mother Earth and our place in the order of life (p. 243) ... Stories are repeated over and over and change over time to reflect life and community. As listeners mature and gain life experience, the meaning and lessons in the stories reveal themselves in different ways. What you discovered in a story as a child can be very different when you are an adult. A story written on paper becomes frozen in time while the beauty of an oral story is that it remains a living, flexible and dynamic part of culture and language. (p. 248)

The above quote describes how the development of a Nehiyaw/Cree identity is viewed as a lifelong process of learning that is grounded in and guided by ceremonies such as storytelling and an individual's active and iterative engagement in reflectivity. Brundige's (2004) study also found that:

Creeness seems to be two things, it is a way of being tied to a particular land (with distinctive knowledge) and it is a general view that sees all beings (human and non-human) as community beings in particular places. So Creeness is an identity and a way of understanding identities. (p. 359)

Accordingly, the development of an Indigenous person's identity is not about arriving at a specific understanding about one's self or a particular way of being. Instead it involves a process of continual and intentional movement towards a more in-depth understanding of one's "Creeness" through one's relationship with the land, community, and all beings (human and non-human) that are part of the land and community. As time passes, how one understands their "Creeness" will change in response to one's environment (land, community, and all beings) and as knowledge and insights are gained through learning about and putting into practice customs and values that have been passed on through stories (Brundige, 2004; Weber-Pillwax, 2001). In summation, 
the stories are the fabric that binds the culture, the community and the family together. Stories weave their way through centuries of connections, thus making the story an integral part of the Swampy Cree person's very being. In effect, I am the story. (Brundige, 2004, p. 363)

Taken together, and Brundige's (2004), Little Bear's (2000), and Weber-Pillwax's (2001) work illustrates the unique assumptions underpinning an Indigenous worldview and the pedagogical and fundamental connection between storytelling and identity development from an Indigenous worldview. Although Indigenous and Western worldviews are unique and appear to be in conflict, Marie Battiste (2005) argues that they are not incompatible. As Battiste (2005) explains:

For as long as Europeans have sought to colonize Indigenous peoples, Indigenous knowledge has been understood as being in binary opposition to "scientific," "western," "Eurocentric," or "modern" knowledge. Eurocentric thinkers dismissed Indigenous knowledge in the same way they dismissed any sociopolitical cultural life they did not understand: they found it to be unsystematic and incapable of meeting the productivity needs of the modern world. Yet, Indigenous scholars discovered that when they tried to use European knowledge to unravel the challenges faced by their people, they met with contradiction and failure, and they began to question the supremacy of Eurocentric thought. In their quest to help their people, Indigenous scholars and professionals turned to ancient knowledge and teachings ... Indigenous scholars discovered that Indigenous knowledge is far more than the binary opposite of western knowledge. As a concept, Indigenous knowledge benchmarks the limitations of Eurocentric theory - its methodology, evidence, and conclusions ... Indigenous knowledge fills the ethical and knowledge gaps in Eurocentric education, research, and scholarship. By animating the voices and experiences of the cognitive "other". (p. 2)

Accordingly, although there are differing assumptions underpinning Indigenous and Western theories of knowledge, it is not the differing presumptions but rather a colonial legacy that privileges and normalizes Western theories of knowledge and oppresses and devalues Indigenous theories of knowledge that is the challenge. Colonization has 
resulted in an academic environment that, although evolving, continues to be dominated by a Eurocentric lens that struggles with acknowledging, taking serious, and valuing Indigenous knowledge.

This thesis demonstrates how the study of racial prejudice can benefit from expanding the theoretical and conceptual imagination beyond the current limits of Western-based theories to identify and examine Indigenous theories of knowledge of racism and its mediation. The result will be more relevant, effective, and inclusive processes of mediation for Indigenous peoples which, to date, has not been possible due to the conceptual constraints that are placed on First Nation communities when Western theories of knowledge are used. These tensions are a part of the legacy of Canada's colonial history and how it unfolded and impacted Indigenous peoples.

\section{Colonialism}

Imperialism unfolded in the Canadian context as colonialism and was based upon a racist belief system that constructed Indigenous peoples and their worldviews as inferior. To more fully understand colonialism requires a brief discussion on imperialism.

It is generally agreed that European imperialism was initiated in the 15th Century and was realized through the following four manifestations: "(1) imperialism as economic expansion; (2) imperialism as the subjugation of 'others'; (3) imperialism as an idea or spirit with many forms of realization; and (4) imperialism as a discursive field of knowledge" (Smith, 2012, p. 60). These manifestations penetrate all aspects of the cultural groups that imperialism comes into contact with. Colonialism involves the movement of peoples from the colonizing nation into the territory of the colonized. The 
colonizers assert ownership of the lands and resources and they seek to transplant their cultural beliefs, practices, and norms into the new location. As such, colonization is conceptualized as imperialism's "outpost" which had and continues to have specific ramifications for Indigenous peoples.

Poka Laenui (2000) provides a definition of colonialism that is grounded in and informed by the experience of Indigenous peoples. Laenui describes colonialism as a social process that is comprised of the following five steps that interconnect: (1) denial and withdrawal, colonizers deny Indigenous culture and Indigenous peoples withdraw from their cultural practices; (2) destruction and eradication, colonizers physically destroy symbols of Indigenous culture to eradicate their culture; (3) denigration, belittlement, and insult, colonizers denigrate, belittle, and insult Indigenous practices, ceremonies, and belief systems while importing institutions that make Indigenous practices and ceremonies illegal; (4) surface accommodation and tokenism, remnants of Indigenous culture that survive the first three steps are tolerated by colonizers and viewed as folklore; and (5) transformation and exploitation, remnants of Indigenous culture, such as music and art, that refuse to disappear are appropriated and further exploited by both Indigenous and non-Indigenous peoples. Furthermore, reflecting upon Said's (1994) argument that colonialism is enacted through power arrangements, Wesley-Esquimaux and Smolewski (2004) argue that:

the political culture of colonial rulers operated within the frames of conquest, exploitation and repression to break existing social patterns and reassemble them according to European standards. Citizenship was to replace kinship; and institutions, law and bureaucracy substituted for face-to-face communal relations. Acts of encroachment, caused by missionaries, settlers or governments, destroyed the central meaning of culture and its entire social structure. This leaves Indigenous people deprived of their cultural traditions and meaning in their lives, which then becomes reduced to a mere physiological routine. (p. 44) 
In addition to illustrating some of the ways in which political power was used to systematically disrupt the social fabric of Indigenous peoples, colonialism also demonstrates a process of subjugation through a process of othering that legislatively legitimized and normalized Western control and worldviews and delegitimized and oppressed Indigenous self-determination and worldviews. This argument was developed in Frantz Fanon's The Wretched of the Earth (1963) where he critically examined what occurred as France colonized Algeria; however, these insights also shed light on colonialism in the context of Turtle Island ${ }^{13}$.

It is widely acknowledged that First Nations' creation stories and oral teachings document how Indigenous peoples have inhabited Turtle Island since time immemorial. These creation stories and oral teachings describe how Indigenous peoples inhabited Turtle Island for 10s of thousands of years and when colonizers and settlers first arrived on Turtle Island they survived because of the help of Indigenous peoples who shared their knowledge and taught them how to survive. However, following the process of colonialism, this arrangement of acknowledging First Nations sovereignty changed drastically with the unilateral enactment of the Indian Act in 1876. The Act legislated a paternalistic relationship between First Nations peoples and the British Crown. Critical to this legislation is the section that states that the Government of Canada has the power to determine who is and who is not eligible for Indian status and declared status Indians wards of the Crown (Royal Commission on Aboriginal Peoples, 1996). This aspect of the legislation represents one of the initial steps that was taken to gain control over First

\footnotetext{
${ }^{13}$ The term Turtle Island is a term used to document and recognize that Indigenous peoples were the first stewards of Turtle Island that was later named Canada by Euro-Canadians. The term Turtle Island and Canada are used interchangeably throughout the remainder of this thesis.
} 
Nations peoples and their identity through the identification of status and non-status Indians while also categorizing First Nations peoples as wards of the state. Daly and Sarkin (2007), Lawrence (2004), and Stanton (2011) all argue that the Indian Act's main objective was and continues to be to assimilate and "civilize" Indians by "killing the Indian in the child". The main mechanism that was used to achieve this objective was the Indian Residential School System (I.R.S.S.) which was emulated from the United States of America's residential school system (Lawrence, 2004). Between the 1870s and 1996 the Government of Canada, in partnership with the Catholic, the Presbyterian, the Methodist, the Anglican, and the United Church, implemented and oversaw Canada's I.R.S.S. (Miller, 1996; Stanton, 2011).

It is estimated that $50 \%$ of the children who entered the I.R.S.S. died while attending these schools (Scott as cited in Miller, 1996). Compulsory attendance facilitated the severing of children from their families and communities for months at a time and in some cases for years at a time (Lawrence, 2004; Royal Commission on Aboriginal Peoples, 1996). While attending the I.R.S.S. children were forbidden to speak their native language or to practice their traditions and culture. Furthermore, many children were routinely subjected to physical, psychological, and sexual abuse at the hands of the I.R.S.S. administrators (Grant, 1996; Lawrence, 2004; Miller, 1996; Royal Commission on Aboriginal Peoples, 1996). The I.R.S.S. began to wind down over the 1960s, but the last I.R.S.S. was not closed in Alberta until 1996 (Lawrence, 2004). As Corntassel, Chaw-win-is, and T'lakwadzi (2009) state:

the residential school era, which can be said to begin in 1874, is one example of the racist policies that were imposed on Indigenous people. Designed to strip Indigenous people of their languages and cultures, the residential schools were administered by the government of Canada and run by four well-known 
denominations or churches. By the time that last residential school closed in 1996, over one-hundred-thousand Indigenous children had been forcibly removed from their homes. (p. 138)

As illustrated in the above quote, the I.R.S.S. and its objective of assimilation was facilitated by a systematic disruption of the passage of Indigenous ways of knowing, being, and doing from one generation to the next. These intentional interruptions resulted in fractured families, communities, and ways of life as First Nations people. Delving further and illustrating the rationale that underpinned colonialism and the I.R.S.S. is the following quote from a speech made by Sir John A. MacDonald, the then Minister of Indian Affairs, and previously the Prime Minister of Canada, during a debate that took place in the House of Commons in 1883:

When the school is on the reserve the child lives with its parents, who are savages; he is surrounded by savages, and though he may learn to read and write his habits, and training and mode of thought are Indian. He is simply a savage who can read and write. It has been strongly pressed on myself, as the head of the Department, that the Indian children should be withdrawn as much as possible from the parental influence, and the way to do that would be to put them in central training industrial schools where they will acquire the habits and modes of thought of white men; so that, after keeping them a number of years away from parental influence until their education is finished, they will be able to go back to their band with the habits of mind, the education, and the industry which they have learned at these schools. (Library of Parliament, 1883, pp. 1108-1109)

This quote provides insight into the racist belief system held by colonialists ${ }^{14}$, such as Sir John A. MacDonald, and used to rationalize the establishment of Canada's I.R.S.S. in order to systematically disrupt Indigenous peoples' ways of life. In forcibly removing children from their families and placing them in I.R.S.S. the colonizers sought to assimilate them to "white men" ways. Because the I.R.S.S. was not officially abolished until the last school closed in Alberta in 1996, the personal consequences of Canada's

\footnotetext{
14 For the purpose of this study colonialist refers to the British Empire's/the Crown's formal and political representatives operating on behalf of the Crown on Turtle Island.
} 
colonial legacy continue to reverberate for Indigenous people and their families to this very day. Moreover, colonial and discriminatory structures and institutions that have created and perpetuated health, wage, and educational gaps between Indigenous and nonIndigenous peoples impact Indigenous peoples on a day-to-day basis (Bourassa et al., 2004; King \& Gracey, 2009; King et al., 2009; Royal Commission of Aboriginal Peoples, 1996). Racism is an ideology of "race" and a set of practices that function to oppress the "inferior" minority while privileging the "superior" majority (Saloojee, 2003) that has real consequences. In Canada racism has been identified as a contributing factor to Canada's Indigenous and non-Indigenous health, education, and income gaps (Bourassa et al., 2004; King \& Gracey, 2009; King et al., 2009; Royal Commission on Aboriginal Peoples, 1996). Canada's historical and continued issues with racism supported by its colonial legacy have produced negative impacts ranging from Indigenous peoples' physical and mental health to systemic underfunding of on-reserve health and social services (Canadian Human Rights Tribunal, 2016). In response to past and present impacts of colonialism, the eminent Indigenous scholars Corntassel (2012), Taiaiake and Corntassel (2005), and Simpson (2015) argue for Indigenous peoples to engage in everyday practices of resurgence.

Taiaiake and Corntassel (2005) define resurgence as:

Indigenous pathways of authentic action and freedom struggle [that] start with people transcending colonialism on an individual basis - a strength that soon reverberates outward from the self to family, clan, community and into all of the broader relationships that form an Indigenous existence. (p. 612)

Further, Taiaiake and Corntassel (2005, p. 613) argue that Indigenous acts of resurgence should be guided by the following five mantras:

(1) Land is Life, 
(2) Language is Power,

(3) Freedom is the Other Side of Fear,

(4) Decolonize your Diet, and

(5) Change Happens one Warrior at a Time.

When put into practice on a day-to-day basis, the above mantras are argued to provide pathways for each person to actively challenge their colonial context by "thinking, speaking, and acting with the conscious intent of regenerating one's indigeneity" (Taiaiake and Corntassel, 2005, p. 613). Delving deeper into the practice of resurgence on an interpersonal level is the following explanation provided by Simpson (2015):

Indigenous internal self-recognition is a core building block of resurgent struggle because it is the mechanism through which we reproduce and amplify Indigeneity. When another Native person recognizes and reflects back to me my Nishnaabe essence, when we interact with each other in an Nishnaabeg way, my Indigeneity deepens. When my Indigeneity grows I fall more in love with my homeland, my family, my culture, my language, more in line with the idea that resurgence is my original instruction, more in line with the thousands of stories that demonstrate how to live a meaningful life and I have more emotional capital to fight and protect what is meaningful to me. (para. 8)

Taken together Taiaiake and Corntassel (2005) and Simpson's (2015) definitions of resurgence call for Indigenous peoples to engage in daily acts where each individual honours their own pathways of regeneration through conscious engagement with their community's land-based practices, ceremonies, oral histories, storytelling, and language. Echoing Brundige and (2004) and Weber-Pillwax's (2001) understanding of one's "Creeness", discussed earlier, Taiaiake and Corntassel (2005) and Simpson's (2015) conceptualization of resurgence is grounded in practices that consciously and continually move one towards the regeneration of their authentic self.

This chapter reviewed the study of racial prejudice, Indigenous knowledge, and Canada's colonial legacy with racism and its impact on Indigenous peoples. Overall, this literature review illustrated how the study of racial prejudice continues to be dominated 
by Western theories of knowledge and why this theoretically and conceptually narrow approach needs to be broadened to include more appropriate and effective theories of knowledge and processes to begin the work of mediating Canada's colonial legacy of racism and eroding the differential impacts that racism has and continues to have on Indigenous peoples and their communities. In response, my research study was designed to address this dearth in the literature by documenting and examining a community-based program grounded in Indigenous knowledge, the Photography Class, utilizing storytelling and photography to mediate racism in a Nehiyaw/Cree community. Further, by expanding the study of prejudice to include Indigenous theories of knowledge on racism and its mediation, I hope that municipal, provincial, and federal governing bodies will be able to abstract my research findings and use them to guide the development of policies and programs that are better able to effectively redress racism between Canada's Indigenous and non-Indigenous peoples. Having contextually situated my research study with the literature, the next chapter outlines and discusses the theoretical framework, methodologies, and methods that informed this research study. 


\section{Chapter 3 - Methods}

In the previous chapter, I argued that Indigenous knowledge and methodologies are critical tools for redressing racism. This chapter explains my multi-pronged methodological approach with a specific focus on the interweaving of Charmaz's (2014) Grounded Theory Methodologies with Indigenous methodologies and reflexivity. Further, I outline the methods (participant observation and interviewing) and data analysis (GTM and narrative analysis) that I employed. Throughout this chapter, I focus on what, how, and why I employed certain tools. I begin with a discussion of postcolonial theory and decolonization and the insights that decolonization offers to researchers.

\section{Postcolonialism and Decolonization}

One of the main contributions that the field of sociology has and continues to make to different bodies of knowledge is what C. Wright Mills termed the sociological imagination (1959). He defined a sociological imagination as the ability "to grasp history and biography and the relations between the two within society ... [and] the capacity to shift from one perspective to another" in order to be able to perceive and examine relationships between individual experiences and the society at large (1959, pp. 6-7). For the purpose of this study, I employed a sociological imagination to develop an understanding of mitigating racism in the context of the students' lived experience with the Photography Class and locating those experiences within the context of Canada's colonial legacy. However, C. Wright Mills's concept of sociological imagination is based upon a Western worldview and, as such, is limited in its ability to take into consideration or account for an Indigenous worldview. Acknowledging this limitation, I 
utilized Smith's $(1999,2012)$ theoretical lens of decolonization to operationalize my sociological imagination to strategically foster a conceptual space that centers Indigenous theories of knowledge and actively resists this study from becoming yet another site of colonialization where Western theories of knowledge are normalized and privileged and Indigenous theories of knowledge are devalued and oppressed.

To assist with disrupting Western theories of knowledge and centering Indigenous theories of knowledge, for the remainder of this thesis I use Nehiyaw/Cree syllabics prior to the English Roman orthography when discussing key concepts/processes and practices to acknowledge, respect, and bridge these unique ways of communicating. For example, "D" $\Delta$ ל०" is Syllabics for Nehiyaw, "Nehiyaw" is Roman orthography for Cree, and "Cree" is English text used to identify this First Nations community. Syllabics have been placed first to respect and to put into practice a teaching that I received that First Nations people were given the gift of spirituality and Syllabics contain the spiritual component of ○" $\Delta$ ל० (Nehiyaw/Cree) language. Therefore, I was taught that Syllabics should be placed first to honour the spiritual aspect of the $\mathrm{C} \| \Delta \circ$ (Nehiyaw/Cree) language (Field note, December 13, 2015). This approach was possible because I followed protocol (offered tobacco) and asked the school Elder L. B. that was also the ๑" $\Delta$ ל० (Nehiyaw/Cree) language teacher to help me with learning the correct Roman orthography and Cree Syllabics.

I acknowledge that this practice of textual presentation may create some discomfort for readers who hold a Western worldview; but this disruptive tactic supports my objective of centering Indigenous theories of knowledge. Its usage is also necessary because it reminds all readers that understanding the perspectives of Indigenous people, 
especially the perspectives described in this study, requires an active and ongoing disruption of Western theories of knowledge.

The use of decolonization as a theoretical lens is also critical because it offers an approach that challenges “ ... research as an institution of knowledge that is embedded in a global system of imperialism and power" (Smith, 2012, p. 20) that privileges Western theories of knowledge to the exclusion of non-western knowledge.

Postcolonial theory provides space for scholars to examine colonialism and its impacts on colonized peoples in a more critical way because it challenges typical Western paradigms. For example, Bhabha (1994), Gilroy (2000), Hall (1996), Said (1978), and Spivak (1994) are some of the prominent scholars whose work laid a conceptual foundation for postcolonial theory and its various fields of study in their identification of concepts such as hybridity (Bhabha, 1994), planetary humanism and strategic universalism (Gilroy, 2000), cultural identity (Hall, 1996), subaltern (Spivak, 1988), and Orientalism (Said, 1978). These contributions to postcolonial theory are significant but they do not inform the theoretical lens that I employ. Instead I make use of the work of the eminent Indigenous scholar Lynda Tuhiwai Smith (2012) and what she terms decolonization.

It is important to note that the term postcolonial is often misinterpreted as denoting a point in time where colonialism is a thing of the past and should be studied as such. However, various scholars (Bourassa et al., 2004; Brittain \& Blackstock, 2015; King \& Gracey, 2009; King et al., 2009; Royal Commissions of Aboriginal Peoples, 1996) have illustrated that Canada's colonialism has not altered toward Indigenous people and continues to be perpetuated through structural institutions. For example, and 
as previously mentioned, the Canadian Human Rights Tribunal identified the government of Canada in 2016 to have been systemically discriminating against First Nations youth and their families by chronically underfunding health and social services in First Nation communities across Canada (Brittain \& Blackstock, 2015; Canadian Human Rights Tribunal, 2016). I also believe that colonialism is not a relic of the past and continues to permeate Canadian society in ways that impact many First Nation peoples and their everyday life experience. Here, as a methodologist, is where my potential bias may serve as a filter through which my data analysis lies. Recognizing that colonialism continues to operate, similar to Smith's conceptualization of decolonization, as a critique of imperialism that "writes back ... from the margins" (2012, p. 63) to "decolonize our [Indigenous] minds, to recover ourselves, to claim a space in which to develop a sense of authentic humanity" (2012, p. 63), I situate myself and my analytical lens for this study.

Smith (2012) explains that decolonization is achieved by weaving together two unique yet interrelated lines of inquiry. The first thread of Smith's inquiry draws upon the concept of:

authenticity, of a time before colonization in which we were intact as indigenous peoples. We had absolute authority over our lives; we were born into and lived in a universe which was entirely of our making. We did not ask, need or want to be "discovered" by Europe. (2012, p. 64)

When applying this line of inquiry, researchers ask what the data illustrate about Indigenous authenticity prior to colonial contact. Having identified what the data reveals about Indigenous authenticity, the second line of inquiry examines how Indigenous peoples "were colonized, and what that has meant in terms of our [Indigenous] immediate past and what it means for our present and future" (Smith, 2012, p. 64). It must be kept in mind that when these two threads are woven together they reveal solutions that can 
take into consideration "the time before, colonized time, and the time before that, precolonized time (Smith, 2012, pp. 64-64). Further, Smith argues that, when solutions are identified through this type of a critique, a process of decolonization can be realized through implementation of the identified solutions. Smith's (2012) articulation of decolonization is critical because it provides both theoretical and conceptual space to center and value the research participants' lived experience through integration rather than negation of Indigenous theories of knowledge. The next section describes how I integrated Smith's theoretical framework as a part of my methodological approach in this study.

\section{Methodologies}

As stated above, this research study is informed by a multi-pronged methodological approach that interweaves Charmaz's (2014) approach to Grounded Theory Methodologies with Indigenous methodologies and reflexivity. In the following section I unpack and explain the different components of my methodological approach and how they informed one another and this research study.

Grounded theory methodologies. Grounded Theory Methodologies (GTM) are inductive methodologies that develop understandings and meaning based on the grounded experiences of those who are studied. There are a variety of grounded theory methodologies but I use Charmaz's (Charmaz, 2006; Charmaz \& Belgrave, 2012) approach to GTM focuses on analyzing social processes that are predominantly unexplored. For example, Charmaz has utilized constructivist GTM to examine social processes that have been marginalized and unexamined such as identity and chronic illness (Charmaz, 1991) as well as the disclosure of illness and disabilities (Charmaz, 
2010). Like Charmaz $(1991,2010)$, my research study examined a marginalized and unexamined social process, a mediation process for racism grounded in Indigenous theories of knowledge, Nehiyaw/Cree in particular.

GTM uses an iterative process where the researcher simultaneously gathers and analyzes data. Data analysis involves a continual testing of emerging categories against subsequent data and a restructuring of categories in light of that data. The end product is the emergence of a substantive theory. This iterative process represents what is considered the hallmark characteristic of GTM (Charmaz \& Belgrave, 2012) and is what makes it attractive for many scholars conducting research with Indigenous peoples and communities (Bainbridge, Whiteside, \& McCalman, 2012; Daveson, O'Callaghan, \& Grocke, 2008; Heath \& Cowley, 2003; Jennings, Kensbock, Junek, Radel, \& Kachel, 2010; McCalman, Tsey, Bainbridge, Shakeshaft, \& Singleton, 2013). Specifically, GTM facilitates space for the emergence and inclusion of Indigenous theories of knowledge through its use of a constant comparison process by which ideas, actions, and concepts are separated, compared, contrasted, and reassembled to develop new understandings. In this way, GTM encourages theory development that reflects the reality of the data rather than producing study findings that are constrained by pre-existing theoretical approaches or hypotheses (Kovach, 2009; Smith, 1999, 2012).

Since the 1990s, there has been a growing call for scholars interested to do research differently and in a more inclusive, meaningful, and sensitive manner (Jones \& Jenkins, 2008; Kovach, 2009; Lawrence, 2004; Smith, 1999, 2012; Wilson, 2008). For example, recognizing the need to take a different approach, a handful of scholars working with Indigenous peoples of Australia have utilized GTM because they have found its 
inductive approach provides an opportunity to work outside of Western-based theories of knowledge (Bainbridge et al., 2012; Daveson et al., 2008; Heath \& Cowley, 2003; Jennings et al., 2010; McCalman et al., 2013). Following their lead, I also utilized GTM to conduct this research study. I discuss how I interwove GTM and Indigenous methodologies and how this multi-pronged approach informed this research study in the next section.

Indigenous methodologies. As a Euro-Canadian working with a Nehiyaw/Cree community it is critical that I locate myself within Canada's colonial landscape and delineate how and why I braided together GTM and Indigenous methodologies. I grewup in northern British Columbia on a farm that was located 45 kilometers north of a small town named Dawson Creek. While growing-up I was not taught that the land that my family and ancestors lived off of were part of Turtle Island or how we were benefiting from colonial and racist policy that gave the land to my ancestors while dispossessing the First Nation peoples that were the inherent caretakers of the land. Over the past 16 years I have had the honour of working with and learning from Indigenous Elders and knowledge keepers that have been teaching me about pre and post contact, how we are all Treaty people, and mentoring me on how I, an Indigenous ally, Caucasian, queer, and community-based scholar, can use my skills to constructively disrupt the status quo of Canada's colonial legacy of racist ideologies and practices. This journey brought me to the research study outlined in this thesis where, as discussed earlier, I was asked to conduct a research study in partnership with a First Nation community. However, given the above identities and my location in Canada's colonial landscape, my study required a methodological approach that recognized my own location and that was grounded in 
Indigenous experiences and theories of knowledge. In conducting my literature review, I learned that other researchers (Bainbridge et al., 2012; Daveson et al., 2008; Heath \& Cowley, 2003; Jennings et al., 2010; McCalman, 2013; McCalman et al., 2013), working with Indigenous peoples, used GTM to open up conceptual space for Indigenous voices, experiences, and theories of knowledge. Reflecting upon these scholars' work, I argue that this conceptual space can be opened up further by interweaving GTM with Indigenous methodologies.

Indigenous methodologies are founded upon relational ethics. These ethics are meant to guide researchers in their search for theories of knowledge (Kovach, 2009; Smith, 1999, 2012; Wilson, 2008). Eminent Indigenous scholars Kovach (2009) and Smith $(1999,2012)$ argue that an Indigenous methodology is comprised of certain tenets that are illustrated in Kirkness and Barnhardt's (1991) concept of the 4 R's; respect, relevance, reciprocity, and responsibility. Respect refers to researchers conducting themselves in a manner that acknowledges and values Indigenous knowledge and experience. Relevance refers to the research project being meaningful and useful to Indigenous participants. Reciprocity refers to the research project being mutually beneficial for Indigenous participants and the researcher. Finally, responsibility highlights relational accountability in that the researcher is responsible for, and accountable to, the research participants and their communities as well as to academic institutions.

Reflecting upon Kirkness and Barnhardt's (1991) 4 R's, I argue that each of the tenets represents a type of relational accountability among the researcher, research participants, and the intent/impact of the research project. This argument is supported by 
Meyer (2003). Meyer, an Indigenous scholar, states that Indigenous knowledge is relational and experiential. Furthermore, Meyer argues that Indigenous knowledge is located in narratives that illuminate how each of us is interconnected and has a relational accountability to one another. In a similar vein, Charmaz's (2003) constructivist approach to GTM recognizes and responds to the intersubjective/relational aspects of the research process, thereby making her approach to GTM compatible with Indigenous methodologies. For example, Charmaz's (2003) approach to GTM “assumes the relativism of multiple social realities, recognizes the mutual creation of knowledge by the viewer and viewed, and aims towards an interpretive understanding of subjects' meanings" (2003, p. 250). In other words, Charmaz's approach to GTM is designed to give voice to participants, to co-construct data, and to capture multiple realities.

Another tenet of Charmaz's GTM is to produce meaningful research for both the participants and the researcher through the iterative and inductive process (Charmaz, 2003). As such, I contend that Charmaz's GTM provides the methodological space to allow a researcher to follow the four R's of respect, relevance, reciprocity, and responsibility while identifying and examining the multiple realities of Indigenous research participants. It is contingent upon the researcher to integrate an understanding of Indigenous methodologies into a more general GTM approach (Denzin, 2010).

This integration is not without its challenges. To date there is an absence of specific literature articulating how to obtain integration. In response to this gap, I decided to incorporate Kirkness and Barnhardt's (1991) tenets of Indigenous methodologies with Charmaz's (2014) tenets of GTM in my study to establish a research methodology that supports a process of decolonization and the documentation of a 
ত" $\Delta$ ל० (Nehiyaw/Cree) practice that reflected the participants' lived experience with racism and their worldview. Below in the methods section I detail how I aligned these two methodologies with one another.

\section{Methods}

In preparation for my proposed research study, I developed a research partnership with the Chief and Council, the school, and school Elders. This partnership included discussions of whether and how the project could have value to both the community and myself. It also included discussions on how to proceed appropriately with the research project, how to include students and parents in the process, and how to co-construct meaning from the data. The students in the class and the school personnel that were involved with the Photography Class comprised the two primary target groups for the study; but the impact of the project on the wider community was also considered.

To be included in the study students had to be in Grades 7, 8, or 9, self-identify as Indigenous, and be taking part in the 2015-2016 Photography Class. Twenty-one (21) Indigenous youth fit this criteria. There were also three school Elders and five school personnel (two teachers, two teaching assistants, and one coordinator/school counselor) who were eligible to be included because they were directly involved the 2015-2016 Photography Class.

To assist with recruitment, I hired a Research Assistant from the school who spoke to each student individually to see if they would be willing to participate. An Information Letter describing my research study was circulated in their school newsletter. After the Information Letter was distributed, the Research Assistant contacted the parents/caregiver of each of the potential student participants to ask if she and I could 
meet with them to discuss the research study and to ascertain whether or not they agreed to their child taking part in the research study. Parents were approached first because, due to their age, no students could participate without parental approval. However, the research protocol required both the youth and parent/caregiver's consent. One parent did not consent to their child taking part and we were unable to connect with two other parents/caregivers. This meant that 6 of the 21 students were unable to take part in the research study.

Once the parent/caregiver's consent was obtained, the Research Assistant and I met with the student to discuss the research project and to ask whether or not they would like to take part. I explained that those students who chose not to participate in the study would experience no negative consequences and they could still take part in the Photography Class. I also explained that participating students could change their mind and withdraw their consent at any point during the data collection and verification phases of the study. After the data gathering and verification process was completed participants also had 1 month to withdraw from the study. In total, there were 19 research participants who took part in the study. Twelve of the 15 students with parent/caregiver consent also agreed to take part in participant observation and to be interviewed. However, due to variable attendance rates only eight of the nine students took part in a one-on-one interview. I also interviewed two school Elders and five school personnel (roles identified above) who were directly involved with the Photography Class.

Participant observation and interviewing. GTM aims to capture a lived experience of individuals and of phenomenon, in this case the students' lived experience with the Photography Class. Effectively capturing this experience required participant 
observation. I took part in participant observation throughout the Photography Class actively observing what was happening (Fetterman, 1998). It is important to note that I was not a full participant. I observed, interacted with participants, and took part in class activities. But, as recommended, I refrained from intervening in order to limit my impact on the day-to-day activities and discussions (Prus, Lorenz Dietz, \& Shaffir, 1997). In total, I attended 21 40-minute classes that took place once a week from November 25, 2015 to June 02 , 2016. I focused my observations on student interactions with each other, with the facilitator, and with the school Elders. I focused my observations on how students used photography and written text to construct understandings of their individual and collective lived experiences with racism and its mediation. After each class concluded and once I was in a private space, I documented my observations in the form of field notes. Attending all the class and documenting my observations in field notes allowed me to develop a more in-depth understanding of the participants' experiences with the Photography Class. It also allowed me to compare and contrast what occurred during the various classes and to develop key themes and questions for the later interviews (DeWalt, DeWalt, \& Wayland, 1998).

While participant observation allows researchers to get close to research participants and to develop in-depth understandings, one of the main limitations of participant observation is that the researcher's presence can impact the participants' experiences because it can influence what they are willing and not willing to discuss with a researcher present. Further, their remarks may be shaped by what they think the researcher wants to hear. However, this individual attention to my presence is difficult to maintain over a long period of time and because this observation took place over almost 8 
months, I believe these effects on my observations and data analysis were limited. That length of time also permitted time to build trust between me and the students so they were much more open than they might have been if my participant observation was of a shorter duration.

Another study limitation emerged because nine of the 21 students and/or their parent/guardian did not agree to take part in the research study. As previously mentioned, one parent/caregiver did not consent, two parents/caregivers could not be reached to inquire about consent, and three students did not agree to take part in the research study, resulting in nine students not taking part in any aspect of the research study (participant observation of a one-on-one interview). Accordingly, my field notes and reflective journal did not include any information on or about the students who did not have the required consent ${ }^{15}$. Although significant, the impact of limiting the data gathering process of nine of the students was mitigated (to the extent possible) by the inclusion of the students' book as a data set that contained information about all 21 of the students and their lived experience with the Photography Class. It was possible to include the students' book because it was intended for and is in circulation in the public domain (e.g., public libraries). This study's data, including the book, is detailed in the next chapter.

Once the Photography Class concluded in April and after the students had approved the final draft of their book, I began interviewing students and school personnel

\footnotetext{
${ }^{15}$ Limiting the participant observation aspect of the data gathering process to 15 of the 21 students had a limited impact on the study because approximately half of the sessions (December to February) were characterized by the students predominantly listening to and learning from Elders. Further, the remaining sessions (March to April) entailed various activities where certain students were more comfortable with taking part in the classroom discussions. Fortunately these students were the research participants that had consented to take part in the participant observation component of this study.
} 
to further explore data that was gathered through participant observation. The interviews allowed for the development of a more nuanced understanding of the students' lived experience with the program.

The Coordinator explained to me that each year as the school year comes to an end over the months of May and June student attendance rates begin to dwindle fostering variable attendance rates. To accommodate, to the extent possible, this variability in attendance rates I traveled out to the community on five separate occasions. Over the duration of these trips to the community I conducted one-on-one interviews with eight of the 12 students, five school personnel, and two school Elders. The interviews, to be discussed in the next section, took place in the school in a classroom during school hours between May 25, 2016 to June 12, 2016 and ranged in length from 5 minutes to 60 minutes in duration. Each of the participants made significant contributions to the study; however, the school Elders and personnel, as knowledge holders and community members, provided particular insight into the historical and contemporary context surrounding the students lived experience with the Photography Class. While the student interviews provided insight into their lived experience with the Photography Class, the role and impact of Elder involvement, and the effects the Class had on them as individuals and as community members.

There were key informants who played critical roles in these studies. For the purpose of this research study a key informant refers to research participants that provided extensive and detailed insights (Payne \& Payne, 2004) into their own and others' lived experience with the Photography Class and/or what was happening in the data during the analysis phase. The first key informant for the study was Elder D. M., a 
respected knowledge holder of $\mathrm{O} \Delta$ ל० (Nehiyaw/Cree) teachings, practices, the community's historical and contemporary experience with Canada's colonial legacy of racism, and the I.R.S.S. In addition to assisting me with data analysis, and as previously mentioned, he took part in all but one of the classes. Because he worked closely with the students in class and attended almost all sessions, he was valuable in assisting me with developing an understanding of both the Photography Class experiences and the wider context within which those experiences were interpreted and defined.

A second key informant, S. H. ${ }^{16}$, the coordinator of the Photography Class since its inception in 2010, provided insights into the Photography Class, its purpose, and how the program impacted students. Two students, D. C. and K. L., were also key informants. Through their in-depth interviews they provided insights into the students' lived experience with the Photography Class. Both of these students took on leadership roles and were spokespeople for their cohort at different times throughout the program. For example, K. L. took on a leading role when students were forming their book's narrative and D. C. embraced the role of co-master of ceremonies during the book launch. Although I have identified four key informants that provided pivotal information, this study's findings were only possible because of the information that was shared by each of the research participants during my observation sessions and through individual conversations.

Interviewing. Interviewing is one of the most commonly used methods in qualitative research. Frey and Oishi (1995) define an interview as "a purposeful

\footnotetext{
${ }^{16}$ In order to protect the anonymity and confidentiality of research participants I have used initials to refer to individuals that took part in this study and not specified their name.
} 
conversation in which one person asks prepared questions (interviewer) and another answers them (respondent)" (p. 1). There are different types of interviews and they differ in what degree the interviewer directs the conversation. Typically, researchers use one of three types of interviews: (1) structured, (2) semi-structured, or (3) narrative interviews (Stuckey, 2013). I conducted semi-structured interviews that consist of the researcher using open-ended questions such as "Can you tell me about" to explore certain themes and topics. The themes and topics for my semi-structured interviews were based on the participant observation and the iterative review process in my study. By using openended questions, I was able to explore the interviewee's point of view on specific topics while leaving conversational space to adapt questions and capture the participants' constructions of their experience with the phenomenon and to explore new ideas that surfaced during the interview (Rubin \& Rubin, 2012; Stuckey, 2013). In alignment with Charmaz's approach to GTM, I employed a type of semi-structured interview that Charmaz (2014) terms intensive interviewing.

Semi-structured interviews are designed to gather rich data on a particular phenomenon in order to develop an in-depth and nuanced understanding of the phenomenon. However, it is important to note that although structure is required, it should not control the direction and/or content of an interview. Instead, structure should assist the interviewer with developing a more nuanced understanding of the interviewee's construction of their lived experience with the research topic or phenomena (Charmaz, 2014).

Charmaz (2014) defines intensive interviewing as a "flexible, emergent technique that; combines flexibility and control, opens interactional space for ideas and issues to 
arise, allows possibilities for immediate follow-up on these ideas and issues, results from interviewers and interview participants' co-construction of the interview conversation" (pp. 58-59). For the purpose of this study, control refers to the interview structure and more specifically to my use of probes to develop a deeper understanding of how the interviewee constructed their lived experience, not to control the direction or content of an interview. I engaged in intensive interviews by:

ask[ing] the participant to describe and reflect upon his or her experiences in ways that seldom occur in everyday life. The interviewer listens, observes with sensitivity, and encourages the person to talk. Hence, in this conversation, the participant does most of the talking. (p. 58)

In addition, during each interview I used a technique termed mirroring (Charmaz, 2014) or confirmation and clarification probes (Rubin \& Rubin, 2012). Confirmation probes or mirroring occur when the interviewer summarizes what they think they heard the interviewee say and then ask if the summary is accurate or needs to be adjusted (Charmaz, 2014; Rubin \& Rubin, 2012). In contrast, clarification probes are employed when the interviewer asks "Can you run that by me again, I'm afraid I did not follow it" (Rubin \& Rubin, 2012, p. 141). By employing these types of probing techniques I ensured that I understood the participants' construction of their lived experience.

Intensive interviewing also provided me with the opportunity to put Charmaz's GTM and Indigenous methodologies into practice by taking the view that each interview "takes place within a culture at a specific historical time and social context" (Charmaz, 2014, p. 57). Significantly, intensive interviewing, although structured around the topic of inquiry, is not prescriptive and fostered conversational space for me to actively engage the four tenets of Indigenous Methodology (i.e., respect, relevance, reciprocity, \& responsibility). Thus, I intentionally integrated a process of decolonization into the data 
gathering process by interweaving and implementing Kirkness and Barnhardt's (1991) 4 R's and Charmaz's (2014) tenets of GTM throughout the interview process to acknowledge, value, and understand the youths' constructions of their lived experience with the Photography Class. I describe that process in more detail in the next section.

\section{Integrating the 4 R's and GTM}

Charmaz's (2014) tenet of giving participants voice reflects the Indigenous tenet of respect in that each participant produced meaning and understanding based on their values and experience which I acknowledged and valued by seeking to understand and incorporate each of the research participants' unique and collective lived experiences into the analysis process. I also practiced the tenet of respect by including cultural protocols such as offering prints, tobacco, honorarium, and remuneration as appropriate.

Charmaz's (2014) tenet of co-constructing data fostered opportunities for the research process to be mutually meaningful and therefore of reciprocal benefit for both the research participants and myself. For example, through the process of coconstructing data, the research participants and myself gained an in-depth understanding of their lived experience with the Photography Class and the documentation of their community's Nehiyaw/Cree practice of Kisewatotatowin/awakening Kiskisohkemowin/remembering. In addition, these findings are to be summarized in a report provided to the school so they can use it as part of future funding applications for the Photography Class.

The Indigenous tenet of relevance was practiced through Charmaz's (2014) principle of capturing multiple realities thereby ensuring that each of the participants' values and experience informed the research process. In this way, the emergence of the 
substantive theory that emerged in the study reflected a process of mediation of racism that was informed by Indigenous-based theories of knowledge.

Finally, by practicing the tenets of respect and giving voice, reciprocity and coconstructing data, relevance and capturing multiple realities I was able to pragmatically respond to and be accountable to the research participants in ways that put into practice the Indigenous tenet of responsibility. Before discussing the analysis process that I utilized, I return to the third aspect of my methodology, reflexivity, to discuss when, how, and why I employed this methodology.

\section{Reflexivity}

In alignment with Charmaz's (2012) constructivist approach to GTM, my research study made "the following assumptions: (a) multiple realities exist, (b) data reflect researchers' and participants' mutual constructions, and (c) the researcher enters, however incompletely, the participant's world and is affected by it" (Charmaz \& Belgrave, 2012, p. 349). In this manner, GTM obtains data through a qualitative methodology that acknowledges and responds to the inter-subjective environment from which the findings emerge.

A researcher's role does not end with simply recognizing intersubjectivity alone. Prominent GTM researchers such Charmaz and Belgrave (2012) and Lynch (2008) highlight the need for reflexivity. Simply stated, reflexivity is the human capacity for self-consciousness (Bond \& Bond, 1986). More specifically, reflexivity is the ability to critically acknowledge and grapple with the intersubjective environment that the research process unfolds within (Charmaz \& Belgrave, 2012). For example, feminists have called for a praxis of reflexivity in order to account for the impacts of dominant discourse and 
power imbalances on the researcher, research participants, and the study itself (DeVault, 1990; Finlay, 2012). Building upon this growing field of literature, I employed a praxis of reflexivity to acknowledge and account for the intersubjective environment that my research study took place within me. I will provide a more in-depth discussion on reflexivity and how I implemented this practice to acknowledge and mitigate (to the extent possible) later in this chapter. To understand that discussion, however, it is necessary to address the complexity of the research context.

In sections above, I presented an uncomplicated view of intensive interviewing. Interviews can give rise, however, to certain limitations and potential challenges, especially when the researcher, as I did, conducted interviews outside their cultural group. In acknowledgement of the complexities of cross-cultural interviewing, this section outlines my position as a non-Indigenous constructivist grounded theorist who interwove tenets of Indigenous and critical reflexive methodologies to make visible and mitigate (as much as possible) the challenges related to language, power, insider and outsider status, and representation. Findings obtained through interviews are not often used to draw generalizations; however, this latter limitation (representation) is not of particular concern because my study sought to draw theoretically plausible rather than generalizable conclusions (Charmaz \& Belgrave, 2012). In addition, it is important to keep in mind that I worked from a constructivist position which means that I viewed the research participants' interview as an interpretation of their experience that occurred in dialogue with me and resulted in a co-construction of their experience. Therefore, my understanding of their experience is my interpretation of their lived experience (Charmaz, 2006, 2014). This multilayer interpretive situation can present a slippery slope for me to 
misinterpret a participant's experience when conducting research and analyzing my data. Next I discuss two methods that I used to mitigate misinterpretations related to language and linguistic incongruence.

Language. Language can be defined as "a system for expressing or communicating thoughts and feelings through speech sounds or written symbols" (VandenBos, 2015, p. 585). But language is much more complex that this in its use. For example, De Vault (1990) argues that female voices can be oppressed due to the linguistic incongruence between a dominant discourse that is based upon male experience, not female experience. As with women, Indigenous peoples' ways of knowing, doing, and being are not accurately represented in dominant discourse (Rousell \& Giles, 2012; Smith, 2012; Wilson, 2008). For example, prior to colonial contact Indigenous peoples managed education, governance, research, and health care (Royal Commission on Aboriginal Peoples, 1996; Wilson, 2008). However, the colonizers viewed Indigenous peoples as uneducated and uncivilized; they did not recognize these systems and established mechanisms to assimilate/"civilize" Indigenous peoples (Lawrence, 2004; Royal Commission on Aboriginal Peoples, 1996). Further, the dominant discourse portrayed and continues to predominantly portray Indigenous peoples as uneducated and uncivilized. If not addressed, the incongruence between the dominant discourse and Indigenous discourse could render cross-cultural research and interviews, in particular, as another site for the perpetuation of dominant discourse thereby limiting a study's capacity to document and understand Indigenous participants' lived experience. Addressing this dilemma requires the interviewer to be reflective about her/his approach. In response, during interviews I embraced the role of an active listener and 
used probing techniques to develop an in-depth understanding of the participant's lived experience, not to question their presentations or oppress their voice or experience through interrogation. For example, if a participant referred to wicihitowin to describe the Photography Class I respectfully used a clarification probe (e.g., can you tell me more about what you mean by wicihitowin?) rather than asking "What is that?" or, "Why do you do that?". In this way, I learned that wicihitowin is a \" $\Delta$ ל० (Nehiyaw/Cree) word that refers to a process that involves people coming together to share and help one another (Sinclair, Bruyere, \& Hart, 2009). I also practiced reciprocity and responsibility by consulting with school Elders and participants (to the extent possible) during the analysis process through follow-up interviews to ensure that my findings and my interpretations of those findings were relevant and meaningful. I took these steps to challenge potential impacts of dominant discourse throughout the research process.

Another way that I challenged the incongruence between dominant discourse and marginalized discourse was through the use of a technique mentioned earlier called "mirroring". Mirroring means that I actively listened for and made mental notes of the words and concepts that each interviewee used during their interview to communicate their experience (Charmaz, 2014). I then echoed their words, descriptions, and concepts when asking follow-up questions in order to open up a linguistic space for each participant to communicate their experience in their own words and language.

As previously mentioned, I also practiced a structured form of critical reflexivity in an attempt to strategically limit my own potential oppression of participants' communication by keeping a reflective journal. 
After each interview, I transcribed the digital recording and then read the transcript. As I engaged in these activities I also made entries in my reflective journal to critically reflect upon my ability to hear and echo the participants' words and concepts and interrogate whether or not I had effectively fostered an interviewing environment that opened up a linguistic space for the interviewee to communicate their experience in their own words. As discussed earlier, while making journal entries I strived to document and discern my ability to employ Kirkness and Barnhardt's (1991) tenets of Indigenous methodologies during each interview. This type of critical reflection was important because my ability to practice the tenets of respect, reciprocity, relevance, and responsibility had an impact upon my ability to open up linguistic space for interviewees to communicate their experience. It is important to note that the measures I took during (i.e., mental reflexivity, mirroring, and probing techniques) and after (i.e., maintenance of a reflexive journal) each interview only limited but did not eliminate the possibility of inadvertently oppressing an interviewee's linguistic space.

Power. Another critical factor that can have an impact on the interview process is power. For the purpose of this paper, power refers to the relationship between the researcher and interviewees and in particular who (i.e., interviewer or interviewee) controls what is discussed during the interview. As stated earlier, by embracing Charmaz's (2014) constructivist approach to GTM's I view interviews as a coconstruction that takes place between the researcher and the interviewee. However, as Charmaz (2014) states the:

Researcher has a topic to pursue. Research participants have problems to solve, goals to pursue, and actions to perform, and they hold assumptions, form ideas, and have feelings about all of these concerns. Both interviewer and interview participant bring their own priorities, knowledge, and concerns to the interview 
situation. (pp. 57-58)

The situation described in the above quote illustrates some of the challenges that can arise when conducting interviews. Ryen (2002) echoes Charmaz when he argues that interviews do not represent a static relationship where the interview process identifies the respondent's truth. Instead, the interview is a process where the researcher and interviewee construct a conversation that results in findings that represent partial truths or interpretations of interpretations that are theoretically plausible. Thus, interview findings are not meant to be generalizable; they are context specific. Given that my research study occurred in a context where interviews and interview data are co-constructions, it is important to articulate how the interviewee and I were positioned during the interview process and how power imbalances were acknowledged and addressed through intensive interviewing and my practice of critical reflexivity.

During each interview, I attempted to modify the traditional power dynamic where the researcher is the authority figure and expert and the interviewee is an object of study by practicing a feminist and Indigenous positionality. As such, interviewees were positioned as the expert and authority of their experience while I was positioned as the learner (Lather, 1991; Wilson, 2008) whose responsibility was to learn from, not learn about, the participants' experience (Kovach, 2009). Furthermore, my role was to hear the interviewees' experience and interpret their experience in a respectful and iterative manner without letting my preconceptions and assumptions impact the findings (Charmaz \& Belgrave, 2012; Jones \& Jenkins, 2008; Smith, 2012). In addition, by using intensive interviewing my main objective was to begin the interview by clearly articulating the experience that I was interested in learning from. For example, I clearly stated that I was 
interested in learning about the Photography Class from the interviewee's experience with the class. After coherently communicating my research topic/question it was my role to sit back and embrace the position of an active listener and learner and only interject, when necessary, through follow-up questions, mirroring, and/or probing techniques.

Although the interviewee and I co-constructed the interview, when I positioned myself as an active listener and learner, the interviewee became positioned as the authority who guided the direction and content of conversation. There was a tension here because in asking the initial question I set some parameters for the interview discussion which had an element of structural power and control (Charmaz, 2006, 2014). However, when I took on the role of an active listener, opportunities for me to oppress an interviewee's voice and experience as well as opportunities for my assumptions and preconceptions to influence the direction and content of the interview were limited. This constraint on the power of my position as interviewer was established at the very beginning of the interview because, after stating the research topic/question, I let the interviewee take control over the direction and content of the ensuing conversation. That said, I did not assume that the use of intensive interviewing was enough to dismantle the traditional power dynamics between interviewer and interviewee. Therefore, as with language, I employed the practice of critical reflexivity through the continual maintenance of a reflexive journal to acknowledge and mitigate, to the extent possible, any challenges related to power that arose during interviews. Next I briefly discuss the insider and outsider status and how I attempted to address this problematic. 
Insider outsider status. Elliot Liebow's (1967) classic study Tally's Corner was an ethnographic study that examined child-rearing practices in low-income families in the District of Columbia. Liebow, who was a Jewish graduate student, conducted fieldwork with low-income African American males. During this study, Liebow developed the concept of a chain-link fence that illuminates the core issues of insider and outsider status. For example, while reflecting upon his experience Liebow states that even though he became quite "tight" with the research participants he was relegated to an outsider status because of his race, education, occupation, residence, and speech. These aspects of his identity ensured that:

the wall between us [researcher and research participants] remained, or better, the chain-link fence, since despite that barriers we were able to look at each other, walk alongside each other, talk and occasionally touch fingers. When two people stand-up close to the fence on either side, without touching it, they can look through the interstices and forget that they are looking through a fence. (pp. 250251)

Within this quote lies the crux of the long-standing insider and outsider debate which asks whether the researcher's status as an insider and/or outsider influences the research process and findings. And if so, does this matter and what is the most appropriate means for addressing this situation? This debate was of utmost importance to my study because I conducted interviews outside my cultural group. Although culture is the most obvious axis of intersection, there are other components of identity such as social status, education, gender, ability, sexual orientation, and age that can intersect in complex ways and required consideration. For example, an interview with a person that identifies as a middle class, queer, female will intersect in different ways than an interview with a person that identifies as a working class, heterosexual, male. Next I outline the main 
insider and outsider debates and discuss how I attempted to acknowledge and manage this problematic.

The binary concepts of the "insider" and "outsider" can provide a useful conceptual framework for researchers such as myself with respect to what my status can mean to the interview process. For example, if a researcher self-identifies as an outsider they have distance from the topic and the ability to be more objective (McCracken, 1988). Recent debates, especially those offered in the feminist research literature, have questioned and complicated this insider/outsider binary and brought forward more nuanced understandings of the potential impacts of insider and outsider status on the interview process (Corbin-Dwyer \& Buckle, 2009; Gair, 2012; Hayfield \& Huxley, 2015; Tang, 2007).

Of particular concern for scholars exploring Indigenous issues is how the binary notion of insider and outsider status can essentialize identity. Coombes (2013), Jones and Jenkins (2008), and Smith (2012) argue that, similar to all identities, Indigenous identities are not static or homogenous. Furthermore, non-Indigenous and Indigenous identities were and continue to be constituted by the colonial processes (e.g., Canada's Indian Act) that systematically and institutionally limit Indigenous identities as static and traditional (Coombes, 2013; Jones \& Jenkins, 2008). To be effective in studying and presenting the impact of colonialism on Indigenous people, researchers cannot ignore binary terms that symbolize difference such as insider and outsider status. As Jones and Jenkins (2008) state:

indigenous peoples - as a matter of political, practical, and identity survival as indigenous peoples - insist on a profound difference at the self-other border. The hyphen is non-negotiable. Indeed, in the indigene-colonizer research and teaching 
work, the hyphen is to be protected and asserted and is a positive site of productive methodological work. (p. 475)

Jones and Jenkins (2008) do not question the concept of insider-outsider status in and of itself. Instead, they question how this notion is conceptualized, what it means for Indigenous people and others, and who benefits. As a way to reclaim the insider-outsider debate, Jones and Jenkins pragmatically replace the notion of insider and outsider status with the concept of the indigene-colonizer hyphen. Their conceptualization of the hyphen represents a "stroke that both enforces difference and makes the link between. The hyphen's space does not demand destructive good understanding; indeed, it is a space that insists on ignorance and therefore a perpetual lack of clarity and certainty" (Jones \& Jenkins, 2008, p. 482).

Jones and Jenkins (2008) also argue that research should work from within the space represented by the hyphen, the tensions of difference, and uncertainty to foster a "positive site of productive methodological work" not methodological work that conceptually dissolves and replaces the hyphen with a collective "we". Given the colonial legacy of non-Indigenous researchers speaking for and over Indigenous peoples, I view this rejection of a collective "we" as a political act aimed at advancing Indigenous peoples' ability and space to speak for themselves. Because I find Jones and Jenkins (2008) concept of an indigene-colonizer hyphen useful as a conceptual tool, I embraced their approach as a way of assisting me with remembering, acknowledging, and interrogating the unique historical/political and colonial/relational context within which my research interviews took place.

Although cultural identity is a significant concern for my project and required a sensitive and pragmatic approach there are other elements that compose one's identity 
that also required consideration in my study. For example, an individual's identity can be comprised of, but not limited to, social status, education, gender, ability, sexual orientation, and age. These factors intersect in complex ways during the interview process. Working from a constructivist stance, Ryan, Kofman, and Aaron (2011) and Ryen (2002) argue that how a researcher or interviewee self-identifies or how the researcher is perceived by the interviewee is not determinative. Similar to Charmaz (2014), they argue that interviews result in a co-construction of meaning and that meaning is always affected by such processes as how interviewer and interviewee perceive self and others. Thus, it is important for the researcher to take steps to acknowledge and account for both their own identities and the interviewee's identities when analyzing data.

It is at this point that Jones and Jenkins' (2008) concept of an indigene-colonizer hyphen becomes a useful tool for data analysis. Specifically, the indigene-colonizer hyphen cautions us not to attempt to construct a "we" out of differences but to recognize that there are tensions within research projects and research data that recognition of these key differences may highlight in ways that deter us from creating and presenting a single worldview. For these reasons, I integrated Jones and Jenkins (2008) concept of the indigene-colonizer hyphen as a part of my methodological approach to facilitate a more respectful and reciprocal interview approach and a more relevant and responsible data analysis process that did not conflate but instead facilitated a historically and politically aware discussion across difference. Thus, for example, the cautions that Jones and Jenkins (2008), Ryan et al., (2011), and Ryen (2002) offer were addressed though my praxis of critical reflexivity. The complexities of language and power were also 
highlighted for me through maintenance of my reflexive journal and my continual attempt to acknowledge, interrogate, and mitigate (to the extent possible) the problematics surrounding insider and outsider status.

Representation. Representation and knowledge production refer to who is speaking for whom and for whose benefit. As with language, power, and insider outsider status, the problematic of representation requires engagement with critical reflexivity which I tried to accomplish through my practice of reflexive journaling. However, from reviewing the literature on Indigenous methodologies it is clear that I should not and cannot speak for or over Indigenous peoples as this would be akin to a perpetuation of colonialism (Kovach, 2009; Lawrence, 2004; Smith, 2012). Yet the task before me as a graduate student and researcher necessitated that I engage with Indigenous research participants through an iterative process of intensive interviewing and data analysis with the ultimate goal of facilitating the emergence of a substantive theory. Following these activities, I will defend my thesis and disseminate the findings. However, I argue that how I do this determines whether or not I have contributed to or resisted the colonial act of speaking for and over Indigenous peoples.

Given my epistemological orientation as a constructivist, I worked from the claim that the substantive theory that emerged during this research study represents coconstructed truths that are theoretically plausible and hold analytic power (Charmaz, 2006). Specifically, I argue that, when grounded theory's inductive approach and Charmaz's constructivist (2014) approach were pragmatically interwoven with Indigenous knowledge (as I did through the use of reflexive methodologies), fostered conversational (interview), conceptual (memos), and theoretical (substantive theory) 
space emerged that heard, took seriously, and valued the research participants' lived experiences with the Photography Class. To ensure that this process was successful, as with the complexity of language, power, and insider and outsider status, after each interview I engaged in critical reflexivity through my practice of reflexive journaling to identify and interrogate whether or not I was taking seriously and valuing the participants' voice and experience.

Further, once I completed the analysis process (outlined in the following section), I invited all of the research participants (school Elders, students, and school personnel) to take part in a verification process at the school during school hours to ensure that the study's findings reflected their lived experience, was meaningful, respectful, and accurate. During this verification process, none of the participants, including the students, disagreed with the findings and the majority expressed gratitude for the opportunity to be part of the Photography Class (Field note, April 4, 2017). This process reassured me that I had engaged in a more equitable and transparent co-construction of the participants' lived experience. However, the participants' involvement in the verification process does not dissolve the fact that I hold the ultimate responsibility of defending my thesis and disseminating the findings. Here lies the tension of representation for me because I have to present and defend my research project without speaking for or over participants. This tension fundamentally illustrates why I employed a mixed methodological approach that interwove GTM, Indigenous methodologies, and reflexivity to mitigate, to the extent possible, this study from being another site of colonial practices that oppressed Indigenous theories of knowledge and experience. 
I outline the methodological procedures that I used to analyze my data in the remainder of this chapter. For reading purposes I have presented the data gathering process (participant observation and interviewing) and the data analysis process (initial coding, focused coding, and theoretical sampling) in separate sections. However, in practice these processes were iterative and continually co-occurring. My data analysis results appear in the next chapter.

\section{Data Analysis}

Before delving into the data analysis, it is important for readers to understand that the $\mathrm{O}^{\prime \prime} \Delta$ ל० (Nehiyaw/Cree) stories and teachings discussed in the remainder of this thesis were, in and of themselves, not the focus and were out of scope of this study. Further, because I am not the knowledge holder of these stories or teachings, they are not mine to share in general or in this thesis. If you are interested in learning about the teachings identified in this study, I encourage you to approach Elders who are knowledge holders and offer the appropriate protocol to receive these teachings. What was appropriate and what I do discuss in this thesis is captured best in a conversation that I had with Elder E. B., after the Photography Class had concluded. During this discussion, Elder E. B. said to me that, "the stories that were shared during the [Photography Class] are now part of your story" (Personal Communication, June 01, 2016). Further, Elder L. B. shared with me two ঢ" $\Delta$ ל० (Nehiyaw/Cree) phrases to help me understand my role: asonamakewin (sharing of knowledge) and casonamakeyin (one who shares). After giving much thought to Elder E. B.'s words and Elder L. B.'s phrases, I have come to understand that my role and responsibility as a researcher is to tell my story of the research process and data analysis. That story is shaped by the stories that were shared 
by the research participants in this study and how those stories became woven into a thread of narrative that illuminated their individual and collective lived experiences with the Photography Class.

This section of the chapter outlines the analytic process that informed this research study and how I interwove Charmaz's (2014) GTM approach with narrative analysis. As with the data gathering process, my data analysis was informed mainly by Charmaz's approach to GTM; however, I revised her approach to ensure that this aspect of the research study was sensitive to and in alignment with how data was shared, in narrative, by Photography Class participants. Below I discuss how each of the three steps of analysis (initial coding, focused coding, and theoretical sampling) unfolded and facilitated the emergence of a substantive theory.

Initial coding. After conducting each interview, transcribing the digital recording, and making entries in my reflexive journal, I engaged in initial coding. This type of coding entailed going through the documents line-by-line to ascertain what was happening in the data. For Charmaz (2014):

Coding gives you tools for interrogating, sorting, and synthesizing hundreds of pages of interviews, field notes, documents and other texts. Interrogating your data means that you take them apart and examine how people enact or respond to events, what meanings they hold, and how and why these actions and meanings evolved. Whether we have collected stories, scenes, or written statements, we study and define these materials to analyze what happened and what they might mean. (p. 113)

Further, each "code sets up a relationship with your data, and with your respondents" (Star, 2007, p. 80) with the objective of understanding what the data means. The coding process is not based upon neutral observations; rather, codes result from my interpretation of the data. Glaser (1978) refers to this form of analysis as coding in 
gerunds. A gerund is a noun formed from a verb by adding-ing to the verb. By using gerunds to guide my coding, I focused on actions and sequences in the data. In total, this phase of the analysis process resulted in the identification of 463 initial codes and 1 in vivo code.

In vivo codes refer to the special terms that participants use as a symbolic marker (Charmaz, 2014). There are four different types of in vivo codes; "[1] terms that everyone 'knows' that flag condensed but significant meanings, [2] a participant's innovative term that captures meaning or experience, [3] insider shorthand terms reflecting a particular group's perspective, and [4] statements that crystalize participants' actions or concerns" (p. 134). The in vivo code that was identified during this phase of analysis was termed "Standing-up." "Standing-up" reflected the fourth type of in vivo code identified by Charmaz (2014) in that it was a statement that emerged in the data and referred to the students' concern for and action of standing-up and naming themselves before someone else could use racist terms and/or racist ideology against them. Identification of an in vivo code such as "standing up" helped to ensure that the analysis process was grounded in the research participants' point of view and experience. The overall significance of this in vivo code is discussed in more detail in Chapter 4; however, my identification of initials codes for all of the data sets (interview transcripts, field notes, reflexive journal, text from the students' published book) and one in vivo code, enabled me to move into the second phase of analysis - focused coding.

Focused coding. The second phase of GTM analysis is termed focused coding. During this coding phase I began to "sift, sort, synthesize, and analyze large amounts of data ... [to make decisions] about which of the initial codes make the most analytic 
sense" (Charmaz, 2014, p. 138). Throughout this process, I continually asked "what larger analytic story they [the codes and data] indicate" (Charmaz, 2014, p. 124). This line of inquiry is critical because it facilitates the emergence of a more in-depth understanding of what is happening in the data by identifying which of the initial codes reflect higher level constructs. Codes with higher level constructs are termed core codes because they encapsulate many of the initial codes found through line-by-line coding. Further, as Charmaz (2014) explains, core codes make analytic sense because they hold significance, emerge more frequently, and have "more theoretical reach, direction, and centrality" (p. 141). Codes that meet the above criteria are theoretically plausible and bring the findings closer to reflecting what is happening in the data on a theoretical level.

While conducting this phase of analysis I found myself struggling to synthesize the initial codes into more theoretical core codes. I began to reflect upon the fact that this study was conducted with a First Nation community that continues to practice its oral tradition of storytelling and that the data reflected this practice. Therefore, line-by-line analysis was too small of a unit of analysis and had inadvertently fragmented what was happening in the data. This incongruence between the unit of analysis (line-by-line) and the manner in which data was shared (storytelling) resulted in my inability to synthesize and identify which of the initial codes were core codes and theoretically plausible (Memo, October 6, 2016). In response, I revised my approach by moving from a line-byline unit of analysis to a paragraph-by-paragraph approach that enabled a stronger understanding of the interviewees' way of communicating through "longer stretches of talk that take the form of narrative" (Riessman, 1990, p. 1195). This revision to the GTM analysis process is where my data analysis began to take a narrative turn. 
Narrative analysis. Porter Abbot (2002), a prominent literary scholar, states that "narrative is the representation of events, consisting of story and narrative discourse, story is an event or sequence of events (the action), and narrative discourse is those events as represented" (p. 16, original emphasis). Marie-Laure Ryan (2007) also notes that "narrative is about problem solving; narrative is about conflict; narrative is about interpersonal relations; narrative is about human experience; and narrative is about the temporality of existence" (p. 24). Like Charmaz's (2014) approach to GTM, a narrative analysis focuses on what is happening in the data by identifying and examining actions and sequences. Unlike GTM, narrative analysis does not use coding strategies such as line-by-line coding and in vivo codes but focuses instead on codes that explicate temporality and the sequence of the participants' storied experience (Floersch, Longhofer, Kranke, \& Townsend, 2010). Challenging this methodological tradition, Floersch et al.'s (2010) study examined adolescent experience with psychotropic treatment by interweaving Charmaz's GTM with narrative analysis. Building upon that research methodology, my research study also incorporated narrative analysis with Charmaz's (2014) GTM by broadening my units of analysis and providing the analytic space needed to facilitate the emergence of a storied understanding of the students' lived experience with the Photography Class.

Utilizing this revised approach, I re-analyzed the data (interview transcripts, field notes, reflexive journal, text from the students' published book) on a paragraph-byparagraph basis. This analysis resulted in the emergence of 26 initial codes and the identification of the same in vivo code that surfaced during the first phase of line-by-line coding. Following the identification of the 26 initial codes, I re-engaged in the process of 
focused coding by sifting and sorting initial codes and comparing and contrasting these codes with data (interview transcripts, the students' published book, and filed notes) and the 1 in vivo code to analytically lift the codes through the identification of the theoretically plausible codes. This phase of analysis resulted in the 26 initial codes being collapsed into 7 core codes that made the most analytic sense, held significance, emerged more frequently, and had "more theoretical reach, direction, and centrality" (Charmaz, 2014, p. 141).

Having identified seven theoretically plausible codes, I began to reflect upon the fact that the data had been gathered and analyzed through the English language. This was of concern for me because as a consequence $\mathrm{C}^{\prime \prime} \Delta$ ל० (Nehiyaw/Cree) words and phrases that had been shared by Elders, school personnel, and students had been unintentionally marginalized thereby limiting the research study's capacity to capture what was happening in the data and ultimately the students' lives experience with the Photography Class (Reflective Journal Entry, October 25, 2016). Further, as it is widely acknowledged, one cannot understand an Indigenous worldview without first understanding the language because certain ideas and concepts do not exist in the English language. In response, I re-analyzed the data to identify $\mathrm{C}^{\| \prime} \Delta$ ל० (Nehiyaw/Cree) words and phrases to purposefully move away from my reliance on the English language and move towards grounding the analysis process in the $\mathrm{C}^{\prime \prime} \Delta$ ל० (Nehiyaw/Cree) language.

This strategic examination of the data facilitated the identification of three ত" $\Delta$ ל० (Nehiyaw/Cree) words and one ૪" $\Delta$ ל० (Nehiyaw/Cree) phrase (Memo, October $29,2016)$. Following the identification of the three \" $\Delta$ ל० (Nehiyaw/Cree) words and 
one $\mathrm{C}^{\|} \Delta$ ל० (Nehiyaw/Cree) phrase, I engaged in what I refer to as collaborative memo writing. Lempert (2007) states that "[m]emo writing is the methodological link, the distillation process, through which the researcher transforms data into theory" (p. 345).

Memo writing. Traditionally memo writing is an analytic technique that is used independently by the researcher(s) to document findings that arise while iteratively comparing codes with codes, codes with data, and data with data. Memo writing assists with the process of analytically lifting codes to categories that articulate the assumptions, processes, and actions that each category represents. Each category is then unpacked and the characteristics that constitute each category are identified and scrutinized through comparisons with data and other categories. Through this process, categories come to explicate ideas, processes, and events in the data and make the relationships between categories visible. However, acknowledging my cultural and linguistic limitations as a non-Indigenous individual, I took the unique approach of making the technique of memo writing a collaborative activity.

Collaborative memo writing entailed me going to the community and meeting with research participants that were able to meet with me to examine the seven core

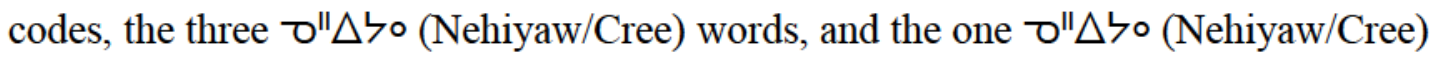
phrase. Three school Elders (D. M., E. B., \& L. B.) and three school personnel (S. H., S. W., \& T. L.) met with me to discuss if and how these findings were related to one another. What emerged from this discussion was the finding that the three ૪" $\Delta$ ૫০ (Nehiyaw/Cree) words and one $\mathrm{O}^{\prime \prime} \Delta$ ל० (Nehiyaw/Cree) phrase represented yet a higher level of construct that Charmaz (2014) terms a core category. Further, the seven core codes, respectively, represented the different properties of the four core categories I had 
identified in my previous coding exercises using English language (Memo, December 06, 2016). These findings are discussed in more detail in the following chapter. For now, what is important to note is how I revised the memo writing process to include school Elders and school personnel and how their participation was critical to the emergence of the four core categories that analytically lifted the findings to a higher level of construct. Having analytically lifted the data to a higher level of construct and having identified the core categories and their respective properties, I moved into the final phase of analysis, theoretical sampling.

\section{Theoretical Sampling}

As I transitioned into the analytic phase of theoretical sampling, I entered into the final phase of analysis where I ensured that the core categories were clearly delineated, robust, and illuminated variations within and between the categories. Charmaz defines theoretical sampling as a:

type of grounded theory sampling in which the researcher aims to develop the properties of his or her developing categories or theory ... [by] the researcher seek[ing out] people, events, or information to illuminate and define the boundaries and relevance of the categories. (2006, p. 189)

In practice, theoretical sampling means going back into the field to gather additional data through interviews that ask targeted questions to assist with grappling and working through theoretical dilemmas and gaps. To assist with this task and before going back to the community to engage in theoretical sampling, I sketched a diagram that transformed the findings thus far into a visual representation of the four core categories and the relationships within and between each of the core categories. After drafting the diagram, I went back to community to meet with the same group of research participants that took part in the collaborative memo writing session (Elder D. M., E. B., \& L. B., and school 
personnel, S. H., S. W., \& T. L.). The purpose of this visit was to review the diagram to further probe and interrogate the core categories, their properties, and the variations within and between the categories.

During this discussion, participants shared that the diagram of the four core categories, their properties, and relationship within and between the categories accurately captured the students' lived experience with the Photography Class (Field note, December, 13, 2106) and did not require any revisions. I did not want to rush this process so I left a copy of the diagram with each of the research participants so that they could have additional time to review and provide feedback. After 3 weeks passed I returned to community to discuss the diagram. During this visit only the school Elders (D. M., E. B., \& L. B.) were available to meet with me. Irrespective of the students' absence, as knowledge holders the school Elders' contributions during this meeting proved to be a pivotal point in the analysis process.

As I sat down with the school Elders they began to share that the diagram and its four core categories, and the properties and relationship within and between the categories, were accurate. However, something was missing from the diagram. They went on to share that what was missing was a higher level of understanding of what the diagram was depicting. In particular, they shared that the diagram was reflecting the renewal of a $\mathrm{C}_{\|}^{\prime \prime} \triangle \circ$ (Nehiyaw/Cree) practice that had been disrupted by the I.R.S.S. Prior to this disruption and since time immemorial, this practice had been passed from one generation to the next and this year's Photography Class represented a renewal of this practice (Field note, January 11, 2017). At this point in the analytic process, and after making this revision to the diagram, the findings had reached a point of saturation. 
Saturation highlights the primary characteristic of grounded theory in that grounded theorists seek out and utilize data to systematically and progressively lift analytic ideas to a point where a theory emerges that "accounts for the full range of relevant experiences in the data" (Charmaz, 2014, p. 206). In contrast, quantitative studies using deductive approaches employ a pre-identified theory to probe data thereby theoretically and systematically limiting what can be learned from the data. Returning to grounded theory's process of theoretical sampling, I utilized this technique until the categories reached a point of saturation. In grounded theory, saturation does not mean that there is no new data or patterns observed in the data. Rather, saturation means that: theoretical categories are "saturated" with data. In other words your categories and your established properties account for patterns in your data (in Charmaz, 2014; Glaser, 1978; Holton, 2007; Weiner, 2007) ... [and] you have defined, checked, and explained the relationships between categories and the range of variation within and between your categories. (Charmaz, 2014, p. 213)

As previously mentioned, I went out to the community and presented the findings to all of the research participants (students, school personal, and school Elders) and each participant verified my findings. In this way, through my employment of a revised approach that interwove Charmaz's GTM with narrative analysis, this phase of the research study achieved "increasingly more abstract levels of analysis" (Charmaz \& Belgrave, 2012, p. 348). Significantly, that analytical process resulted in the emergence

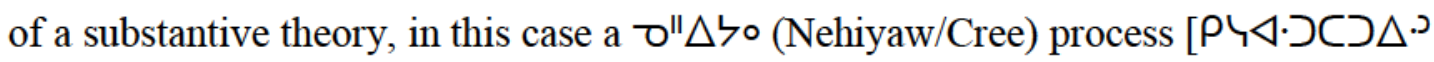

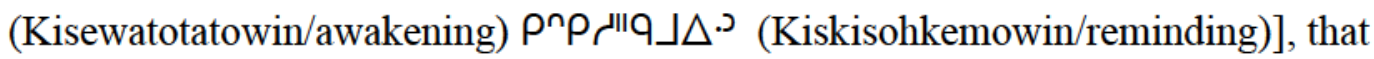
explicated a storied and in-depth understanding of the students' lived experience with the Photography Class. 
This chapter outlined the theoretical framework (decolonization), methodologies, (GTM, Indigenous, and reflexivity), methods (participant observation and interviewing), and analysis (GTM and narrative) that I employed throughout this research study. The ensuing chapter unpacks the findings that emerged as well as their implications for the study of racial prejudice and broader society as we begin to take serious and look for ways to reconcile Canada's colonial legacy and mitigate racism between non-Indigenous and Indigenous peoples. 


\section{Chapter 4 - Data Analysis and Discussion}

An old Cherokee is teaching his grandson about life. "A fight is going on inside $m e$," he said to the boy. "It is a terrible fight and it is between two wolves. One is evil - he is anger, envy, sorrow, regret, greed, arrogance, self-pity, guilt, resentment, inferiority, lies, false pride, superiority, and ego." He continued, "The other is good - he is joy, peace, love, hope, serenity, humility, kindness, benevolence, empathy, generosity, truth, compassion, and faith. The same fight is going on inside you - and inside every other person, too." The grandson thought about it for a minute and then asked his grandfather, "which wolf will win?" The old Cherokee simply replied, "The one you feed" (Field note, December 02, 2015).

During the first session of the Photography Class, the above Cherokee legend was shared with the students. The teaching contained in this legend foreshadowed what would take place over the duration of the course, a process of feeding the inner "good wolf"/practice of love and kindness.

\section{Introduction}

The findings presented in this chapter document the process that the Elders

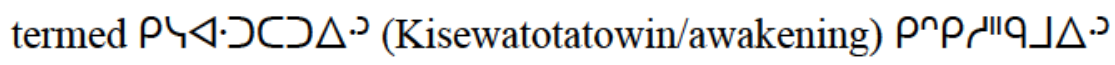

(Kiskisohkemowin/reminding). As I noted in the previous chapter, during the analytical coding process I identified four phases and then confirmed the conceptual model with the Elders. They validated the model and added to it the process of $P 4 \triangleleft \cdot \supset C \supset \Delta \cdot$

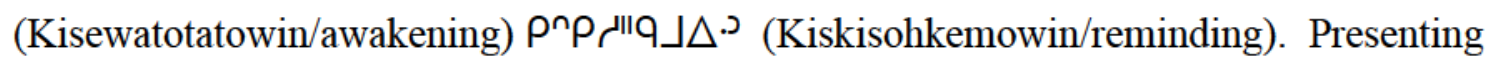
this conceptual frame is challenging because the identification of the four phases, their naming, occurred after the program was completed. In documenting the process below, I use the terms that emerged in the analytical coding. I document the four phases and then discuss the diagram and the impacts that this process had on students. The four phases were defined as: 
(1) $\triangleleft \Delta \cdot$ o $P$ ל (Awina Niya/who I am),

(2) $\nearrow^{\prime \prime} \Delta ৬ \triangleleft `$ (Nehiyawak/Cree people),

(3) $\mathbb{Z}^{\prime \prime} \triangle$ ל० (Nehiyaw/Cree individual), and

(4) $\nmid P^{\prime \prime} \Delta \supset \Delta \cdot{ }^{\supset}$ (Sakihitowin/love and kindness).

Collectively these phases are identified as renewing the development of a specific

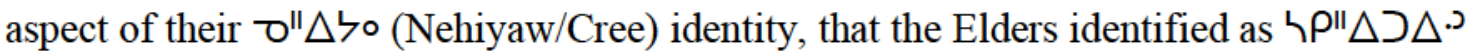
(Sakihitowin/love and kindness). This aspect of the Cree people's identity was interrupted by the Residential Schools ${ }^{17}$. As such, it represents an impact of racism. This program, as a process of renewing $\nmid \rho^{\|} \Delta \supset \Delta^{\cdot} \cdot$ (Sakihitowin/love and kindness), is also a process for mediating the impacts of colonization and racism. Utilizing an approach of descriptive narrative, I describe why the students said they made their book and the approach that was used. Following that I unpack each of the four phases to delineate what occurred during each phase and its purpose. After examining the four phases, I identify and discuss the conceptual model that summarizes the main findings and three impacts (self-expression, sense of well-being, and agents of social change) related to the process of renewing $\nmid \rho^{\|} \Delta \supset \Delta^{\supset}$ (Sakihitowin/love and kindness). Having outlined the main findings, I then utilize Smith's (2012) lens of decolonization to examine and discuss how the findings represent a locally informed process of decolonization.

The purpose of the photography class. Since 2010 , Grades 7,8 , and 9 students have annually published a book with a broad purpose of providing themselves, their community, and broader society with a more complete narrative about who they are than

\footnotetext{
${ }^{17}$ Thus far I have utilized the term Indian Residential School System (I.R.S.S.). However, research participants used the term Residential Schools. Therefore, to reflect the language utilized by research participants I use the term Residential Schools throughout the remainder of this thesis.
} 
was predominantly circulated in mainstream media. For example, S. H., the Coordinator, explained that:

Back in 2010, was when we started the book, I was thinking about what the public narrative looked like. Having worked in the community for a number of years, it did not feel fully accurate to me. I wanted to ask the students about the way in which main stream media was representing their community. I invited a group of junior high students and asked them if they felt the media provided a fair and accurate representation of their community. Their response acknowledged that some of the issues being represented in media were accurate, but that the media provided a very narrow and incomplete version of their community. We also discussed the question of identity and self-determination. I asked them if they wanted to challenge that public narrative and they agreed to do so. We used photography as a medium to explore the internal and external landscapes of identity, representation and agency. This is how the project was started. In some ways, the project did have its roots in understanding and addressing systemic racism. It was definitely aimed at looking at identity politics, the history of Indigenous and non-Indigenous relationships and how we understand or don't understand each other. (S. H., Interview, June 08, 2016)

While previous Photography Class books dealt with Indigenous and non-Indigenous relations and how these two groups understand each other, those books did not deal specifically with racism, the focus of the book for 2016. Further, this Photography Class was identified by S. W. a member of school staff and parent as the first time that this community had formally facilitated a discussion on racism. S. W. shared that:

This project is important to me because we are a tiny community and nobody has ever touched on racism in this fashion and said "hey let's talk about racism", nobody has ever gone there. And ... it is important because we do need to be educated on racism. Absolutely. (S. W., Interview, May 25, 2016)

C. C., also a member of school staff and parent stated that:

It was kind of like to me, it was kind of a touchy subject to talk about, but after a while I thought it was a good idea that the students, do this. It is a touchy subject but sometimes you need to talk about racism. (C. C., Interview, May 25, 2016)

Certainly, talking about the trauma that racist practices have had and continue to have is not an easy task. The Photography Class was designed to provide a safe environment 
where the students could come together with the support and guidance of community members (school personnel, parents, and Elders) to learn how Canada's colonial practices and racist ideology have shaped their communities' past and continue to shape (distort) how dominant society perceives them. Recognizing the incongruence between the dominant narrative and their lived experience, the students decided that this year's book would tackle the issue of racism for the following reasons:

We made this book to see and be seen. As First Nations youth, we are affected by racism. We have been labelled. We have been discriminated against. The struggle is real. Residential schools hurt our families. We are thankful for the guidance from our Elders. We are here to say we will overcome discrimination and hardships. We know not everyone labels us and we sometimes label others but we should stand together not against each other. All in all, we are all humans. We hope our book helps our community, our people, ourselves, and anyone who reads this book. Things can get better. $\left(\right.$ Book $^{18}, 2016$, p. 2)

The above quote is from a collective statement that the students published as an opening statement in their book. It links the harm that was experienced by their ancestors who attended the Residential schools and racism. The quote also states that they made this book "to see themselves and be seen by others". For the students, it was important to be seen so that readers can understand the impact of racism (both historical and current) on them, their families, and their community. With the guidance of their Elders, the students wanted their book to redress this harm by coming together and writing a more complete and positive narrative. This would help them, their community, their people, and readers in general to understand who they are. K. L., one of the students, unpacked their collective statement further when he explained that:

[this book,] it gives us ... this is like a voice for us right here. It is going to go in [to different communities] ... and just by them reading this book it is going to be,

\footnotetext{
${ }^{18}$ In order to protect the anonymity and confidentiality of research participants I have used the generic title "Book" to refer to the student's 2016 publication.
} 
not exactly us speaking, but [by reading] . . . what we said and the pictures that we took [they will hear us]. (K. L., Interview, June 01, 2016)

K. L.'s statement captures the sentiments of his fellow students, in that their book was one way for their voices to be metaphorically heard through the photos and the statements that they wove together to tell a particular story about who they are. Further, the story that they told about who they are was in dialogue with and specifically challenging and complicating the dominant narrative. As R. C., a student, stated as part of her speech during the book launch at the end of the course, "I joined the [Photography Class] because I wanted to help people understand that we are more than a stereotype" (R. C., Interview, June 02, 2016). D. C., another student, explained that their book was important:

Because we are showing some of our culture in this and expressing ourselves as the way we feel about our own life and stuff like that, showing the bright side, not the bad side and stuff. ... a lot of people when they went to residential school turned to drinking, that is why mostly all of the Natives drink, but I want be one of those Natives that does not drink and I want to try [to] rise up to be something great and try to bring everybody with me and not leave everybody in the town site and around here just to rot. [And] I want our voices to be heard. (D. C., Interview, May 25, 2016)

These quotes illustrate how the students perceived their book as a tool to author and share a more complete and positive narrative about who they are. It is important to note that the above quotes also illustrate how the students recognize that their community continues to be impacted by the Residential School era, that some members drink to cope with this colonial legacy' and that the Residential Schools led to intergenerational trauma. The students also communicated that although they have been negatively impacted and labelled by a colonial and racist narrative, they intend to rise above these labels to do great things by becoming a physician (D. E., Book, 2016, p. 43), engineer (R. 
C., Book, 2016, p. 23), counsellor (J. J., Interview, May 25, 2016), Elder (K. L., Book, 2016, p. 21). Further, with their awareness of how dominant society perceives them through a racist lens, the students sought to influence wider societal perceptions by providing a more complete and positive narrative than the predominantly racist narrative that continues to be circulated in the mainstream media. Having established what they wanted to achieve with their book, a more complete and positive narrative about who they are, the next step was to identify how to accomplish this objective. Following First Nation protocol, this entailed seeking out the guidance of an Elder to identify the approach that should be taken to achieve their goal.

The approach. At this point in the Photography Class, the students knew that they wanted to be seen for who they are and that the tool they would use to attain this goal was their book. The question before the students and the Coordinator was how to achieve this goal. As discussed in the first chapter and following protocol, the Coordinator approached one of the school Elders, Elder D. M., and explained the theme and objective of the book and asked for guidance on what approach should be taken. I was present during this discussion and listened while Elder D. M. explained to the Coordinator that it would be good if the students could meet with community Elders to receive the Seven Sacred Teachings. Elder D. M. did not explain the reasoning behind his suggestion (Field note, November 25, 2015). Over the years, I have come to understand that Elders give guidance not answers. Their guidance is designed to help 
you move towards an understanding but is up to you to seek-out the meaning of the guidance conveyed.

S. H. incorporated Elder D. M.'s guidance into the Photography Class by approaching seven community Elders, following protocol and in collaboration with Elder D. M., to ask if they would each agree to provide one of the Seven Sacred Teachings to the students. The Elders agreed, thereby establishing an overall approach to the Photography Class that was characterized by storytelling. This approach continued throughout the course (Field note, December 02, 2016). While the approach of storytelling provides insight into what structure the course used it does not describe how Elder D. M.'s guidance was integrated into the Photography Class to develop the students' identities. This guidance is unpacked in the following section where I identify and discuss the four phases that comprise the process of $P \backslash \triangleleft \cdot \supset C \supset \Delta^{\circ}$

(Kisewatotatowin/awakening) $\rho^{n} \rho$ P students found the space to develop their own ๑" $\Delta$ ל० (Nehiyaw/Cree) identity and create a more complete and positive personal narrative about who they are and for them to both see and be seen. At this juncture in my telling of this reconstructed descriptive narrative, it is important to note that although Elder D. M.'s guidance may seem simple on the surface upon further examination his advice was critical in in this developmental process and determined several factors that informed how the Photography Class unfolded.

Elder D. M. understood that, for the students to achieve their goal of authoring a narrative where they could be seen for who they are, they first required a sense of self as a \" $\Delta$ ל० (Nehiyaw/Cree individual), that is, they had to be able to see for themselves who they are. To guide development of this sense of self, Elder D. M. sought to connect 
the students to $\nearrow^{\prime \prime} \Delta$ ל० (Nehiyaw/Cree) teachings and help them put these teachings into practice. To achieve this goal, Elder D. M. used the traditional teaching/learning technique of storytelling. As discussed in the literature review, storytelling is a tool that has been, and continues to be, used to foster space that intentionally and continually moves toward a more in-depth understanding of, in this case, one's "Creeness" (Brundige, 2004; Weber-Pillwax, 2001). The stories offered by Elder D. M. contain teachings about $\mathrm{C}^{\|} \Delta$ ל० (Nehiyaw/Cree) customs and values. More important, when these teachings are put into practice a sense of one's identity as a \" $\Delta$ \০ (Nehiyaw/Cree individual) begins to develop (Brundige, 2004; Weber-Pillwax, 2001). Specifically, through the presentation of a $\nearrow^{\| \prime} \Delta$ ל० (Nehiyaw/Cree) worldview, storytelling and identity development are braided together and simultaneously co-occurring. Reflecting this aspect of Indigenous theories of knowledge, Elder D. M.'s guidance identified an approach informed by a specific method (storytelling) and specific content (Seven Sacred Teachings). This approach fostered a specific learning environment where the students developed their identity as a informative way that allowed them to be able to see who they are (Memo, November 23, 2017). This learning environment did not occur by accident. It was facilitated through the use of an Indigenous approach to education and the application of the four (Nehiyaw/Cree) principles of teaching (informing, teaching, guiding and encouraging).

Indigenous education. Before delving into the four elements of the process of

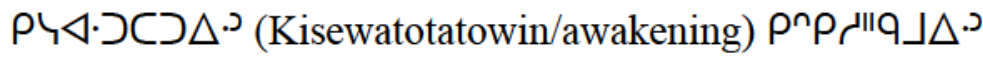

(Kiskisohkemowin/reminding), it is important to understand the educational context in 
which the Photography Class was situated and how this context influenced this study's findings. During the theoretical sampling phase of this study, C. C., one of the school personnel and a parent, stopped me on my way out of the school and said that she would like to share something with me (Field note, January 11, 2017). We were unable to connect at that time so I traveled back to community 2 weeks later. During our discussion, C. C. shared with me the four \" $\Delta$ ל० (Nehiyaw/Cree) principles of teaching (informing, teaching, guiding, and encouraging) and how they had been passed on to C. C. by her mosom/grandpa. C. C. stated that she wanted to share these principles with me so that I could have a better understanding of the students' experience with the Photography Class (Field note, January 24, 2017).

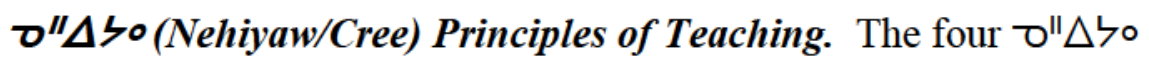
(Nehiyaw/Cree) principles of teaching refer to the use of storytelling to teach. Elders pass along their knowledge of the past (informing) and their knowledge of the ד $\triangle$ "ל० (Nehiyaw/Cree) way of life (teaching) to the next generation, in the school context, to the students. During these two phases of learning students primarily listened to the Elder. After these processes, the Elders transition to the role and responsibility of guiding and encouraging the students as they put into practice the knowledge that was shared during the informing and teaching phase (Field note, January 24, 2017). In the context of this study and as will be evidenced in the ensuing sections, the Elders' voice and livedexperience primarily informed the first and second phase of addressing racism and developing the book. The students' voices and lived experiences predominantly informed the third and fourth phase as they became storytellers themselves. The result is that in the data analysis presented below the Elders' voices predominate in the first two 
phases and the students' in the latter two phases as they found their voice and told their own stories about who they are.

The school Elders (D. M., E. B., \& L. B.) also explained a fundamental difference between Western and ð" $\Delta$ ל० (Nehiyaw/Cree) conceptualization and approach to education. This distinction was important for understanding the processes I observed in the class and the roles of the students and the Elders in those processes. The Elders told me that, in a Western approach a teacher is considered as 'the expert' whose role it is to pass their knowledge to students who are understood to have no prior knowledge of the subject areas. In contrast, although Elders, like teachers are experts as knowledge holders, their role is not to pass their knowledge to students; but to remind youth that the knowledge is already in them. Thus, the role of the Elder is not to 'teach.' Rather, it is to awaken and remind the youth of this knowledge. Comparably, it is the youth's responsibility to learn and make sense of this knowledge for themselves with the guidance of Elders (Field note, January 11, 2017).

The Elders described this difference as a fundamental distinction between Western and \" $\triangle$ ל० (Nehiyaw/Cree) understandings of how knowledge is passed from one generation to the next and, hence, how education is characterized culturally. A Western approach to education assumes that individuals are a "tabula rasa" and develop knowledge as the instructor passes their knowledge to the student. In contrast, a ૪" $\Delta$ ૪ (Nehiyaw/Cree) approach to education assumes that an individual carries the knowledge of their ancestors within them and this knowledge will be accessed when and as needed. Further, the Elders shared that the four phases of the process of $P \backslash \triangleleft \cdot \supset C \supset \Delta^{\cdot}$ 


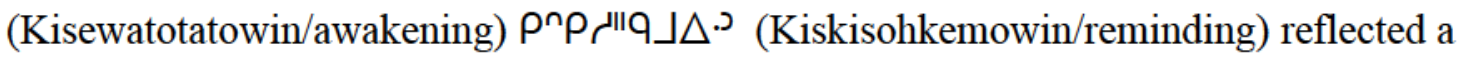
ত" $\Delta$ ל० (Nehiyaw/Cree) approach to teaching that ultimately awakened and reminded the youth of a specific aspect of their identity, $\nmid P \| \Delta \supset \Delta^{\supset}$ (Sakihitowin/love and kindness) (Field note, January 11, 2017).

The approach used during the Photography Class wove together the renewal ceremony of storytelling and $\mathrm{O}^{\|} \Delta ל \circ$ (Nehiyaw/Cree) principles of teachings. Given that the teachings relied on narrative, throughout the remainder of this chapter I use Arthur Frank's work on narrative analysis to assist with framing and unpacking the four phases. Frank studies illness through narrative analysis with a particular focus on stories told from the perspective of individuals experiencing illness $(1995,1997,1998,2000) . \mathrm{He}$ argues that a story is a dialogical process that occurs within and through the relationship between the storyteller and their audience (Frank, 2000, 2002). Frank explains that, for the storyteller, "[s]tories are always already there enabling people to take up identities and delimiting their identity possibilities ... [that are] circumscribed by the availability of narrative resources.... [Narrative resources are] the stories that people know [that] set the parameters of what they can imagine" (2000, p. 45). Therefore, one's identity and identity possibilities are part of an ongoing process that is interlinked with and shaped through the stories that we are told and the stories that we tell ourselves and others.

Frank believes an individual's sense of self emerges and transforms through the process of storytelling: a process that assists with making one's life legible, narratable, and of value to self and others. As discussed earlier, the Indigenous worldview perceives identity development as a lifelong process of learning guided by the renewal ceremony of 
storytelling that teaches and reaffirms cultural customs and values. Further as an individual reflects on these stories and puts the customs and values into practice, knowledge and insights are gained that continually guide the development of one's identity (Brundige, 2004; Weber-Pillwax, 2001). Given the conceptual and heuristic parallels between Brundige (2004) and Frank's (2000, 2002) and Weber-Pillwax (2001) understanding of stories and storytelling in the development of one's identity I use Frank's notion of narrative resources to assist with framing and unpacking the fourphases that comprised the process of $\rho \triangleleft \triangleleft \cdot כ C \supset \Delta^{\supset}$ (Kisewatotatowin/awakening)

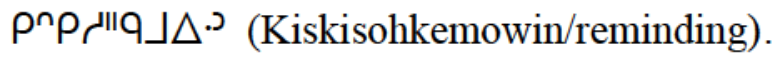

\section{Four-Phase Process}

In the ensuing four sections I examine and discuss how the four phases that were found to comprise the process of $P \hookrightarrow \triangleleft \cdot \supset C \supset \Delta^{\top}$ (Kisewatotatowin/awakening) $\left.\rho^{n} \rho{ }^{\prime l l} \mathrm{q}\right\lrcorner \Delta^{\cdot د}$ (Kiskisohkemowin/reminding) represent one way of renewing a particular

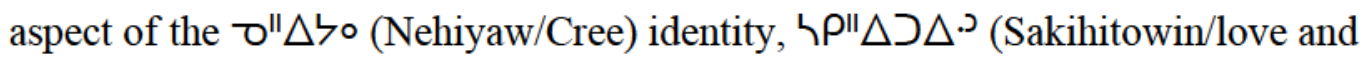
kindness). I begin by illustrating how the initial phase of this process, termed $\triangleleft \Delta \cdot{ }^{\circ} \mathrm{Q} P$ (Awina Niya/who I am), began this renewal process by informing the students about their community's past and developing a stronger awareness of the community's lived experience with Residential Schools and racism. It is important to note that although I discuss this process in a linear manner, this was a cyclical and iterative process.

Phase one: $\triangleleft \Delta \cdot a$ $P$ (Awina Niya/who I am). $\triangleleft \Delta \cdot \mathrm{Q} P$ ל (Awina Niya/who I am) was the first phase of the process of $P \hookrightarrow \triangleleft \cdot \supset C \supset \Delta^{\cdot}$ (Kisewatotatowin/awakening)

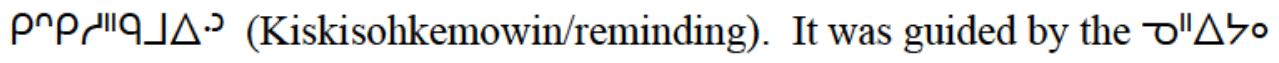


(Nehiyaw/Cree) teaching principle of informing (Field note, January 24, 2016). The initial teaching principle of informing primarily occurred over the first month of the Photography Class. The focus of the Photography Class was on racism. The stories provided in phase one provided the students with specific narrative resources to foster awareness of Residential Schools and racism that helped them locate their lived experience within the landscape of Canada's colonial legacy and make their lived experience more comprehensible.

First narrative resource. Elder D. M. provided the first narrative resource to the students when he shared a teaching through a personal story about the community's past that was grounded in his lived experience as a child forced to attend Residential Schools. When sharing his story with the students, Elder D. M. did not go into specifics about what his life was like before, during, or after his time at the Residential Schools. Rather, he explained a specific impact that the Residential Schools had had on him. In particular, he shared ${ }^{19}$ that during his time at the Residential Schools he was taught that he was of no value, unworthy of love, and taught a practice of hate (Field note, February 24, 2016). This practice of hate disrupted what he had been previously taught by his family and community, a practice of $\left\lfloor\rho " \Delta \supset \Delta^{\cdot} \cdot\right.$ (Sakihitowin/love and kindness).

Of particular importance for D. M. was how, by teaching the children a practice of hate, the Residential Schools disrupted the community's practice of $\left\lfloor\rho " \Delta \supset \Delta^{\cdot \supset}\right.$ (Sakihitowin/love and kindness) (Field note, February 24, 2016). He also shared that he had not reconnected with his practice of $\left\lfloor\rho^{\prime \prime} \Delta \supset \Delta^{\supset}\right.$ (Sakihitowin/love and kindness) until

\footnotetext{
${ }^{19}$ For this narrative I am paraphrasing because I did not have prior permission to digitally record this particular class.
} 
he was an adult and one way that he ensures that this praxis is part of his everyday life is by "telling his grandkids how much he loves them every day" (Field note, February 24 , 2017). By sharing this example with the students, Elder D. M. was illustrating that $\left\lfloor P \| \Delta \supset \Delta^{\supset}\right.$ (Sakihitowin/love and kindness) is a practice that occurs in relationship and, as such, connects people in a positive and supportive manner as opposed to what he experienced while at the Residential Schools, isolation and hate.

Elder D. M. did not provide in-depth details about his experience with the Residential Schools, because this type of information was not necessary for the students to glean what he wanted them to understand about their community's past, especially how the Residential Schools had disrupted the community's practice of $h \rho " \Delta \supset \Delta \cdot$ J (Sakihitowin/love and kindness) by introducing a practice of hate. His narrative also reminded them that although the practice of $\left\langle\rho " \Delta \supset \Delta^{\top} \supset\right.$ (Sakihitowin/love and kindness) had been interrupted, it was not destroyed. Elder D. M.'s return to Walking the Red Road, that is, his return to "remembering, renewing, and restoring our traditional roles and values that brings life; so as to continually move forward 'in a healthy way' as Indigenous People" (Red Road Healing Society, 2017) was evidence that the Residential Schools had not destroyed these practices. In fact, his narrative offered a personal example that they were there and could be followed and expressed even if they had been 'taken away'. In this way, by sharing this teaching Elder D. M. also demonstrated to the students that they too could, if they had not already done so, begin Walking the Red Road by remembering, renewing, and restoring their practice of $\left\langle\rho " \Delta \supset \Delta^{\top} \cdot\right.$ (Sakihitowin/love and kindness). 
The following excerpt from an interview with T. L., a school personnel and a parent, provides further insight into how Elder D. M.'s teaching about his time in Residential Schools affirmed cultural practices and ð" $\Delta$ \০ (Nehiyaw/Cree) identity development when he explained that:

I know with D. M. that he was in Residential School so ... He brings some light on his experiences with the kids and how he dealt with it. How he dealt with it and then, I do not know, it is hard to explain. It is kind of like he is sharing his experiences with the kids there and how he kind of went through it and then being, I do not know, it is hard to explain because he was taken away. I cannot speak on his behalf so it is kind of hard to say. He was taken away from his family, see I cannot even explain that because ... I cannot talk for them in regards to that. I just know that it is awesome for those two Elders to be involved because all they are doing is just sharing their experiences and then like you said, resiliency. You know it was hard on the community, stuff like that, had an impact on the culture and with the two gentlemen here, the Elders [D. M. and E. B.], after they came out of Residential [Schools], then they, you know they are regaining some of their cultural identity back and they were just sharing it with the kids. (T. L., June 12, 2016)

The above quote supports the finding that Elder D. M.'s teaching about

Residential Schools provided students with a particular narrative resource that helped to develop the students' awareness of their community's past by learning about how the Residential Schools had disrupted their culture and then learning about their $\Delta$ " $\Delta$ ל (Nehiyaw/Cree) identity. By sharing this narrative resource Elder D. M. helped the students' understand their own contemporary lived experience by developing their awareness about how their community was disconnected from a specific aspect of their

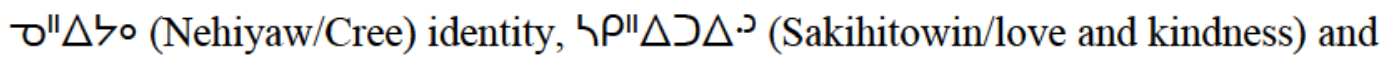
demonstrating that it was not always like this. More important, he demonstrated that, if it were possible for him to reconnect with these aspects of his own ד $\Delta$ \ל (Nehiyaw/Cree) 
identity, $\nmid P \| \Delta \supset \Delta^{\supset}$ (Sakihitowin/love and kindness), then, it was possible for them to also re-connect with their ד" $\Delta$ ל० (Nehiyaw/Cree) identity.

Building upon this first narrative recourse, the second narrative resource shared with the students is described in the next section. That narrative resource consists of stories about what the community was like before the Residential Schools introduced a practice of hate and how the Residential Schools were the consequence of the colonial implementation of racist ideologies that introduced racism to their community.

Second narrative resource. On two separate occasions, I had the opportunity to sit down and talk with Elder L. S. and two school personnel who were also parents (S. W. and C. C.) about what life was like before the Residential Schools. During these discussions, they shared with me that the word 'racism' never existed in the ס" $\Delta$ ל० (Nehiyaw/Cree) language. They went on to explain that there is no word for racism because it was the custom of $\mathrm{O}^{\prime \prime} \Delta \mathrm{\zeta}$ (Nehiyaw/Cree) people to practice good relations. The practice of good relations required people to get along, respect others, and never cause harm to one another. Further, every person had a responsibility to ensure they did no harm. For example, if you were going to say or do something that could potentially cause harm to someone it was your responsibility to prevent this by walking away (Field notes, February 11, 2016; May 25, 2017). Support for this description was provided in a community document that was shared with me by T. L.

This document was the policy and procedures manual for the Community and Family Services Agency developed by the community to ensure that the agency's programs and services were guided by the community's ঢ" $\Delta$ ל० (Nehiyaw/Cree) 
customary laws. When discussing the customary law of good relations, the document directs that "No person deserves more or less respect for their being and should not be made to feel "put down" by you, avoid hurting another's heart as you would avoid a deadly poison" (Community and Family Services Agency ${ }^{20}, 2000$, para. 5). The English language is used to document and communicate $\mathrm{乙}^{\prime \prime} \Delta$ ל० (Nehiyaw/Cree) customary law placed conceptual limitations upon what could and could not be included in the document. It is evident, however, that the community members' understanding of the customary law is one that forbids practices, such as racism, that can cause harm to others and supports practices such as $h \rho^{\prime \prime} \Delta \supset \Delta^{\supset}$ (Sakihitowin/love and kindness). The practice of $\nmid \rho " \Delta \supset \Delta^{\top}$ (Sakihitowin/love and kindness) is discussed further in the next section. At this point, what is important to understand is that the Community and Family Services Agency (2000) document echoes the following example by Elder L. S.'s in his teachings to the students that racism was not, and is not currently a part of the $\mathrm{Z} " \Delta$ ל० (Nehiyaw/Cree) way of life.

Elder L. S. was teaching on Honour. Near the end of his teaching, he looked at me and pointed to the whiteboard where he had drawn various visuals to help the students understand his teaching. He then stated to both myself and the students that, "there is no racism here (on the whiteboard)". He went on to explain "that you do not see racism there because it was not and is not part of the $\mathrm{D} " \Delta$ ל० (Nehiyaw/Cree) way of life" (Field note, March 11, 2016). During a later conversation, Elder L. S. explained to me, that this does not mean that there were never conflicts within or between communities. However,

\footnotetext{
${ }^{20}$ In order to protect the anonymity and confidentiality of research participants I have used the generic name "Community and Family Services Agency" to refer to this agency.
} 
these conflicts were not based upon an ideology of racism because this was not and is not part of the ד" $\Delta$ ל० (Nehiyaw/Cree) worldview or language (L. S., Personal Communication, February 11, 2016). With these comments, Elder L. S. was cautioning us not to conflate conflict with racism. Racism, he stressed, is a particular type of conflict that occurred and continues to occur within the context of a colonial value system that ascribes superiority to one group (non-Indigenous/Euro-Canadians) and inferiority to another group (Indigenous peoples) (Memo, February 12, 2016). This value system, of one group being superior and the other inferior, was introduced to their community through the Residential Schools.

Another way the second narrative resource about racism was shared with the students was after Elder D. M.'s teaching on the Residential Schools and how it taught him a practice of hate. The Coordinator shared with the students the following quote (previously presented) from a debate that took place in the House of Commons in Ottawa, Ontario in1883 where Sir John A. MacDonald, then the Minister of Indian Affairs and Canada's first Prime Minister argued in favour of Residential Schools:

When the school is on the reserve the child lives with its parents, who are savages; he is surrounded by savages, and though he may learn to read and write his habits, and training and mode of thought are Indian. He is simply a savage who can read and write. It has been strongly pressed on myself, as the head of the Department, that the Indian children should be withdrawn as much as possible from the parental influence, and the way to do that would be to put them in central training industrial schools where the will acquire the habits and modes of thought of white men; so that, after keeping them a number of years away from parental influence until their education is finished, they will be able to go back to their band with the habits of mind, the education, and the industry which they have learned at these schools. (Library of Parliament, 1883, pp. 1108-1109)

The above quote illustrated to the students that the Residential Schools were founded upon a discriminatory belief system that perceived First Nations peoples as 
"uncivilized" and "savages" in needed of "correction". Racism was not simply an 'unforeseen' by-product of the Residential Schools. This quote also demonstrated that the Residential Schools were intended to destroy traditional cultural practices by systematically and forcibly assimilating First Nations children to "white" ways of knowing, being, and doing. After sharing the above quote, the Coordinator connected the racist belief system of the past with the student's everyday experience by discussing the concepts of stereotypes, prejudice, and racism and then asking the students if they had examples that they would like to share from their own experience with racism. Collectively the students discussed how they have experienced being labelled and treated as unintelligent, unable to learn, drunks, and addicts. Interestingly, a common experience discussed by the students was being followed while shopping because they were perceived as shoplifters (Field note, January 06, 2016).

As evidenced by the students' self-reported experiences with racism and the teachings of the Elders, racism did not cease when Canada's last Residential School closed in Alberta in 1996. The students and their community continue to be impacted by both contemporary racist practices that have persisted as part of Canada's dominant discourse that continues to be utilized by non-Indigenous peoples to relate to, understand, and interact with Indigenous peoples and by the impact of racism experienced by community members within the schools after they returned to their communities.

Delving deeper into the Residential Schools and their impact on Indigenous peoples, during one of their classes the students attended an art exhibit in Edmonton entitled the Lebret Residential Petroglyphs. This art exhibit displayed a series of photos of Saskatchewan's, now demolished, Lebret Residential School and the markings left 
behind by the children that attended this Residential School. The exhibit focused on the physical and cultural degradation that the children suffered while attending the school by presenting a series of photos that ranged from a brick that had etched on it the words "gateway to hell" to a picture of the gate to the entrance of the Residential School. This experience provided the students with a powerful way to learn more about the colonial legacy of the Residential Schools and develop a more in-depth understanding of how these institutions impacted the children and youth that attended them (Field note, January 20, 2016). It did this by allowing them to see what the children wrote rather than what had been written or said about them by others.

As noted above, this initial phase was guided by the $\nearrow^{\prime \prime} \Delta$ ל० (Nehiyaw/Cree) teaching principle of informing and was characterized by the students predominantly listening and observing. However, it was possible to retrospectively gain insights into the student's experiences with this phase through my examination of the students' book and through one-on-one interviews. For example, while reflecting upon the Lebret Residential Petroglyphs and what they had learned over the duration of the Photography Class about the Residential Schools, the students included the following collective statement in their book:

[Our book] seeks to name the truth. A truth that has remained a blind spot in the consciousness of mainstream Canadians. Naming the truth requires we look at and understand the enduring effects of an attempted cultural genocide. With the genocide of Elders, [we] First Nation youth set out to better understand the impact of racism and aim to challenge individual and systemic discrimination. Like the Lebret Residential School children, [name of community] First Nation youth mark their life, THEY ARE HERE. They mark the change beginning to take place. They name themselves as a way to step out from under the enduring effects of the Residential School System. They are Cree students of [name of school], [name of community]. They are what they dream to be. (Book, 2016, p. 6 , original emphasis) 
Clearly, the students understood the Residential School system as an attempt at cultural genocide and were able to link this to their experiences with racism and with "the enduring effect of an attempted cultural genocide" on their community. They also recognized that this colonial legacy of racism is a truth that is "a blind spot in the consciousness of mainstream Canadians" rarely acknowledged but always present and impacting their lived experience as $\mathrm{C}^{\|} \Delta$ \० (Nehiyaw/Cree) youth.

The impact of informing also emerged in the interviews. Student interviews ranged from approximately 5 minutes to 23 minutes in duration. Further my use of intensive interviewing fostered space for each of the interviewees to determine the direction, content and length of the interview (Charmaz, 2014). Resulting in significant diversity across the type of content and level of detail that each interviewee provided during their interview. Although each interviewee provided valuable insights into their lived experience with the Photography Class, as previously discussed, two students (D. C. and K. L.) were identified as key informants.

D. C. and K. L., were particularly valuable informants because they provided extensive and detailed insight into several aspects of the students' lives experience with the Photography Class (Payne \& Payne, 2004). As such, D. C. and K. L. are quoted extensively throughout the remainder of this chapter. It is important to note that what was shared during interviews with the six additional students did not contradict or conflict with what D. C. and K. L. shared and is presented in this chapter. Further, in the section of this chapter that discusses phase three, I include data from all 21 of the students. As previously discussed, this was only possible because certain data sets (student statements and individual narratives) were included in their published book and 
available for public consumption (e.g., public libraries). These data sets illustrate that what D. C. and K. L. articulated during their on-on-one interviews aligned with their fellow students' lived experience with the Photography Class. For example, during my one-on-one interview with D. C. he stated that:

my kokum[/grandma], she went to residential school, and she said it was pretty bad over there and they were treated pretty badly. I just want that to change and it felt pretty good to actually open-up about stuff like that, [and that] people are actually recognizing what happened to our people. While everybody [else] lived all right, our people lived in these schools. They [our people] had to go through hard things and harsh things, [it] just messed up our culture mostly because they made us lose most of our culture, but they could not kill the culture because our culture lasts forever. (D. C., Personal Interview, May 25, 2016)

Together, D. C.'s quote and the collective statement demonstrate how the narrative resources provided during this phase match in ways that located and made legible their lived experience within the landscape of Canada's colonial legacy of Residential Schools and praxis of racism/hate.

To summarize, these narratives inform and develop understanding of what happened in the past and why this understanding is important to ד" $\Delta$ ל० (Nehiyaw/Cree) identity, community and culture. As Elder D. M. explained to me during an informal conversation, informing the students about the past is important because the students must "first look back to be able to understand their present" (D. M., Personal Communication, December 13, 2016). Reflecting upon Elder D. M.'s statement, it was clear to me that this initial phase of the teaching was not about the students finding answers to the question $\triangleleft \Delta \cdot \mathrm{O} \rho$ ל (Awina Niya/who I am). Rather, the first narrative resource provided by Elder D. M. was about raising the students' awareness of their community's past in relation to Residential Schools and how those experiences disrupted 


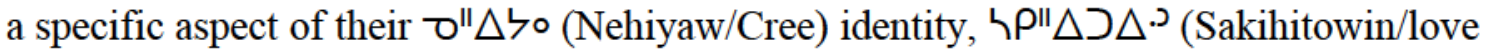
and kindness).

The second narrative resource provided by Elder L. S. also raised the students' awareness about who they are and who they are not by disrupting the dominant narrative that continues to normalize racism as an inherent characteristic of all cultures and peoples and teaching the students that racism was not and is not part of \" $\Delta$ ל० (Nehiyaw/Cree) way of life. In a similar fashion, the Coordinators' presentation on the House of Commons debate provided a wider vantage point for the process by stressing that cultural genocide was not an 'unfortunate' byproduct of the Residential School system but its core purpose. Finally, the art exhibit allowed the students to see how individual children and youth strived to retain a voice and to announce their \" $\Delta$ ૫० (Nehiyaw/Cree) identity within a racist system designed to eradicate that very identity. All of this information fostered space for students to make their community's past more legible and to connect that past with their contemporary experience with racism in ways that created a stronger

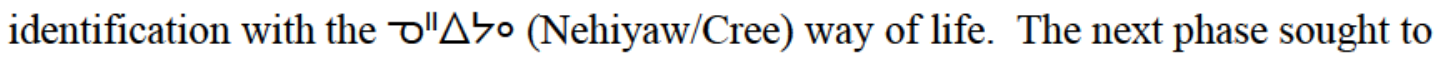

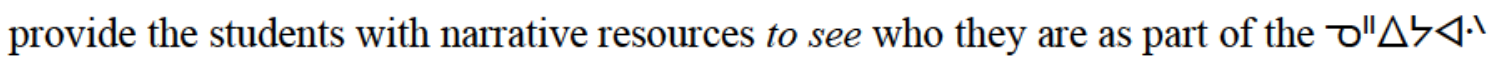
(Nehiyawak/Cree people).

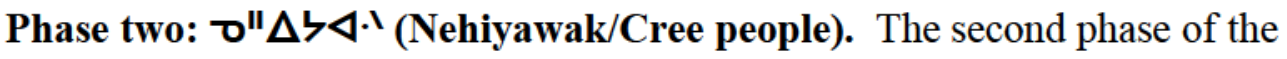

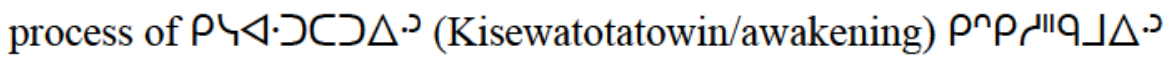
(Kiskisohkemowin/reminding) was ד" $\Delta ৬ \triangleleft \cdot `$ (Nehiyawak/who I am as part of the Cree people) and was guided by the $\nearrow^{\| \prime} \Delta$ ל० (Nehiyaw/Cree) teaching principle termed teaching. In the context of this research study, the principle of teaching primarily 
occurred over the second month of the Photography Class. Teaching focused on Elders sharing the sacred teachings. This phase built upon phase one by providing students with two narrative resources about who they are as part of the $\searrow^{\prime \prime} \Delta ৬ \triangleleft^{\prime \prime}$ (Nehiyawak/Cree people) with a particular focus on two traditional teachings the practice of $\nmid \rho " \Delta \supset \Delta^{\prime} \cdot$ (Sakihitowin/love and kindness) and Courage. At this point it is important reiterate that the $\mathrm{O}^{\prime \prime} \Delta$ ४० (Nehiyaw/Cree) teachings in and of themselves were not the focus of this study. Further, I am not the knowledge holder of these teachings and therefore they are not mine to document or share in general or in this thesis. Irrespective of this situation, my role and responsibility as a researcher was to elucidate how the teachings informed the students' lived experience and in the context of this phase their understandings of what it means to be part of the $\mathrm{O}^{\prime \prime} \Delta ৬ \triangleleft \triangleleft \cdot$ (Nehiyawak/Cree people).

Before delving into the content of phase two of the process of $P 4 \triangleleft \cdot \supset C \supset \Delta^{\cdot}$

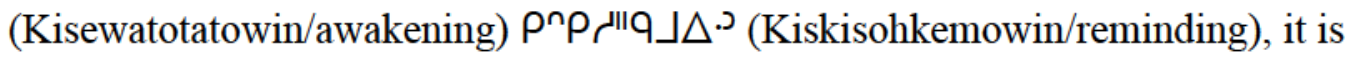
important to discuss a significant factor that was emphasized by several research participants and identified as a key component to this particular phase, the Elders.

Elders: Finite opportunity. Elders were perceived as a critical component of this phase of the teaching process. Providing insight into why is the following excerpt from an interview with S. W., a school personnel and parent:

Interviewer: Could you speak about why it was important to connect Elders and youth?

Interviewee: Well, our Elders today, it is so sad when you think about it because the Elders we have now, after those Elders are gone we are going to get new Elders, and when they are gone all their knowledge leaves with them. I mean that is why it is important for our kids to be with them now, to learn from them, to know the teachings that they will have to teach [when they are Elders]. And to 
respect them and then to pass those on to their kids. One reason why I think it is good for them to connect too is because that old spirit and that young spirit, you know, they get to be together and bring life to each other. And our kids can learn so much from the Elders and that is the thing about today the kids do not have time to go and sit with an Elder. They are lost today, they think they know everything about life. I wish that somebody had told me when I was young to spend all the time you can with Elders. Go and visit your kokum, go and visit your mosom, go and do these things for them, go and clean up, go and cut some wood for them, make some tea for them, cook for them. Nobody really carries that today ... And I just wish that our kids would realize that they [our Elders] are not here forever, and that we are really blessed to have them and their knowledge. (S. W., Interview, May 25, 2016)

The above quote represents what several school personnel who were also parents shared with me, that the involvement of Elders was of particular importance because they are getting older and the teachings and knowledge that they hold will disappear when they pass if they have not had the opportunity to pass this knowledge on to the next generation. There is a finite and shrinking window of time in which to ensure that the teachings and knowledge that are held by Elders is not lost and with it the stories that develop one's ד" $\Delta$ ל० (Nehiyaw/Cree) identity (Brundige, 2004; Weber-Pillwax, 2001). Understanding this situation, this phase strategically connected Elders and students to pass the Seven Sacred Teachings to the students.

As noted above, Elders and their teachings are of great importance to their communities. As a researcher and an outsider, I needed to be aware of this in this phase of the research. I was cognizant of the colonial legacy that has led to a distrust of First Nation communities of being researched and a distrust of researchers. All too often, researchers and their studies have predominantly had no benefit for communities and communities have had little to no control over research studies. Being conscious of this history, and reflecting my use of Indigenous methodologies, I inquired about, and respected, the unique levels of consent that were agreed to by each of the Elders during 
their interactions with me. This attitude and research approach is reflected in the material presented in this section.

In preparation for Phase Two of the process of $P \backslash \triangleleft \cdot \supset C \supset \Delta^{\cdot}$

(Kisewatotatowin/awakening) $\rho^{n} \rho \overbrace{}^{\prime l} \mathrm{q}\lrcorner \Delta^{\supset}$ (Kiskisohkemowin/reminding), Elder D. M. provided introductory teachings on each of the Seven Sacred Teachings to prepare the students for when they would meet with community Elders (Field note, January 13, 2016). The plan was to follow-up the introductory teachings with more in-depth teachings from community Elders. However, due to extenuating circumstances related to Elders' health and scheduling challenges it was not possible for the students to receive three of the more in-depth teachings on Respect, Honesty, and Humility. Irrespective the students did receive teachings on Truth, Wisdom, Courage, and Love. The teachings of particular significance to this study were Elder D. M.'s teaching on $\nmid \rho " \Delta \supset \Delta^{\text {J }}$ (Sakihitowin/love and kindness) and Elder L. S.'s teaching on Courage. The focus on these two teachings emerged during the third phase when the students were deciding the narrative arc that would guide the development of their book and its narrative. I will explain this decision further in a later section of this chapter when I discuss phase three. Next, I discuss the sacred teaching that Elder D. M. shared with the students, $\nmid P \| \Delta \supset \Delta^{\prime} \cdot$ (Sakihitowin/love and kindness) and that represents the third narrative resource.

Third narrative resource. In the following description, I weave together quotes to re-construct what Elder D. M. shared with the students during this teaching on $\left\llcorner\rho^{\prime \prime} \Delta \supset \Delta^{\cdot}\right.$ (Sakihitowin/love). This teaching was about believing in love, showing love to others, and learning to love and believe in yourself. He provided specific examples to 
the students to illustrate what this practice looks like in everyday practice. For example, he encouraged the students to "show love" in order to "receive love". He went on to explain that "when you say it out loud [tell people that you love them, e.g., kokum and mosom], it comes back to you, you will start loving yourself". He then asked the students to think about "what have you been told about yourself, you are no good or you are savage, and do you believe those things?". Instead of believing these negative messages, Elder D. M. encouraged the students to "believe in $\langle\rho " \Delta \supset \Delta \cdot$. (Sakihitowin/love)" by "learning to love and believe in yourself".

He shared that " $\backslash \rho$ " $\Delta \supset \Delta^{\supset}$ (Sakihitowin/love) is powerful" because "if you can show love, you start to feel more and more love for yourself". In contrast, "if you are told you are no good, you're a savage, you start to believe it. But when you speak with love you will start to feel love. Through my life I have learned to love myself and learned that this world is not all hatred" (Field note, January 13, 2016). Not only did Elder D. M. provide examples of $\left\langle\rho " \Delta \supset \Delta^{\supset}\right.$ (Sakihitowin/love) to the students to help them understand and think about what this teaching can look like as part of their everyday life; he also linked this practice to the capacity to imagine themselves beyond the confines of racist stereotypes such as "being no good" or "savage". It is important to note that Elder D. M. did not prescribe what lies beyond the parameters created by racist stereotypes because this was up to each of the students to seek out for themselves. Rather, he encouraged the students to go on a journey of finding out who they are and to bring a practice of $\left\lfloor\rho^{\prime \prime} \Delta \supset \Delta^{\cdot} \cdot\right.$ (Sakihitowin/love) along with them.

At this point it is important to recall the Cherokee Legend the Coordinator shared with the students during the initial class. The moral of this legend is that your lived 
experience is characterized by what you feed the "good wolf"/love and kindness or the "bad wolf"/hate. Elder D. M.'s teaching reflected the moral of the Cherokee Legend in that he was encouraging the students to feed their inner "good wolf" by putting the teaching of $\left\langle P^{\prime \prime} \Delta \supset \Delta^{\cdot}\right.$ (Sakihitowin/love) into practice in their everyday life. Further, Elder D. M.'s teaching provided the students with a narrative that made the $h \rho " \Delta \supset \Delta^{\prime}$ ' (Sakihitowin/love) aspect of the $\mathrm{O}^{\prime \prime} \Delta$ ל० (Nehiyaw/Cree) identity clear and accessible through the everyday performance of such acts as telling people they love them. The ongoing day-to-day enactment of small positive acts of love is something that every person can undertake easily.

The third narrative resource also provided the students with a more accurate and positive understanding of what it means to be part of the $\mathrm{O}^{\prime \prime} \Delta ৬ \triangleleft \cdot \backslash$ (Nehiyawak/Cree people). This provision of positive images and counter narratives stood in strong contrast to the racist narratives provided by the dominant culture. The stress here was on providing the teachings not on having the students learn them or memorize their content. Rather it was to offer an alternate perspective that they could use to develop their

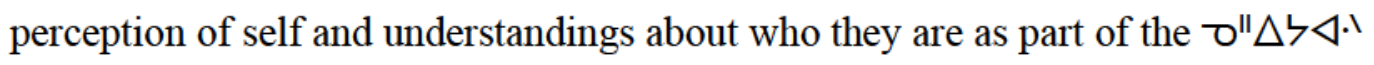
(Nehiyawak/Cree people).

Having learned about the teaching and practice of $\left\langle\rho " \Delta \Delta^{\top} \Delta^{\supset}\right.$ (Sakihitowin/love), the students were then exposed to other teachings. Elder L. S.'s teaching on the practice of Courage reinforced why it is important for students to begin a journey of knowing who they are as part of the $\mathrm{O}^{\prime \prime} \Delta ৬ \triangleleft \cdot `$ (Nehiyawak/Cree people). 
Fourth narrative resource. As noted above, prior to this phase of the research I asked each Elder to what extent I could include their sacred teaching in this study. Elder L. S. said that I could digitally record his teaching and that the recording would be kept for the school and community archives. He did not want me to detail his teaching in this study and wanted me to limit my documentation to the overall message of his teaching. These were different conditions from those of Elder D. M. and shaped the ways in which I collected and presented data on the teachings. As per my agreement with Elder L. S., the main message of his teaching on Courage was that it is important for the students to stand-up and name themselves before someone else does using racist stereotypes (Field note, February 9, 2016). As was previously mentioned in the Methods chapter, a detailed analysis of my field notes led to the development of this in vivo code termed Standing-up during the first phase of analysis. Specific details outlining the process of Standing-up are not included here as was agreed to with Elder L. S.; however, I did observe that students appeared to gain a sense of personal empowerment from being able to describe themselves in positive contrast to racist stereotypes. I also saw students standing-up in different situations outside of the classroom thereby (e.g., during the book launch that is detailed in a later section of this chapter) noting the teachings had had a long-term effect (Field note, June 2, 2016).

While we have the content/messages that Elder D. M. and Elder L. S. teachings offer, the impact of those teaching on the students is more difficult to ascertain. The teaching themselves took up the entire class and there was no discussion of them within the class. Further, this second phase was guided by the $\mathrm{O}^{\prime \prime} \Delta$ ל० (Nehiyaw/Cree) teaching principle of teaching and as such this phase was intended to be about the students 
listening to and absorbing what they were being taught. It was not possible within the design and scope of the study to gain insight into the impact(s) of this phase in the class beyond my observation that the students actively listen during each of the teachings (Field notes, January 13, 2016; February 9, 2016). I was able, however, to retrospectively inquire into the students' experience with this phase while conducting face-to-face interviews. For example, while asking D. C. what it meant to him to have the Elders come to the school and be part of this phase of the Photography Class he shared that:

It felt pretty good because Elders can teach you a lot of things about a lot of stuff because they are really cultural and stuff like that. And I know as a kid I always used to like to go to ceremonies and stuff like that, and it was pretty fun, I used to like drumming, I still do. And E. B., he's a pretty strong Elder, and can teach you a lot, even D. M., and my Mosom, he tells me a lot of crazy stories about his time, but he was pretty cultural. But a lot of people when they went to Residential School turned to drinking, that is why mostly all of the Natives drink, but I want to be one of those Natives that does not drink and try rise up to be something great, and try bringing everybody with me and not leave everybody in the town site and around here just to rot. (D. C., Interview, June 1, 2016)

Comparably, J. J., stated "That it [having the Elders present] was making me think of the future. In ways that I do not really understand". After a few moments of silence passed, I probed her statement by asking if what she was referring to that what Elders have shared "you carry them [the Elders teachings] with you and they will make sense sometime in your future when you need them" J. J. responded by stating "yeah" (J. J., Interview, May 25, 2016).

D. C. and J. J.'s statements capture how they thought this second phase was related to the students' lived experience of (1) looking forward and (2) becoming something great. D. C.'s quote spoke of looking forward to a future that has yet to be defined. This perspective is significant because, as previously discussed, the mainstream 
narrative depicts their future as one characterized by poverty, substance use, and criminality; a future the students rejected. D. C. also imagined a future where he and his fellow students have moved beyond the intergenerational impact of Residential Schools, especially substance abuse, "to be something great". There is an awareness of the continued impacts of Residential Schools on some community members and a belief that this does not have to be his or the future of his fellow students. For J. J. there was an awareness that the teachings may not make sense to her now but that in the future she will be faced with situations where they will help her. Further the students did not perceive the Elders' teachings either as prescriptive or determining who they should be now or in the future. Instead, as articulated by D. C., it was up to them to see and reach beyond racist stereotypes to attain a future beyond the colonial parameters forced upon their ancestors through the Residential Schools.

This approach reflects an Indigenous worldview in which identity development is a lifelong process of learning guided by the renewal ceremony of storytelling that teaches and reiterates for community members the customs and values underpinning what it means to be part of the $\oslash^{\prime \prime} \Delta ל \triangleleft \cdot `$ (Nehiyawak/Cree people). Individuals reflect on these stories and put the customs and values into practice. In the process, knowledge and insights are gained that guide the development of one's identity (Brundige, 2004; WeberPillwax, 2001). The stories guide, to the extent that one puts these teachings into practice, but they do not determine the development of identity. The individual is on a lifelong journey that is connected to and guided by the stories but they decide, on an ongoing basis, how to incorporate the values and customs contained in the stories into their thoughts and actions, and hence into their identity. 
Given the importance of stories in the identity development of the students and how the Residential Schools had systematically disrupted their community's ability to know and share these stories, this phase sought to provide specific teachings as both a counter narrative to the dominant culture's racist narrative and to guide the students' journey of identity development. It is important to stress that the implementation of the ○" $\Delta$ ל० (Nehiyaw/Cree) principle of teaching re-connected youth and their Elders to a relationship that was integrated into the community members' lives prior to the Residential Schools. This process revealed links between the Elders and their lived experience that helped the students develop an understanding of who they are as part of the $\mathrm{O}^{\prime \prime} \Delta ৬ \triangleleft \cdot$ ' (Nehiyawak/Cree people). Next, I discuss the third phase, that was characterized by the students contemplating and putting into action the Elder D. M. and L. S.'s teachings.

Phase three: (3) $\mathbb{Z}^{\prime \prime} \Delta ל \circ$ (Nehiyaw/Cree). The third phase of this process of

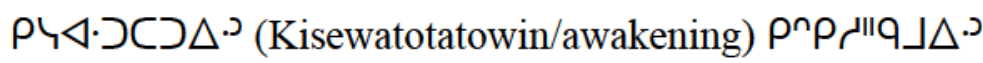
(Kiskisohkemowin/reminding) was termed \" $\triangle$ ל० (Nehiyaw/Cree individual) and integrated the third principle of the $\mathrm{\nearrow}^{\|} \Delta$ \० (Nehiyaw/Cree) teaching principle termed guiding. Within the context of this research study the principle of guiding took place over a 2-month period between March and April 2016 and was characterized by the Coordinator and Elder D. M. guiding the development of the students' ability to compile their own narrative about who they are as a $\mathrm{\nearrow} \|$ ל० (Nehiyaw/Cree) and ultimately author their book. This phase involved a significant transformation where the students moved from attentive listeners (phase one and two) to an active learning role where they 
began to contemplate and ultimately put into practice the teachings of $h \rho \| \Delta \supset \Delta \cdot \supset$

(Sakihitowin/love and kindness) and Courage. The following sections describe the stages involved in this transformation process.

Contemplating. Prior to the class on February 24, 2016, one of the students, K. L., approached the Coordinator and asked if he could lead a discussion with his fellow students to talk about the main message of Elder D. M. and L. S.'s teachings and how this message related to their book. The Coordinator supported this idea and K. L. began the class by asking his fellow students to think about:

Who they are, who is going to name them, and what are the consequences if it is not them who names themselves? (Field note, February 24, 2016)

This event represents the moment in the Photography Class when the students decided to focus on the teachings of $५ \rho \| \Delta \supset \Delta^{\supset}$ (Sakihitowin/love and kindness) and Courage. The decision to focus on two of the Seven Sacred Teachings provides an example of how, at different moments in the students' lives, in this case within the context of the Photography Class, the students reflected upon and put into practice the values and norms shared with them through the renewal process of storytelling. In the context of this research study and as will be detailed below, the students decided that the teachings of $\nmid \rho^{\|} \Delta \supset \Delta^{\supset}$ (Sakihitowin/love and kindness) and Courage were the most helpful with mediating racism.

I did not have permission to digitally record regular class sessions, such as the discussion that occurred during this class. I relied on my field notes to document the discussion in response to K. L.'s questions. The students talked about:

how they understand racism as negative thoughts and ideas that are not based on the truth about who they are. . . . and if these are just ideas then they can be 
replaced with other ideas that are based on the truth about who they are ... and concluded that the first step to mitigate the impact of racism on them is to identify themselves before someone else does and that this would be at the core of their book. Further they discussed that the ability to identify who they are does not mean that racism is not going to impact them. However, if they know who they are they will be stronger in who they are. (Field note, February 24, 2016)

The discussion reflected students' contemplation of the main message of Elder L. S.'s teaching on Courage. In particular, they focused on the meaning of Elder L. S.'s teaching in the context of their book and of their lived experience with racism. Reflecting upon these two considerations, the students decided to use their book as an opportunity to get to know and therefore be strong in who they are as

Further by being strong in who they are as a ד" $\Delta$ ל० (Nehiyaw/Cree) this would serve as a mediator of impact of racist ideas about who they were because by knowing for themselves who they are they could counter misinformed attempts to define them. They recognized that although they may be impacted by systemic racism, they would not in and of themselves be defined by these racist stereotypes. Further they decided to use their book as a way to collectively stand-up and name themselves as a way to provide the broader public with more accurate ideas about who they are and to challenge and mediate stereotypes held by greater society. Therefore, during this class they decided to use their book as a way to mediate interpersonal impacts of racism and to challenge and mediate racist ideas that are held by society at large. Having identified more specific objectives on what they wanted to achieve with their book, the next step entailed the students moving from contemplation to practice.

Practicing: First activity. The objectives of the book necessitated the students being able to identify and to communicate who they are. Two activities were used to 
fostered opportunities for the students to think about and identify, within the context (the particular time and space) of the class, who they are as a $\mathrm{O}^{\prime \prime} \Delta$ ל० (Nehiyaw/Cree) youth. The first activity that the students took part in was photocopying one of their hands. After completing this task, the Coordinator asked them to independently:

(1) think about what makes you unique, (2) to think about what you share with other students as part of the $\mathrm{O}^{\prime \prime} \Delta ל \triangleleft \cdot `$ (Nehiyawak/Cree people), (3) write your ideas on the photocopy of your hand. (Field note, March 2, 2016)

The Coordinator shared with me that she designed this exercise to provide a safe space for the students to being thinking about and practice naming themselves. The students were hesitant about completing this activity. Seeing that the students were uncertain about what to write, the Coordinator asked Elder D. M. to take the final minutes of the class to share with the students a teaching about what it means to be $\mathrm{C}$ (Nehiyaw/Cree). In response, he explained that the Creator had gifted their community with a sacred name. For example, he explained that the ${ }^{\prime \prime} \Delta ל \triangleleft \cdot `$ (Nehiyawak/Cree people) we were given the gift of being named and given the teachings of the four elements of human beings and life; spiritual, physical, emotional and mental. Part of the students' life long journey as a practice the teachings that were gifted to their community (Field note, March 2, 2016).

Elder D. M. also told the students that it is important for those students who had not already done so, to receive their $\mathrm{C} \| \Delta \circ$ (Nehiyaw/Cree) name (also commonly referred to as a spirit name) through a naming ceremony. The naming ceremony is understood as an important step in developing one's identity because one's ד (Nehiyaw/Cree) name provides insight into a person's traits, spirit, strengths, purpose in 
life, and protection (Field note, March 2, 2016) ${ }^{21}$. As with the previous teachings provided by the Elders this teaching was shared as an option for current and future consideration, not as a directive.

What Elder D. M. provided, having noticed that the youth were hesitant about completing the activity, was guidance to the students. He offered them ways to learn about who they are: (1) learning about the four sacred gifts that were given to the $\oslash^{\prime \prime} \Delta ৬ \triangleleft \cdot `$ (Nehiyawak/Cree people) by the Creator and (2) taking part in a naming ceremony to receive their \" $\Delta$ ל० (Nehiyaw/Cree) name. Elder D. M.'s guidance was

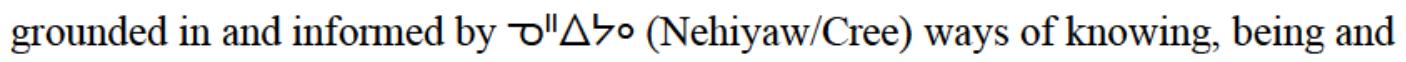
doing. His guidance was more about offering the students a way to seek-out and learn about who they are rather than providing a predefined description of who they $\operatorname{are}^{22}$. In this way, Elder D. M.'s guidance illustrates how the Photography Class served as an initial step in providing the students with language and tools that they could use long after the class ends as they continue on their life journey of developing their identity as a O" $\Delta$ ל० (Nehiyaw/Cree). Thus, despite the fact that this first activity concluded with Elder D. M.'s teachings and without the students completing this particular exercise, the class goal of having the students consider what it means to be $\mathrm{C}^{\prime \prime} \Delta$ ל० (Nehiyaw/Cree) had been met. The second activity provided an additional opportunity for students to think about and identify who they are.

\footnotetext{
${ }^{21}$ As with the teaching on $\nmid \rho^{\|} \triangle \supset \Delta^{\supset}$ (Sakihitowin/love) and Courage, it is not appropriate for me to provide a detailed description of the teaching on the four sacred gifts or a naming ceremony.

${ }^{22}$ It is important to note that this guidance reaches beyond the timeframe of this study and further research at a later point in time would be required to examine if and to what extend students were impacted by this particular form of guidance.
} 
Practicing: Second activity. During the March 16, 2016 class the Coordinator provided another opportunity for students to think about and identify who they are. This exercise was more structured. The class began with the Coordinator discussing how everyone has different roles in their family and community and that these roles define certain aspects of who they are as a $\nearrow^{\prime \prime} \Delta ל \circ$ (Nehiyaw/Cree individual). For example, individuals can be a sister, brother, friend, dancer, athlete, or drummer. Students were then asked to think about the different roles that they perform in their family and community and then complete the sentence "I am " on an exercise sheet. Having had a week to think about what Elder D. M. had shared at the end of the previous class and having more detailed instructions and examples, this time the students were able to complete the exercise with little to no hesitation.

Having written down words about who they are, the Coordinator asked the students if they wanted to write the words from their exercise sheet on their arm or hand with a marker and then take photos of themselves while standing in front of the school as one way to visually capture who they are. The students were excited about this activity. They immediately grabbed markers and wrote their words on either their arm or hand. Then, in pairs, they took turns going outside to take two photos; one of them standing in front of the school and one of their arms or hands with their written words. Within 15 minutes all students had completed this exercise (Field note, March 24, 2016).

Summarized below in Table 1 and Table 2 are all 21 of the students' statements that emerged from this exercise and were written on their arms or hands, photographed, and published in their book. These words were not the focus of this research study; however, they provide insight into the students' lived experience and as such I analyzed 
and themed their statements. This analysis found that each of the students' statements about who they are as a $\nearrow^{\prime \prime} \Delta$ ל० (Nehiyaw/Cree individual) were positive and were characterized by intrapersonal or relational descriptors. For example, the words presented below in Table 1 capture students' statements that describe individual characteristics related to an action, accomplishment, or self-esteem. In total. $43 \%$ of the students reflected intrapersonal descriptors. In contrast, the words presented below in Table 2 illustrates students' statements that describe relational characteristics related to their "Creeness", the teachings of $\nmid \rho^{\|} \Delta \supset \Delta^{\supset}$ (Sakihitowin/love and kindness), Courage, Truth, and the Seven Sacred teachings. In total, 57\% of the students' statements reflected relational descriptors.

Table 1: Intrapersonal Descriptors

\begin{tabular}{|l|l|}
\hline Themes & Statements \\
\hline Action & \\
\hline & I AM SEARCHING ${ }^{23}$. (R. C., Book, p. 24) \\
\hline Accomplishment & I AM SEEING; I AM SEEKING. (S. W., Book, p. 26) \\
\hline & \\
\hline & I AM AN ATHLETE. (J. J., Book, p. 38) \\
\hline & I AM A GOOD STUDENT. (D. E., Book, P. 44) \\
\hline Self-Esteem & I AM A TRADITIONAL DANCER. (C. S., Book, p. 36) \\
\hline & \\
\hline & I AM INDEPENDENT. (L. S., Book, p. 40) \\
\hline & I am strong. (C. M., Book, p. 42) \\
\hline & I am CONFIDENT. (H. S., Book, p. 42) \\
\hline & I'm Blessed. (H. C., Book, p. 46) \\
\hline
\end{tabular}

Table 2: Relational Descriptors

\begin{tabular}{|l|l|}
\hline \multicolumn{1}{|c|}{ Themes } & Students' Statements \\
\hline "Creeness" & \\
\hline & I AM LIFE, I AM Proud to Be Native. (D. C., Book, p. 56) \\
\hline & I AM CREE. (J. P., Book, p. 58) \\
\hline & I AM CREE; I AM PROUD. (D. P., Book, p. 60) \\
\hline & I AM PROUD. (C.L., Book, p. 52) \\
\hline Love and Kindness & \\
\hline & I AM LOVING; I AM BRAVE. (K. L., Book, p. 22) \\
\hline & I AM KIND. (C. M., Book, p. 30) \\
\hline
\end{tabular}

${ }^{23}$ Each student placed emphasis on certain words by using capital letters. In one case, H. S., also underlined the capital letters to express additional emphasis. Also, the text presented in column two are quotes from the students' book. 


\begin{tabular}{|l|l|}
\hline Courage & I AM LOVING. (B. F., Book, p. 32) \\
\hline Truth & COURAGE. (A. P., Book, p. 28) \\
\hline & \multicolumn{1}{|c|}{ I am Truthful. (C. R., Book, p. 34) } \\
\hline Seven Sacred Teachings & I AM THE REAL HONEST. (D. C., Book, p. 50) \\
\hline & $\begin{array}{l}\text { TRUTH; LOVE; RESPECT; COURAGE; HUMILITY; } \\
\text { WISDOM; HONESTY; NEHIYAW. (J. C., Book, p. 48) }\end{array}$ \\
\hline & $\begin{array}{l}\text { I AM LOVE; HONESTY; HUMILITY; TRUTH; COURAGE; } \\
\text { RESPECT; WISDOM. (N. M., Book, p. 54) }\end{array}$ \\
\hline
\end{tabular}

Tables 1 and 2 illustrates how the students began to identity who they are as a ๑" $\triangle$ ל० (Nehiyaw/Cree individual) through the use of positive, succinct, and declarative statements. Further the students' statements are unique. This diversity illustrates that the students were not simply repeating the teachings that the Elders had shared during phase one and two. Instead, the students' statements demonstrate that they listened to, reflected upon, and then responded using the different aspects of the Elders' teachings that resonated with them at that moment in their life journey. The diversity in how the students identified and named themselves is what would be expected because each of the students are at different points in their life journey and they have different traits. For example, J. J.'s intrapersonal and accomplishment oriented statement of "I AM AN ATHLETE" (Book, 2016, p. 38) is unique from D. C.'s relational and "Creeness" oriented statement of "I AM LIFE, I AM Proud to Be Native" (Book, 2016, p. 56). These unique statements illustrate how the students were reflecting upon and responding from where they were in their lived experience thus far and that the program was resonating with each of the students and is evident in their statements.

Although I have divided the students' statements into two categories, intrapersonal and relational, these descriptors are not mutually exclusive. Rather they are analytical categories that are experientially connected. For example, through their own 
words, these students collectively illustrated a braiding together of the Elders teachings with examples of intrapersonal characteristics that begin to describe their contemporary identity as a \" $\Delta$ ל० (Nehiyaw/Cree individual). These statements are significant because in the context of their overarching objective to author a more complete and positive narrative about who they are, these statements represent the first step that the students took to develop their own narrative and move towards their stated goal. These statements also represent the first step that the students took to put Elder D. M.'s teachings on $\nmid P \| \Delta \supset \Delta^{\cdot}$ (Sakihitowin/love and kindness) into practice through positive self-identification and Elder L. S.'s teaching on Courage into practice by naming themselves. Having identified certain aspects of who they are, the next class entailed the process through which the students determined the particular narrative structure that would frame the individual and collective stories that they would share in their book.

Identifying the over arching narrative. Over the months of January and February, students were assigned cameras on a weekly and rotating basis. During their assigned week, students were asked by the Coordinator to take photos that captured who they are. Over this period of time the students took over 300 hundred photos. The photos ranged from images of different people in the students' lives (e.g., school personnel, Kokom and Mosom, siblings, friends, etc.) to pictures of land and place (e.g., eagles, horizons, mountains, their school, etc.). The photos in and of themselves were not the focus of analysis or this study. Rather the focus and what I discuss in this section is 
how the photos were used as a conceptual tool to help the students identify a narrative arc that would anchor the development of their book.

Prior to the April 6, 2016 class the Coordinator had printed all of the students' photos and placed them on a large table for the students to see as they entered the classroom. Once all of the students were in the class, she asked each student to choose one photo that they thought should go in their book. Once everyone had chosen a photo, the next task was to identify the order that they would appear in their book. The Coordinator asked the students which photo should appear first in the book. After a few seconds passed without discussion one of the students handed their photo to the Coordinator who then stuck the photo on the white board for everyone to see. This process was repeated until each of the photos were ordered and placed on the white board. Two of the students identified two photos, instead of one, resulting in a total of 25 photos being placed on the white board. By choosing 25 of the 300 photos, the students were refining and moving closer to the identification of a narrative arc.

Again the photos in and of themselves were not the focus of this study. Rather what was of importance was understanding how the photos were utilized as a conceptual device to help the students identify a narrative arc. Accordingly, my field notes from this exercise did not discuss each of the 25 photos as individual entities; instead, they targeted the photos that were identified by the students as having the most significant meaning and that ultimately informed the narrative arc that emerged during this exercise.

After identifying 25 photographs, the next step entailed the Coordinator asking the students what each of the photos meant to them so they could identify the narrative arc that was grounded in and shared through the photos (Field note, April 6, 2016). The 
following excerpt paraphrases how this process unfolded. The ultimate result was an

identification of three themes that represented distinct components of a narrative arc:

(1) Indigenous rights,

(2) Elders role as knowledge holders, and

(3) Standing-up for who you are.

For example, once the 25 photos were ordered and placed on the white board:

S. H. went through each of the photos first to last and following the order that was identified by the students and asked the students as a group "why did you put this one here?". As S. H. engaged in this line of questioning, a story started to emerge that started with a photo of a Treaty 6 medallion. The students' shared that the Treaty 6 medallion represented their rights as Indigenous peoples that have existed since time immemorial and the relational accountability between the Crown and Treaty 6 peoples. The next photos that were identified as having particular significance were of Elders and images that represented sacred teachings (e.g., the eagle/ $h P^{\prime \prime} \Delta \supset \Delta^{\cdot}$ (Sakihitowin/love and kindness), practices (e.g., hide tanning), and ceremony (e.g., volcanic rock/grandfathers). The students explained that the photos of the Elders, sacred teachings, practices, and ceremony were important because they represented the role that Elders have as knowledge holders who pass along their knowledge to the next generation to teach them about who they are as they learn about the sacred teachings, practices, and ceremonies. The students also discussed how they might not use the Elders' knowledge today or tomorrow, but, by learning from Elders, they will have this knowledge when they need it. The next set of photos were of the students themselves. The students concluded this exercise by discussing that these photos represented that sometimes they were going to have to stand on their own and that they needed to be ready and willing to do this. However, to stand on their own would require them to know who they are. Once they know who they are they will be able to stand up for who you are even when they stand alone. The Coordinator thanked the students for their participation. Reflecting upon today's class, I am struck by how easily the narrative arc emerged and how there were no points or moments of contention between students' decisions about what photos to use, the order of the photos, or what the photos represented. I also want to stress that the Coordinator's role was significant because she actively guided the students through this exercise. However, it was the students' photos, decisions, and ideas about what the photos represented that informed the narrative arc that emerged. (Field note, April 6, 2016, emphasis added)

The above excerpt from my field notes demonstrates how this exercise facilitated the emergence of a narrative arc that overall was positive and had the following three points along its continuum: (1) Indigenous rights, (2) Elders role in knowing who they 
are, and (3) Standing-up for who you are. Similar to the previous exercise where the students made statements about who they are, this activity illustrates how the students were not simply recalling and repeating what the Elders had shared during phase one and two. In fact, as with the students' statements in that previous activity, their narrative arc illustrates that they listened to, reflected upon, and then collectively responded to the photos with different aspects of the Elders' teachings that resonated with them at this particular moment to attain a specific objective, the identification of a narrative arc for their book. For example, and as previously discussed, Elder L. S.'s teaching on Courage taught the students that it is important to stand-up and name themselves before someone else names them using racist stereotypes (Field note, February 9, 2016). Reflecting upon this teaching and responding from where they were in their lived experience the students shared "that sometimes they were going to have to stand on their own and that they needed to be ready and willing to do this. However, to stand on their own would require them to know who they are. Once they know who they are they will be able to stand up for who you are even when they stand alone" (Field note, April 6, 2018). The narrative arc that emerged from this activity also illustrates how the students' understandings of who they are was becoming more nuanced and reflected in how they moved from a state of hesitation (exercise one) to a state of actively naming themselves in a way that located them within Canada's colonial landscape (theme 1) and within their \" $\Delta$ ל० (Nehiyaw/Cree) community and worldview (theme 2 and 3).

The identification of a narrative arc represented the second step that the students took to move closer to their goal of authoring a more complete and positive narrative about who they are. In particular, the narrative arc and its three characteristics provided a 
frame to guide rather than determine, the development of students' individual narratives (detailed in the next section). Further the narrative arc represents the second step that students took to put into practice Elder D. M.'s teachings on $\nmid \rho " \Delta \supset \Delta^{\prime}$ J

(Sakihitowin/love and kindness) by developing a more nuanced understanding of what it means to be part of their $\mathrm{Z}^{\prime \prime} \Delta$ ל० (Nehiyaw/Cree) community and identification of how Elder L. S.'s teaching on Courage resonated with them at this particular time in their journey and informed how they can mitigate the impact of racism; by knowing and being strong in who they are. It is important to note that the process described in this section did not determine what photos each of the students would put into their book as part of their individual narrative nor did it determine the context of their individual narratives. Instead the narrative arc was placed around the students' individual narratives by informing the beginning and end of their book while simultaneously holding space for the students to tell their own stories.

Developing individual narratives. Having collectively identified the narrative arc of their book, the next activity entailed each of the students writing individual narratives and then developing a two-page narrative that used visual (their photos) and textual content (their statement and individual narrative) to illustrate who they are. This task was accomplished by the students weaving together the photos that they took over the months of January and February, their statement from the March 24, 2016 exercise (Field note, March 16, 2016), and their individual narratives about who they are. To determine what the students wanted to include on their two pages and to develop their individual narratives, the Coordinator met with each student individually. I did not take part in this aspect of the Photography Class because the Coordinator thought that my presence 
would have been too intrusive for the student and I agreed. Although I was not part of this component of the Photography Class I was able to gain insight into the students' lived experience through their individual contributions to the book.

Summarized below in Table 3 and Table 4 are all 21 of the students' individual narratives that were composed during their one-on-one sessions with the Coordinator and then published in their book. For each of the students the format that was used to present their narrative entailed two pages with the first page presenting the image of their arm or hand with their written statement. The photo of their arm or hand was blown-up to fit the size of the page thereby placing emphasis on this component of the students' individual narrative. The second page (beside and to the right of the first page) presented a photo of the student standing in front of their school ${ }^{24}$, the individual narratives that were developed during the one-on-one sessions with the Coordinator, and two to four of their own photos. The criterion of only using their own photos significantly narrowed the students' options when compiling their individual narrative, but, ensured that their narrative was grounded in and informed by their own lived experience. Collectively the photos were the same as the ones used earlier to identify the narrative arc and as such ranged from images of different people in the students' lives (e.g., school personnel, Kokom and Mosom, siblings, friends, etc.) to pictures of land and place (e.g., eagles, horizons, mountains, their school, etc.).

Although interesting, the photos, as with the students' statements, in and of themselves were not the focus of analysis or this research study. Rather, in this section I focus on the textual content of the students' two-page individual narratives. Those

\footnotetext{
${ }^{24}$ As previously discussed, the photos of the students in front of their school were taken as part of the March 24, 2016 exercise when the students also took photos of their arms or hands with their statements written on their arms or hands.
} 
narratives ranged in length from 5 words (D. C., Book, 2016, p. 50) to 317 words (K. L., Book, 2016, p. 23). The narratives also built upon the students' earlier statements in terms of continuing a pattern of positive identification; but, illustrated more nuanced and complex descriptions that tended to weave together a pattern of intrapersonal and relational characteristics. To illustrate the relationship between the students' earlier statements and their individual narratives, column two of Table 3 and 4 below contain the same student statements previously presented in Table 1 and 2 . In comparison, column three of Table 3 and 4 present the students' individual narratives. Additionally, I purposefully maintained the format previously used in Table 1 and 2 for Table 3 and 4 to illustrate how the students progressed in their ability to define self from when they wrote their individual statements to when they wrote their individual narratives. In consequence, Table 3 is titled "Intrapersonal Narratives" and I maintained the theme of intrapersonal descriptors related to action, accomplishment, and self-esteem and then added the third column with the student's corresponding individual narrative because it builds upon the intrapersonal statements to include relational descriptors. Table 4 is titled "Relational Narratives" and I maintained the theme of relational descriptors related to "Creeness", the teachings of $५ \rho " \Delta \supset \Delta^{\supset}$ (Sakihitowin/love and kindness), Courage, Truth, and the Seven Sacred Teachings and then added the third column with the student's corresponding individual narrative that builds upon their relational statements to include intrapersonal descriptors.

\section{Table 3: Intrapersonal Narratives}

\begin{tabular}{|l|l|l|}
\hline Theme and Citation $^{25}$ & Statement & Individual Narrative \\
\hline Action & & \\
\hline
\end{tabular}

\footnotetext{
${ }^{25}$ For readability purposes, citations for the students' statements that are quoted in column two and column three are presented in column one.
} 


\begin{tabular}{|c|c|c|}
\hline R. C., Book, pp. 24-25. & I AM SEARCHING ${ }^{26}$. & $\begin{array}{l}\text { I am searching for happiness. I am searching to belong. I } \\
\text { am searching to be respected. I am searching for my for } \\
\text { my dream to come true. I dream to be an engineer. I } \\
\text { want to build bridges. I will do what it takes to follow } \\
\text { my dream. }\end{array}$ \\
\hline S. W., Book, pp. 26-27. & $\begin{array}{l}\text { I AM SEEING. I AM } \\
\text { SEEKING. }\end{array}$ & $\begin{array}{l}\text { I am seeking. I try to be confident. I try to be strong. I } \\
\text { try to be brave. I am looking for Hope Courage } \\
\text { Confidence Truth. I trust that if I look hard I will find } \\
\text { what I am looking for. I will see. }\end{array}$ \\
\hline \multicolumn{3}{|l|}{ Accomplishment } \\
\hline J. J., Book, pp. 38-39. & I AM AN ATHLETE. & $\begin{array}{l}\text { I am Nehiyaw. I am a Daughter. I am an Athlete. I am } \\
\text { Helpful. I am a Protector. }\end{array}$ \\
\hline D. E., Book, pp. 46-47. & $\begin{array}{l}\text { I AM A GOOD } \\
\text { STUDENT. }\end{array}$ & $\begin{array}{l}\text { I am a good student ... I want to be a Doctor. I want to } \\
\text { help people; so others will have better lives. I am a good } \\
\text { person and I want more people to see that. I am Native } \\
\text { and I am Proud. }\end{array}$ \\
\hline C. S., Book, pp. 36-37. & $\begin{array}{l}\text { I AM A } \\
\text { TRADITIONAL } \\
\text { DANCER. }\end{array}$ & $\begin{array}{l}\text { Don't be afraid to learn new things. Don't be afraid to } \\
\text { ask questions. Don't be afraid to make mistakes. }\end{array}$ \\
\hline \multicolumn{3}{|l|}{ Self-Esteem } \\
\hline L. S., Book, pp. 40-41. & I AM INDEPENDENT. & $\begin{array}{l}\text { I have the courage to be myself in this world. I trust to } \\
\text { choose the right people to help when I need it. }\end{array}$ \\
\hline C. M., Book, pp. 42-43. & I am strong. & $\begin{array}{l}\text { You don't just get Respect. You have to EARN } \\
\text { RESPECT. }\end{array}$ \\
\hline H. S., Book, pp. 44-45. & I am CONFIDENT. & $\begin{array}{l}\text { To BE CONFIDENT is to BE YOU. To be confident is } \\
\text { to believe in yourself, to push yourself to be outing. BE } \\
\text { FEARLESS }\end{array}$ \\
\hline H. C., Book, p. $48-49$ & I'm Blessed. & $\begin{array}{l}\text { I am blessed with family and friends who love me for } \\
\text { who I am. I am blessed with a Mom and Mosom who } \\
\text { teach me to never give up. I am a perfect imperfection .. } \\
\text {. That's me. }\end{array}$ \\
\hline
\end{tabular}

Table 4: Relational Narratives

\begin{tabular}{|c|c|c|}
\hline Theme & Statement & Individual Narrative \\
\hline \multicolumn{3}{|l|}{ Love and Kindness } \\
\hline $\begin{array}{l}\text { K. L., Book, 2016, pp. } \\
22-23 \text {. }\end{array}$ & $\begin{array}{l}\text { I AM LOVING. I AM } \\
\text { BRAVE. }\end{array}$ & $\begin{array}{l}\text { Sometimes I am angry and I want to fight everyone and } \\
\text { everything. What has happened to my people, my } \\
\text { family, it's not fair. I want to use my anger to fight for } \\
\text { what is right. I want to fight to make things better for my } \\
\text { family, my community and all my people. We need to } \\
\text { work to educate ourselves. We need to teach the younger } \\
\text { generation our culture. We do not want them looking up } \\
\text { to gang members. We need to teach them to love who } \\
\text { they are and follow our Cree teachings. We should not } \\
\text { be ashamed of who we are. We are strong and intelligent } \\
\text { people. Yes, some people go through hard times because } \\
\text { of the things they grew up around. We should not judge } \\
\text { people, especially because of the color of their skin. } \\
\text { Some of our families are hurting. We need healing. I } \\
\text { was in Foster Care and I moved to many different homes. } \\
\text { I have been through a lot. Growing up means you have }\end{array}$ \\
\hline
\end{tabular}

${ }^{26}$ In column two and three present quotes from the students' book. Different students placed emphasis on certain words in these by using capital letters, underlines, and/or bold text. 


\begin{tabular}{|c|c|c|}
\hline & & $\begin{array}{l}\text { to move past what we have been through. We need to } \\
\text { look at the positive in who we are and where we come } \\
\text { from. Even if people don't see it we need to see it in } \\
\text { ourselves. No one is perfect. We all have our issues to } \\
\text { go through in different ways. Even though I sometimes } \\
\text { feel angry I know I am caring. I know I am smart. I love } \\
\text { my family. When I grow up, I want to be a man who } \\
\text { works to take care of his family. I want to be a man who } \\
\text { respects women. I want to be a man who is there for his } \\
\text { children. I want to be a man who teaches his children } \\
\text { about our culture. We should not let the past and } \\
\text { discrimination take away from us caring about and } \\
\text { helping each other. All in all, we are all humans. }\end{array}$ \\
\hline C. M., Book, pp. 30-31. & I AM KIND. & $\begin{array}{l}\text { I am kind to all people. If you be kind to people and } \\
\text { animals it will come back to you. Being kind makes me } \\
\text { feel proud and happy. I am loving to all my family, my } \\
\text { school and my community. I follow the Cree teachings } \\
\text { of love that I have been taught. }\end{array}$ \\
\hline B. F., Book, pp. 32-33. & I AM LOVING. & $\begin{array}{l}\text { It is important to love one another. It is important to } \\
\text { know that you are loved. }\end{array}$ \\
\hline \multicolumn{3}{|r|}{ 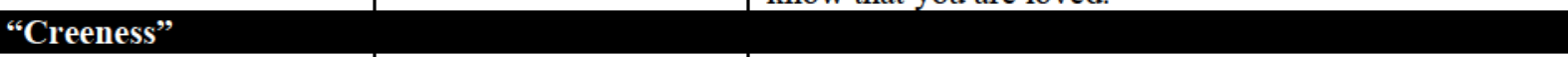 } \\
\hline D. C., Book, pp. 58-59. & $\begin{array}{l}\text { I AM LIFE, I AM } \\
\text { Proud to Be Native. }\end{array}$ & Be proud. Go after what you want. Take a risk. \\
\hline J. P., Book, pp. 60-61. & I AM CREE. & $\begin{array}{l}\text { I respect my culture. I am Cree. If we young people } \\
\text { learn the Cree way then we can pass it on to the next } \\
\text { generation. What did our Ancestors suffer for? We need } \\
\text { to sit down with the Elders so we can learn from them. } \\
\text { We should not let ourselves be distracted by technology. } \\
\text { Let's spend time talking to our Mosoms and Kokoms. } \\
\text { Let's focus on being Cree. }\end{array}$ \\
\hline D. P., Book, pp. 62-63. & $\begin{array}{l}\text { I AM CREE. I AM } \\
\text { PROUD. }\end{array}$ & $\begin{array}{l}\text { I am proud to be Cree. I am proud to be who I am. I can } \\
\text { go out into the world and do many things. I can be many } \\
\text { things but I will always be Cree. }\end{array}$ \\
\hline C.L., Book, pp. 54-55. & I AM PROUD. & $\begin{array}{l}\text { I love my family. I love my Kokom. We need Courage } \\
\text { to live and love. }\end{array}$ \\
\hline \multicolumn{3}{|r|}{ the and } \\
\hline A. P., Book, pp. $28-29$. & COURAGE. & $\begin{array}{l}\text { I have the COURAGE to keep doing the RIGHT } \\
\text { THING. }\end{array}$ \\
\hline \multicolumn{3}{|l|}{ Truth } \\
\hline C. R., Book, pp. 34-35. & I am Truthful. & $\begin{array}{l}\text { We learn from each other. There is no one above or } \\
\text { below. Understand where you are in Life and Learning. } \\
\text { SEEK THE TRUTH. SPEAK THE TRUTH }\end{array}$ \\
\hline D. C., Book, pp. 52-53. & $\begin{array}{l}\text { I AM THE REAL } \\
\text { HONEST. }\end{array}$ & Have the Courage to make Tracks. \\
\hline \multicolumn{3}{|l|}{$\begin{array}{l}\text { Seven Sacred } \\
\text { Teachings }\end{array}$} \\
\hline J. C., Book, pp. 50-51. & $\begin{array}{l}\text { TRUTH LOVE } \\
\text { RESPECT COURAGE } \\
\text { HUMILITY WISDOM } \\
\text { HONESTY } \\
\text { NEHIYAW. } \\
\end{array}$ & $\begin{array}{l}\text { We have our Elders and their stories and their teachings. } \\
\text { We have our families that love us and a place to call } \\
\text { home. We have our traditions. We do what we can to } \\
\text { keep our Cree stories and teachings in our heats. }\end{array}$ \\
\hline N. M., Book, pp. 56-57. & $\begin{array}{l}\text { I AM LOVE } \\
\text { HONESTY } \\
\text { HUMILITY TRUTH }\end{array}$ & $\begin{array}{l}\text { I try to learn the teachings, so when I get older I can } \\
\text { respect myself and other people. My Mosom teaches me } \\
\text { Courage, Respect, truth, Honesty, Humility, Wisdom and }\end{array}$ \\
\hline
\end{tabular}




\begin{tabular}{|l|l|l|}
\hline & $\begin{array}{l}\text { COURAGE RESPECT } \\
\text { WISDOM. }\end{array}$ & $\begin{array}{l}\text { Love. I MIGHT JUST SLAP YOU WITH THE 7 } \\
\text { TEACHINGS, IF YOU'RE LUCKY. CHA }\end{array}$ \\
\hline
\end{tabular}

Tables 3 and 4 illustrate how each of the students moved from succinct and declarative statements to more nuanced and complex descriptions of who they are that build and expand upon their statements by weaving together intrapersonal and relational descriptors. Similar to their individual statements, each of the students' individual narratives were unique. The diversity amongst the students' individual narratives illustrates, again as with their statements, that they were not simply echoing the Elders' teachings. Rather the students were in dialogue with the Elders' teachings in different degrees and with different aspects that resonated with their lived experience. As evident in the progression of their ability to name themselves in more complex and nuanced manners, their dialogue with the Elders' teachings helped the students clarify their lived experience as a $\nearrow^{\| \prime} \Delta$ ל० (Nehiyaw/Cree) individual for themselves and for the book reader. Further the diversity in terms of how and to what extent the Elders' teachings resonated with the different students and informed their individual narratives illustrates that how one identifies and names self is not a fixed journey or destination; instead, it is a continual and iterative process that takes place over a lifetime. For example, on March 24, 2016 S. W. stated that "I AM SEEING. I AM SEEKING" (Book, p. 26, emphasis in original) thereby reflecting the intrapersonal descriptor of specific actions, that is, seeing and seeking. Taking the knowledge gained through the Elders' teaching and building upon those actions, S. W. wrote the following individual narrative (previously presented in Table 3) that:

I am seeking. I try to be confident. I try to be strong. I try to be brave. I am looking for Hope Courage Confidence Truth. I trust that if I look hard I will find what I am looking for. I will see. (Book, 2016, p. 36, original emphasis) 
In contrast, on March 24, 2016 K. L. stated that "I AM LOVING; I AM BRAVE" (Book, p. 22, emphasis in original) and reflected the relational descriptor of $\left\langle\rho " \Delta \supset \Delta^{\prime} \cdot\right.$

(Sakihitowin/love and kindness). Following this statement K. L. composed the following individual narrative (previously presented in Table 4) stating that:

Sometimes I am angry and I want to fight everyone and everything. What has happened to my people, my family, it's not fair. I want to use my anger to fight for what is right. I want to fight to make things better for my family, my community and all my people. We need to work to educate ourselves. We need to teach the younger generation our culture. We do not want them looking up to gang members. We need to teach them to love who they are and follow our Cree teachings. We should not be ashamed of who we are. We are strong and intelligent people. Yes, some people go through hard times because of the things they grew up around. We should not judge people, especially because of the color of their skin. Some of our families are hurting. We need healing. I was in Foster Care and I moved to many different homes. I have been through a lot. Growing up means you have to move past what we have been through. We need to look at the positive in who we are and where we come from. Even if people don't see it we need to see it in ourselves. No one is perfect. We all have our issues to go through in different ways. Even though I sometimes feel angry I know I am caring. I know I am smart. I love my family. When I grow up, I want to be a man who works to take care of his family. I want to be a man who respects women. I want to be a man who is there for his children. I want to be a man who teaches his children about our culture. We should not let the past and discrimination take away from us caring about and helping each other. All in all, we are all humans. (Book, 2016, p. 23)

Both of the students' unique statements and individual narratives represent a snapshot of a specific time and space that reflects where S. W. and K. L. were on their own journey at these two points in the Photography Class. Notably, each statement and individual narrative reflects different aspects of the Elders' teachings that resonated with the student's own lived experience and, as such, reveal an internal dialogue of individual identity formation. In this way, how and to what extent the Elders' teachings about the past (Residential Schools) and shared values and norms (Seven Sacred Teachings) resonated with, and informed, the students' respective narratives was mediated by lived 
experience. For example, as the Photography Class progressed and she was at a different point in her journey, S. W.'s individual narrative articulated intrapersonal descriptors ["I try to be confident. I try to be strong. I try to be brave (Book, 2016, p. 36)] and relational descriptors ["I am looking for Hope Courage Confidence Truth. I trust that if I look hard I will find what I am looking for. I will see" (Book, 2016, p. 36, emphasis in original)]. Therefore, S. W.'s individual narrative illustrates a more nuanced, complex, and authentic understanding of who she is that braided together intrapersonal and relational descriptors.

In contrast, as the Photography Class progressed and K. L. was at a different point in his lived experience and he moved from a succinct and predominantly relational statement to an in-depth description that made visible the complexity of intrapersonal descriptors in relation to his past, present, and future. Thus, K. L. explains how his life has been significantly impacted by the Child Welfare system. Despite these challenges, K. L. believes that "Growing up means you have to move past what we have been through. We need to look at the positive in who we are and where we come from. Even if people don't see it we need to see it in ourselves" (Book, 2016, p. 23). Echoing an earlier sentiment reached collectively by the class through the Elders' teaching on systemic racism, K. L. refuses to be defined by his experiences in the Child Welfare system focuses on the positive in who he is and where he comes from as part of the ๖" $\Delta ৬ \triangleleft \cdot$ ' (Nehiyawak/Cree people). Similar to S. W. but in a different manner, K. L.'s individual narrative illustrates the more nuanced, complex, and authentic understanding of who he is that emerges from braiding together various intrapersonal and relational descriptors. 
An overall examination of the students' individual narratives reveals how each of the students wove together narrative resources that they had gathered through their lived experience and what had been shared by the Elder D. M. and Elder L. S. during their teachings in phase one and two to create their individual narratives. As such, the authorship of their personal narratives represents the third step in the process of authoring a more complete and positive narrative about who they are and a further integration of Elder D. M.'s teachings on $\nmid \rho^{\prime \prime} \Delta \supset \Delta^{\cdot}$ (Sakihitowin/love and kindness) through positive self-identification and Elder L. S.'s teaching on Courage.

The students' two-page narrative comprised 42 pages (pp. 22-63) of the book's 70 pages. Therefore, the students' individual narratives comprised $60 \%$ of the content of their book. The remainder of the book presented photos that were identified during the narrative arc exercise and various supporting quotes that were gathered by the Coordinator from different community members. In particular, pages 1 to 21 and 64 to 70 of the book were comprised of photos and quotes related to the three themes of the narrative arc (Indigenous rights, Elders role as knowledge holders and Standing-up for who you are).

In this third phase the students contemplated their identity, practiced naming themselves, developed a narrative arc, crafted individual narratives, and authored and published a book. Together, all of these activities helped them achieve their goal of authoring a more complete and positive narrative about who they are as $\mathrm{D} " \Delta$ ל० (Nehiyaw/Cree). The next phase was characterized by the students standing-up and naming themselves in a public venue and hence furthering their practice of $น \rho \| \Delta \supset \Delta^{\prime}$. (Sakihitowin/love and kindness) and Courage. 
Phase four: $\nmid \rho " \Delta \Delta^{\cdot}$ ग (Sakihitowin/love and kindness). The fourth and final

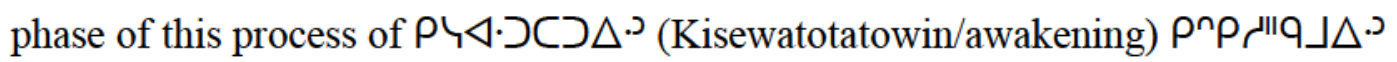
(Kiskisohkemowin/reminding) was termed $\nmid \rho^{\prime \prime} \Delta \supset \Delta^{\cdot}$ (Sakihitowin/love and kindness) and was guided by the \" $\Delta$ ל० (Nehiyaw/Cree) principle of teaching termed encouraging. Within the context of this research study, the principle of encouraging was characterized by community Elders, family and community members celebrating the students' accomplishments and encouraging them to continue their life long journey of learning about who they are as a $\square^{\|} \Delta$ ל० (Nehiyaw/Cree individual). Below I illustrate how this fourth phase unfolded through the Photography Class practice of the students standing-up in a public venue and naming who they are.

\section{Practicing $\left\lfloor p " \Delta \supset \Delta^{.}\right.$(Sakihitowin/love and kindness) and courage. The}

activity that was at the core of this final phase was the book launch that took place on June 2, 2016 at an art gallery in an urban center in Alberta. In addition to the book launch, the students' photos were placed on display and available for public viewing for a 2-week period following this event. The book launch had approximately 100 people in attendance. Attendees included family and community members, Chief and Council, school personnel and residents of the urban center. This group of people gathered to view the students' photos, buy their book, learn about their experience with the Photography Class, and celebrate their accomplishments. For example, while reflecting upon the book launch S. H. stated that:

[What] makes me feel good about the project is the community support. At ... the book launch we have leadership, we have family and we have community members that are there and that fully support the project and the young people who worked so hard on it. And that is an important element of the project 
because the youth are able to see that...their project is valuable ... And that is reflected in the book launch. [For example], every single student was there and everyone had someone there to support them. (S. H., Interview, June 08, 2016)

People attending the book launch from the students' community had to travel 120 kilometers to attend this event. To assist with traveling to and from the event the school provided transportation for family members that did not have access to their own means of transportation. Despite this distance and potential transportation barriers, the highlevel of attendance illustrates that this was an important and valued event. Providing insight into why this was a significant event is what the students shared during the speeches that they made during the book launch.

In total, 9 of the 21 students stood-up at the front of the gallery and shared with the audience what the Photography Class and their book meant to them. Below I provide a sample of the student's speeches that best captured the students lived experience with the Photography Class and the process of making their book:

R. C.'s Speech: I joined the [Photography Class] because I wanted to help people understand we are more than a stereotype. We made this book to "see and be seen". This book encourages people to follow their dreams and accomplish life. I mean, if we can accomplish a book then we can accomplish anything! (R. C., Speech, June 02, 2016)

C. M.'s Speech: Thank you all for coming to our book opening. It was hard making this book but I am glad I did this. I have never been in a book before. This is our school's book and it shows who we are. We are Cree, we are family, we are friends, we are students, we are athletes, we are artists, we are so many things. I feel proud and happy about making this book. (C. M., Speech, June 02, 2016)

J. C.'s Speech: I would like to thank all of you for coming to our school book opening. It really means a lot to me and my school and to all that took part in making this book. I joined the [Photography Class] because I have my pictures in there. I hope that this book helps us accomplish our dreams and helps us in the way we think about ourselves and others. Just because people are from different cultures does not mean that we are not the same in some ways. We are all talented in different ways. (J. C., Speech, June 02, 2016) 
S. W.'s Speech: To know myself is to understand my bloodline, to know who and where I come from, and to know my history and my hopes and dreams. It is important to me to let myself be known and that I make use of my life. There are people who spend their lives hating, fighting, judging, labeling and this hurts themselves and others. We need to look into our hearts. We must seek and find love for ourselves and each other to understand ourselves and others. What does it really mean to love yourself? I think it means to love that you were born into this world and to let our hearts be open and to let our spirits live. (Personal communication, June 02, 2016)

Collectively, R.C, C. M., J. C., and S.O.'s speeches illustrate expressions of love and kindness towards themselves, their family and community, a sense of optimism for their future, value and pride in being $\mathrm{O}^{\prime \prime} \Delta$ ל० (Nehiyaw/Cree), and hope that their book would help others to see and hear them with an open heart and mind. Together, the book launch and to a greater extent, the students that stood-up and made a speech, represent the fourth step that the students took in the development of their practice of $\left\lfloor P \| \Delta \supset \Delta^{\prime} \cdot\right.$ (Sakihitowin/love and kindness) and Courage. More specifically, it was their practice of Courage (standing-up and naming themselves) that made their practice of $\left\langle\rho " \Delta \supset \Delta^{\nu}\right.$ (Sakihitowin/love and kindness) visible and hence a more positive, accurate, and complete narrative about who they are. In turn, this visibility is what made a broader impact possible in-terms of potentially influencing society's ideas about who they are as their narratives entered into circulation in the public realm.

Even though the students were predominantly surrounded by allies at the book launch, this activity took place in an urban centre where the dominant narrative continues to dehumanize and devalue them as Indigenous peoples and underscores the critical role and significance of their practice of Courage. The students' book launch was significant because each of the students put into practice the teaching of Courage by literally 
standing-up, resisting, and challenging the dominant and predominantly racist narrative about who they are by providing the audience with a more complete and positive narrative. They stood up for themselves but also to hopefully change a few hearts and minds along the way by describing to others publicly who they are. Recall that in phase three the students decided to use their book as a way to get to know and be strong in who they are as $\nearrow^{\prime \prime} \Delta$ ל० (Nehiyaw/Cree) youth and to mediate the impact of racism by being strong in who they are. They had also decided to use their book as a way to collectively stand-up and name themselves as a means of challenging the broader public with positive images of $\mathrm{D}^{\|} \Delta$ ל० (Nehiyaw/Cree) youth that defied the racist ideas held by greater society. Taken together their goal was to use their book as a way to mediate the interpersonal impacts of racism and to challenge and mediate racist ideas that are held by society at large. Although the latter challenge of altering racism was beyond the scope of this research study the following section identifies and examines the impacts that the

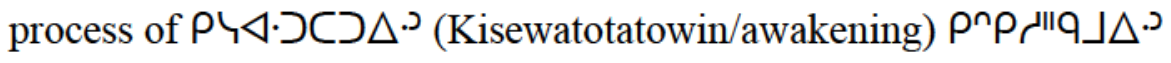
(Kiskisohkemowin/reminding) and it four phases had on the students. In this section I examined the four phases that comprised the process of

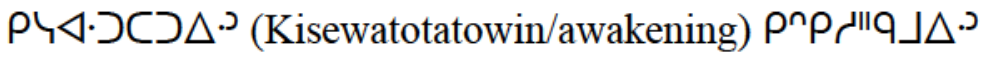

(Kiskisohkemowin/reminding) and their relationship to renewing specifics aspect of the

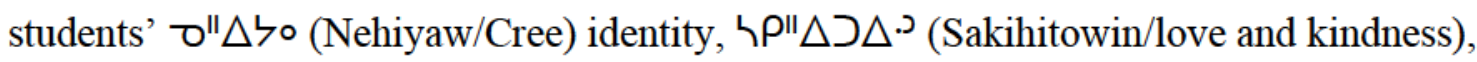
that was disrupted by the Residential Schools. This process was achieved through a practice of Courage where the students stood-up in a public setting and named who they are using \" $\Delta$ ל० (Nehiyaw/Cree) narrative resources (one, two, three, and four) 
characterized by love and pride rather than the colonial and dominant narratives of hate and shame. Having unpacked each of the four phases in previous sections, this following section summarizes the main finding from this study, the conceptual model of the process

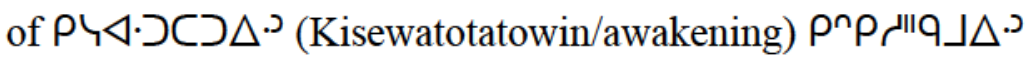

(Kiskisohkemowin/reminding).

\section{Understanding the Process}

Figure 1: $P ५ \triangleleft \cdot \supset C \supset \Delta^{\top}$ (Kisewatotatowin/awakening)

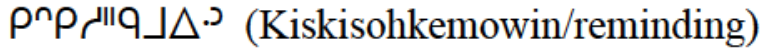

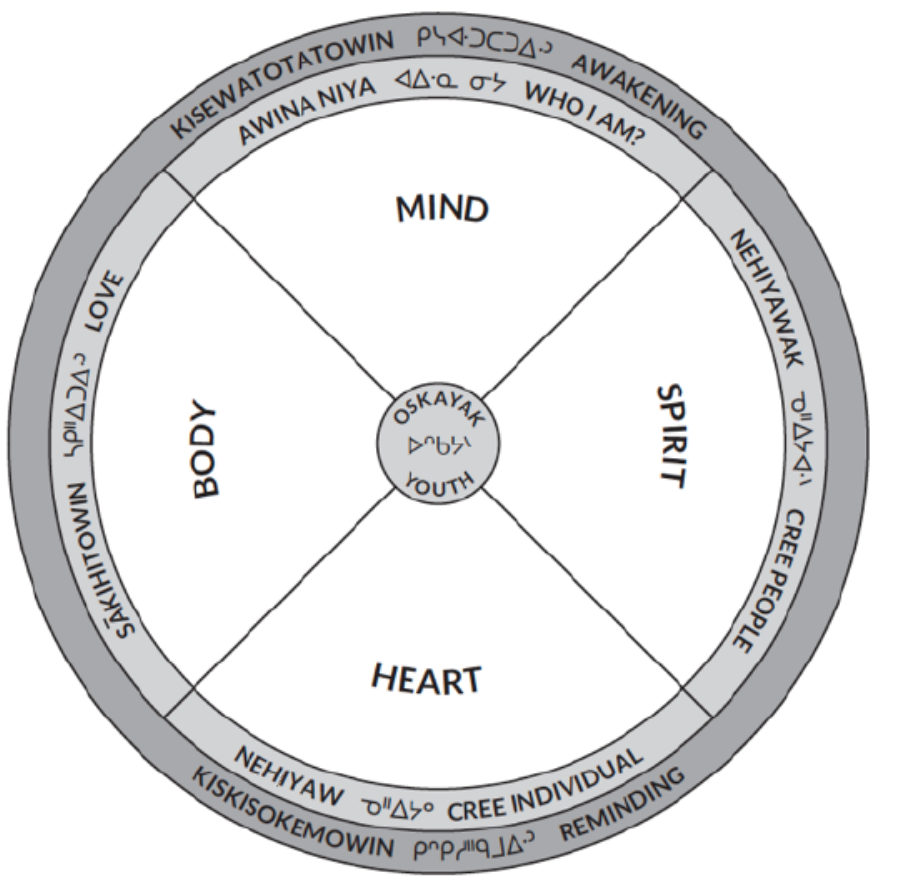

As detailed in Figure 1, the Photography Class combined the sacred teachings and the Aboriginal educational approach in a process of $P \hookrightarrow \triangleleft \cdot \supset C \supset \Delta^{J}$

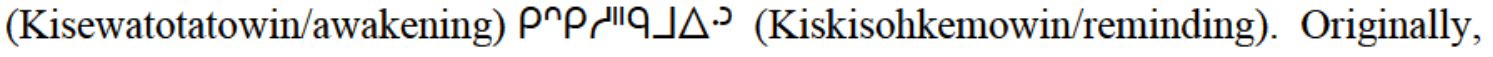
this research project and the Photography Class was focused on addressing racism and during the initial stage of analytical coding, I sought to detail the process that the students 
engaged in to address the impact of racism on them, their families, and their community.

I soon learned, however, that the process involved changing the individual students' perception of self as a $\square^{\prime \prime} \Delta ל \circ$ (Nehiyaw/Cree individual). As discussed in the previous chapter on research methodology, a visual representation of this process emerged during the theoretical sampling phase of analysis. I identified four phases of that process through analytical coding and then I developed them into a conceptual model (see Figure 1) that captures what came to be identified as a process of $P \backslash \triangleleft \cdot \supset C \supset \Delta^{\prime} \mathrm{J}$ (Kisewatotatowin/awakening) $\left.\rho^{n} \rho{ }^{\| !} \mathrm{Q}\right\lrcorner \Delta^{\circ}$ (Kiskisohkemowin/reminding). Before unpacking Figure 1 it is important to note that I used the Medicine Wheel as a framework to assist with developing this visual representation. I employed the framework of a Medicine Wheel because it is epistemologically aligned with and hence was conceptually appropriate for visually representing this study's findings.

Over the years I have been taught by different Elders about the basic tenets of a Medicine Wheel. For example, it is comprised of four interconnected steps that are part of a cyclical, continual, and lifelong learning process that has no particular beginning or end and reflects the ๑" $\Delta$ \०(Nehiyaw/Cree) understanding of identity as a continual, iterative and life long journey (Brundige, 2004; Weber-Pillwax, 2001). To quote Mary Lee a \" $\Delta$ ל० (Nehiyaw/Cree) an Elder from Pelican Lake in northern Saskatchewan: As Cree people, we were given the gift of being named for the four parts of human beings. Nehiyawak, we were called. It means being balanced in the four parts that are found in the four directions of the Medicine Wheel. These four parts for human beings are the spiritual, physical, emotional and mental aspects of the self. We need to try and balance these four parts that were given to us, to function as people. The fire is in the centre of the Medicine Wheel. That is where the meaning of the teachings comes from. For me this fire is also the self. When you look at the Medicine Wheel, you start from self. And as you look out, 
you make your circle. This is how the Medicine Wheel represents the life journey of people. The old people will tell you it is life itself. Look at the four seasons and follow the sun. Spring in the east, summer in the south, fall in the west and winter in the north. It tells the whole story of how all life came into being abundantly bright, rising in the east and then fading away as it moves west and north. All life rises and sets like the sun. What we do in between is our journey. (Four Directions Teachings, 2006)

There are other interpretations of what the quadrants represent. In 2005 a Collaborative Inquiry Committee that was composed of Indigenous and non-Indigenous educators and Elders was struck to develop guidelines and a framework for Aboriginal science, teaching and learning for Southern Saskatchewan. The committee's work centers around the Medicine Wheel and explains that the north quadrant represents the mind and the generation of understanding, the east represents the spirit and connecting with the world around you, the south represents the heart and reflecting on feelings, and the west represents the body and taking action (Ali, 2005). Reflecting upon the above model of four directions and interpretations of their respective elements of the lifelong journey of learning, I explain how the model presented in Figure 1 depicts the process of

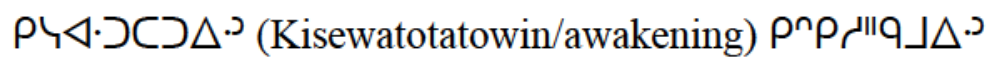

(Kiskisohkemowin/reminding). It is important to note that different First Nation communities can have different ways of depicting the Medicine Wheel and how it is represented in this study is my construction and represents merely one of numerous possibilities.

\section{First Ring: Self}

In line with how the Medicine Wheel, the process of $P \backslash \triangleleft \cdot כ C \supset \Delta^{\cdot}$

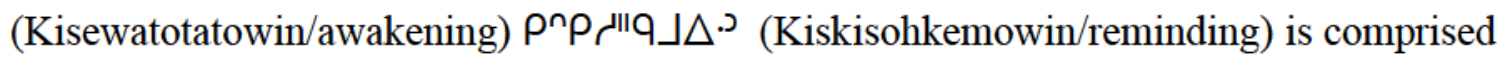
of four quadrants with four centric circles with the students placed in the centre of the 
diagram (see Figure 1). It is important to note that the center of a Medicine Wheel is commonly understood as representing the Creator. This is what Elder Mary Lee was describing when she stated that "The fire is in the centre of the Medicine Wheel. That is where the meaning of the teachings comes from. For me this fire is also the self' (Four Directions Teachings, 2006). The students are placed in the center of the diagram to reflect how the process of learning, as described by Elder Mary Lee, starts with the self. Supporting this positioning in the visual representation is what $\mathrm{S}$. H. stated when discussing the Photography Class:

[developing their identity, this] is what we are trying to get at. You know what is an adolescent's number one job? To develop their identify, who they are in the world. And I cannot tell them who they are. I can encourage them to look in different places and search for different answers to their questions or develop questions for themselves. (S. H., Interview, June 8, 2016)

While reviewing Figure 1, Elder D. M., E. B., and L. B. shared with me that for them the Creator is placed in the middle of the Medicine Wheel (Field note, December 13, 2016). However, to reflect the process documented in this study I placed the youth in the center. My decision to maintain the placement of the youth in the center should not be seen as negating what the Elders shared with me nor the Creator because as described by Elder Mary Lee the self and the Creator are not necessarily separate entities. For example, C. C. explained to me the "Everything is part of the creator. Creator is $\left\llcorner P \| \Delta \supset \Delta^{\supset}\right.$ (Sakihitowin/love and kindness) and $\nmid \rho " \Delta \supset \Delta^{\supset}$ (Sakihitowin/love and kindness) transcends all. All things are alive and related to each other" (C. C., Personal Communication, January 24, 2016). 


\section{Second Ring: Four Components of Self}

The second ring represents the four different components of the self (the mind, spirit, heart, and body). Using the framework of the Medicine Wheel, as previously described, and the study's findings of the aspects of the students' lives that the course addressed, I placed them in the second ring:

(1) the mind in the north quadrant represents the students gathering information about the past understand the present (developing an awareness of their community's practice of $\left\lfloor\rho " \Delta \supset \Delta^{\supset}\right.$ (Sakihitowin/love and kindness) and the introduction of a praxis of hate through the Residential Schools),

(2) the spirit in the east quadrant represents the students connecting with the world around them (their community, the Seven Sacred Teachings, and with each other),

(3) the heart in the south quadrant represents the students reflecting on feelings (their being aware of who they are, being positive about themselves, and about what has happened to them and their community), and

(4) the body in the west quadrant represents the students taking action (through the book, the book launch, and in their life journeys as they go forward).

Having placed the four components of the self into the model, the next step was to understand how the different aspect of the self were engaged during the four phases of

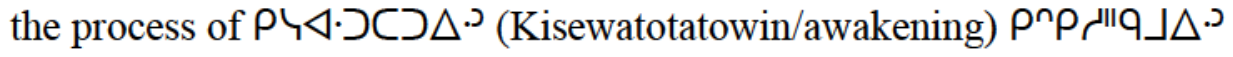

(Kiskisohkemowin/reminding).

\section{Third Ring: Developing Identity}

As discussed above, the initial phase was defined as $\triangleleft \Delta \cdot \mathrm{Q}$ P ל (Awina Niya/who I am). This step of the process of $P \hookrightarrow \triangleleft \cdot \supset C \supset \Delta^{\supset}$ (Kisewatotatowin/awakening) $\rho^{n} \rho$ P (Kiskisohkemowin/reminding) was placed in the northern quadrant because it reflected the students engaging their minds as Elder D. M. raised the students' awareness of their community's past in relation to Residential Schools and how it

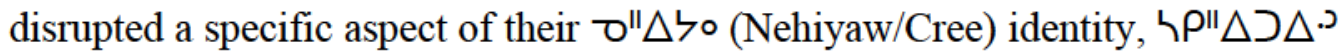


(Sakihitowin/love and kindness) and Elder L. S. developed the students' awareness of how racism was not, and is not, a part of the $\mathrm{C}^{\| \prime} \Delta$ ל० (Nehiyaw/Cree) way of life. Therefore, the first phase was generating the students' understanding of their own location in relation to their community's past and within the contemporary landscape of Canada's colonial legacy. Having fostered space for students to make their community's past more legible by using local narrative resources (one and two), the next phase sought to provide the students with narrative resources to see who they are as part of the ঠ" $\Delta ৬ \triangleleft \cdot `$ (Nehiyawak/Cree people).

The second step of the process of $P 4 \triangleleft \cdot \supset C \supset \Delta^{\cdot}$ (Kisewatotatowin/awakening)

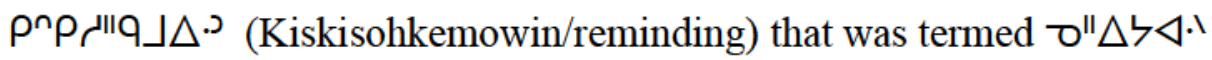
(Nehiyawak/Cree people). Moving clockwise on the wheel, I placed this step in the eastern quadrant. This stage reflected the students engaging their hearts by connecting with love and kindness and with courage to the world around them. This type of engagement was core to Elder D. M.'s shared that sacred teaching of $\left\lfloor\rho " \Delta \supset \Delta^{\prime} \cdot\right.$ (Sakihitowin/love and kindness) and Elder L. S.'s shared that sacred teaching of Courage. As the Elders shared these sacred teachings they were connecting the students in positive ways with their ancestors and the world around them as they learned about values and norms that are tenets of the $\nearrow^{\prime \prime} \Delta ל \triangleleft \cdot `$ (Nehiyawak/Cree people) and their way of life as well as giving them narratives resources (three and four) to develop an understanding of who they are as part of the $\nearrow^{\prime \prime} \Delta ל \triangleleft \cdot I$ (Nehiyawak/Cree people).

The third step of the process of $P \hookrightarrow \triangleleft \cdot \supset C \supset \Delta^{\supset}$ (Kisewatotatowin/awakening)

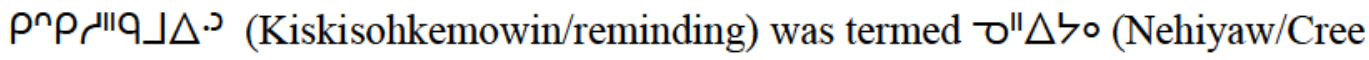


individual). This phase was placed in the southern quadrant because it represented the students engaging their spirit by using the narrative resources provided during phase one (narrative resource one and two) and phase two (narrative resource three and four) to reflect upon who they are as a $\nearrow^{\| \prime} \Delta$ \० (Nehiyaw/Cree individual). This type of engagement was reflected in the development of their ability to name themselves. It was also reflected in their book that provided a more complete and positive narrative about

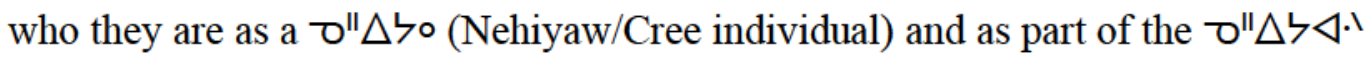
(Nehiyawak/Cree people).

The fourth phase of the process of $\rho \backslash \triangleleft \cdot \supset C \supset \Delta^{\supset}$ (Kisewatotatowin/awakening)

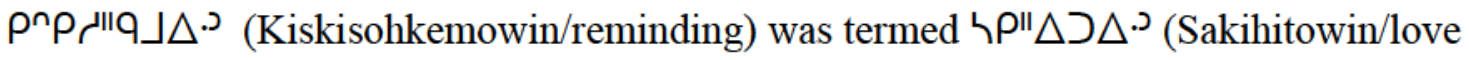
and kindness). I placed this phase in the western quadrant. This fourth phase represented the students engaging their body as they were taking action by standing-up and naming themselves to share with their family, community and the broader public their more complete and positive narrative about who they are. Specifically, the students put into practice Elder D. M.'s teaching on $\left\llcorner\rho^{\prime \prime} \Delta \supset \Delta^{\supset}{ }^{\supset}\right.$ (Sakihitowin/love and kindness) and Elder L. S.'s teaching on Courage. This included taking action by the writing of their narrative in the text which dealt with issues and feelings that were very close to them, attending the book launch and discussing their personal story through public presentations.

As discussed in the previous chapter, I brought Figure 1 with the three rings described above out to the community to review and discuss as part of my theoretical sampling and validation phase. While I was meeting with the school Elders I had the following and pivotal interaction with Elder E. B. After I showed the diagram to Elder D. 
M. and Elder E. B., E. B. pointed to the wall in the hallway of the school and asked me "can you see it?". All I could see was a brick wall that had been painted white so with a sense of humility I responded by saying “all I can see is a white wall?". Elder E. B. pointed to the wall again and said, "cannot you see it up there, we should have that [the diagram] painted on the wall" (Field note, December 13, 2016). This interaction confirmed for me that the diagram had captured how the Elders understood what was happening in the class. During this same visit Elder L. B. shared with me that what the diagram was depicting is a process of $P \zeta \triangleleft \cdot \supset C \Delta^{\circ} \cdot$ (Kisewatotatowin/awakening)

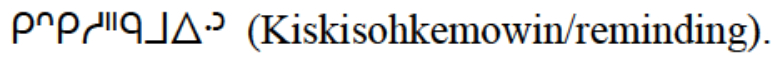

\section{Fourth Ring: Widening the Circle of Practice}

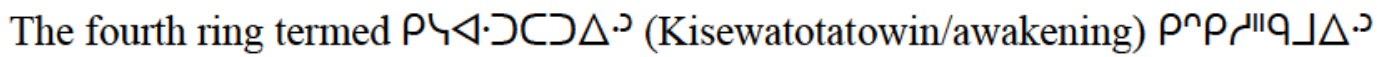
(Kiskisohkemowin/reminding) was not part of the original diagram. It was added because of what Elder L. B. had shared with me while reviewing the diagram. In particular, Elder L. B. explained to me that collectively the four phases represented a

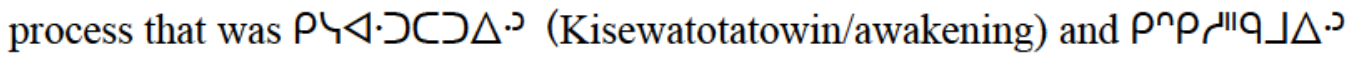
(Kiskisohkemowin/reminding) the students of their practice of $\nmid \rho \| \Delta \supset \Delta \cdot$ J (Sakihitowin/love and kindness). Therefore, and as reflected in Figure 1, I added the fourth ring to incorporate this finding. Further, Elder L. B. shared that phase one, two and three were awakening and reminding the students' of their practice of $h P \| \Delta \supset \Delta . \supset$ (Sakihitowin/love and kindness) love and kindness towards themselves, their family and community. For example, this level of practice was evident in phase three [ (Nehiyawak/Cree people)] when the students were developing their book's narrative that 
braided together their individual and collective narratives. Whereas during the fourth phase $\left[\nmid P \| \Delta \supset \Delta^{\supset}\right.$ (Sakihitowin/love and kindness)] their practice of $\left\lfloor P \| \Delta \supset \Delta^{\supset}\right.$ (Sakihitowin/love and kindness) was broadening beyond themselves, their family and community to include all beings (Field note, December 13, 2016).

Although this broadening of the students' practice of $\left\langle\rho " \Delta \supset \Delta^{\prime}{ }^{J}\right.$ (Sakihitowin/love and kindness) was initiated during the fourth phase, similar to dropping pebble into the water, the practice rippled out into other areas of the students' life and daily interactions. For this reason, I perceived it as a distinct element and represented it visually on the diagram as a part of the fourth ring. In addition, Elder L. B. shared that the fourth ring represents a space where non-Indigenous peoples can be included in the

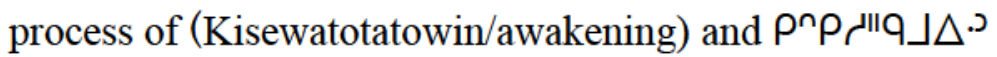

(Kiskisohkemowin/reminding). For example, as the students held their book launch they fostered a space where non-Indigenous peoples had an opportunity to be included in/begin to learn about and understand, if they have not already done so,

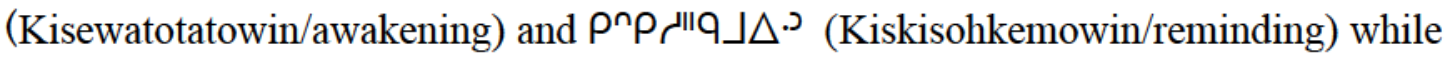
simultaneously affirming their own practice of $\left\langle\rho " \Delta \Delta^{\circ} \Delta^{\supset}\right.$ (Sakihitowin/love and kindness) for themselves, family community and all beings, including First Nations youth (Field note, December 13, 2016).

The insights that Elder L. B. shared with me highlighted for me the four important

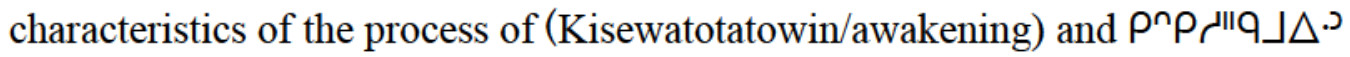
(Kiskisohkemowin/reminding) for [ $\nearrow^{\prime \prime} \Delta ৬ \triangleleft \cdot `$ (Nehiyawak/Cree people)] and the identity of the $\nearrow^{\| \prime} \Delta$ ל० (Nehiyaw/Cree individual). As outlined on the wheel diagram, this 
process starts with the self and is interpersonally/relationally and locally driven (e.g., phase one, two, and three). Second, once one can name themselves and is strong in who they are, the next step of the process broadens into the public realm. Third, once the practice enters the public sphere there is an opportunity to widen the circle of practice as neighboring communities and non-Indigenous peoples observe and experience the students' practice of $\left\langle P^{\prime \prime} \Delta \supset \Delta^{\supset}\right.$ (Sakihitowin/love and kindness). Fourth, this experience

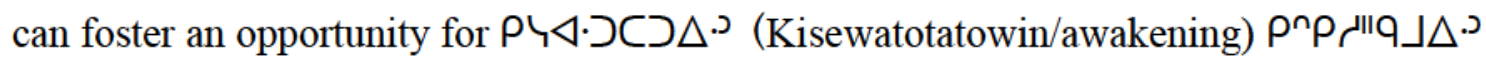
and (Kiskisohkemowin/reminding) non-Indigenous peoples of their practice of $\left\lfloor{ }^{\prime \prime} \Delta \supset \Delta^{\cdot} \cdot\right.$ (Sakihitowin/love and kindness). In this way, the process and steps outlined in the wheel diagram foster conditions for both Indigenous and non-Indigenous peoples to broaden their narrative resources beyond the dominant narrative of colonialism and racism to develop a more complete and positive understanding and way of relating to First Nations youth (Field note, December 13, 2016). The following section discusses the

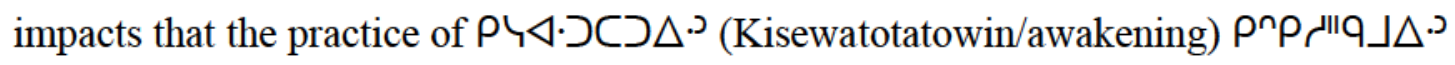
(Kiskisohkemowin/reminding) was found to have had on participating students.

\section{Impacts}

While conducting the analysis phase of this research study three impacts emerged that were associated with the students' practice of $P \ \triangleleft \cdot \supset C \supset \Delta^{\prime}$

(Kisewatotatowin/awakening) $\left.\rho^{n} \rho \Gamma^{\| l} \mathrm{Q}\right\lrcorner \Delta^{\nu}$ (Kiskisohkemowin/reminding). The three impacts that emerged were: (1) self-expression, (2) well-being, and (3) agents of social change. In this section, I discuss each of the impacts and their significance. 
Self-expression. One of the impacts that emerged during this research study was self-expression. For the purpose of this thesis the term self-expression refers to the students self-directing the development of their $\mathrm{O}^{\prime \prime} \Delta$ ל० (Nehiyaw/Cree) identity through the iterative and flexible practice of $P \hookrightarrow \triangleleft \cdot \supset C \supset \Delta^{\supset}$ (Kisewatotatowin/awakening)

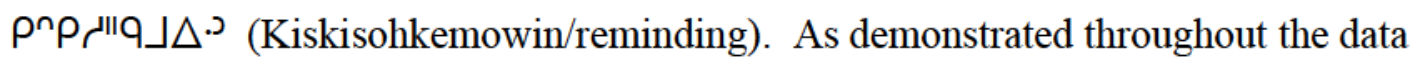
presented thus far, the practice of $P \backslash \triangleleft \cdot \supset C \supset \Delta^{\cdot} \mathrm{J}$ (Kisewatotatowin/awakening) $\left.\rho^{n} \rho \Gamma^{\text {III }}\right\lrcorner \Delta^{\mathcal{J}}$ (Kiskisohkemowin/reminding) fostered space for the students to reflect upon and articulate who they are and ultimately author unique narratives that braided together differing intrapersonal and relational descriptors to name who they are (for examples see Table 3 and Table 4). Flexibility was identified as a key component in the students' experience of self-expression and this did not occur by accident. In the interview excerpt presented below, the Coordinator explains why she used a flexible approach and why this was critical to fostering space for students' self-expression:

over the years I have never been committed to [the Photography Class] having to be this way or that way. We tried to partner [with a school in a neighboring community] this year and one of the challenges was that they wanted a very structured approach and I kept telling her I cannot provide that. I just do not have it [a structure], and that it is not how this project is run ... I have stayed flexible and open to what ... the different groups of students have to offer [and what they want their book to communicate]. Yes, I am responsible as the adult for providing some structure, it cannot be just a free for all, you have to bring your ability to the table and provide some direction. But if we change lanes, that is okay, I am okay with that. And I think that flexibility has allowed me to and allowed the kids to have this [book] as a true expression of self. Which is what we are trying to get at [with the Photography Class]. You know what is an adolescent's number one job? To develop their identity, who they are in the world. And I cannot tell them who they are. I can encourage them to look in different places and search for different answers to their questions or develop questions for themselves. (S. H., Interview, June 8, 2016) 
This quote illustrates how the Coordinator saw the course as fostering space for students to self-direct the development of their identity. Given the space for selfdirection, the book would then reflect what the students want to express, what the Coordinator termed "a true expression of self" rather than what a course with a fixed structure would have allowed the students to express. This is what the Coordinator from the neighboring school was looking for and that $\mathrm{S}$. $\mathrm{H}$. could not provide because they were using a $\nearrow^{\prime \prime} \Delta ל \circ$ (Nehiyaw/Cree) approach to education. More specifically, this approach entailed providing space for the students to continually and intentionally move towards a more in-depth understanding of their "Creeness" as they learned about and put into practice the customs and values that were shared by Elder D. M. and L. S. (Brundige, 2004; Weber-Pillwax, 2001). The students' continual and intentional movement towards a more nuanced understanding of their "Creeness" was illustrated throughout this chapter and in particular in the sections outlining the second and third phase of the practice of

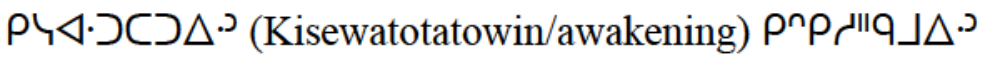

(Kiskisohkemowin/reminding). Reflecting upon the book itself and its content K. L. stated that:

I like it [the book]. It gives us ... this is like a voice for us right here. It is going to go in [to different communities] . . . and just by them reading this book it is going to be, not exactly us speaking, but [by them reading] . . what we said and the pictures that we took [they will hear us]. (K. L., Interview, June 1, 2016)

K. L.'s statement illustrates how the Coordinator's flexible approach successfully facilitated a space for the students to have a voice and demonstrate who they are through the content of their book. Beyond the book itself, the Photography Class was found to have had a direct impact on the youth and their perception of themselves and, in 
particular a feeling of pride in who they are. For example, during an interview with T. L. he stated that:

A lot of the pictures that I see now are of [students] with their heads down [but in the pictures in the book] you know they are really proud of their tradition and who they are, as a person. I think that is really important ... I think, it is important because a lot of people are getting misinterpreted [information] about First Nations peoples and this is a way to show them who we are, as a whole (T. L., Interview, June 12, 2016).

This quote describes T. L.'s observation of how the photos in the book were significant because they captured the students' expression of pride in who they are. T. L. also made a link between the content of the book and the importance of using this book as a tool for correcting dominant society's misconceptions about the youth and who they are as First Nations youth. In addition, this quote provides further evidence of how the Coordinator's flexible approach successfully fostered space for students to compose a narrative that facilitated self-expressions grounded in $\mathrm{Z}^{\prime \prime} \Delta \mathrm{\zeta}$ (Nehiyaw/Cree) pride. Next, I discuss how the Photography Class impacted students' wellbeing.

Well-being. This study found that the Photography Class had effects beyond identity development and self-expression through its positive impact on the students' overall sense of well-being. For the purpose of this study, well-being refers to the students experiencing happiness, pride, and love and kindness. Unpacking what the Photography Class meant and how it positively impacted the students sense of well-being can be demonstrated by what D. C. shared during his speech as one of the two masters of ceremony at the book launch when he noted:

This book helped us out with a lot of problems and kept our minds busy and helped us recognize who we are. This book made us feel happy because we had something to look forward to. Just looking forward to something might not make a lot of sense but to me it makes a lot of sense because this book helped me move forward in life. Instead of feeling alone it helped me express myself in a lot of 
ways, not just one. Thanks for being here to celebrate this book with us. (D. C., Interview, June 02, 2016)

In this quote D. C. makes a link between how the Photography Class, by fostering space to express themselves, gave the students something to look forward to and to feel happy about. More important, this environment helped them to "recognize who we are" and "move forward in life". The following excerpt from D. C.'s interview builds upon and provides further insight into how the Photography Class helped students to "move forward in life," in his statement that:

[the Photography Class] helped out a lot of us through depression and stuff like that, because it helped us express ourselves in ways that we could not on our own, instead of just feeling like that [depressed] all the time. It was a pretty good experience and everything like that, I liked this [class]. And it kept stuff off our minds instead of just feeling kind of depressed and stuff like that ... Yeah, makes me feel like I have something to look forward to instead of not looking forward to anything at all, at least I have something out there instead of not having nothing, feel complete because we actually completed something, and this is my second year, so it is pretty good. (D. C., Interview, May 25, 2016)

As illustrated in the above quote, the Photography Class had a positive impact on the students' overall well-being by providing a dedicated space where they could express themselves "in ways that we could not on our own". In turn, this dedicated space gave students something to look forward to through the opportunity to complete a project, their book. Taken together these characteristics of the Photography Class helped students through their feelings of depression and fostered feelings of happiness. While reflecting upon D. C.'s speech and the Photography Class, the Coordinator shared the following during:

you know when I listened to [D. C.'s] speech, and that being a participant in making this book was a way for him to express himself and feel connected, not alone. What stands out now is over the years, and I am slowly coming to understand that this group that comes together to make this book is a powerful support system, that somehow they join together, and many of the other kids 
talked in their speeches about working together on this. That it was not an individual experience, it was a collective experience. So that stands out. (S. H., Interview, June 8, 2016)

This quote provides further insight into how the Photography Class provided students with a support system by bringing students together to collectively work on authoring and publishing a book. In turn, this collective experience helped students to feel connected and this unity promoted a sense of well-being. In the following section, I discuss how the students and their book were understood as agents of social change.

Agents of social change. Thus far, the impacts that have been discussed have focused on how the Photography Class impacted the students. It is also important to discuss what the study identified about the potential impacts beyond the students themselves. For the purpose of this study, the term agents of social change refers to the students' book positively influencing perception about who they are. For example, during my interview with the Coordinator, she explained that:

I think these young people are agents of social change with this book and in that way we have to understand the project in a very broad way. That books goes out into the public, yes it is kept in [the students'] home and close to the heart, thankfully, that is a priority. But it also finds its way out into libraries across the country, into families' homes, into schools. So in some ways the students and their book are doing a public service. We need to support that. They are providing something very valuable and it has the ability to influence perception. Not saying we can guarantee how it is received, that is outside of our control. But, I think that the book has the ability to influence perception in a good way. Not that life is so simple as good and bad but I think it can stretch our understanding. This book and all of the books that the students have made over the years are a counter to that negative stereotype that exists and are predominant. And I have always believed discrimination exists on a continuum. You have people who simply do not have any way to fully understand that narrative because they have never had any, how do you say it, it is all they know. Now that is not to take people off the hook. At some point we are all responsible for our thinking. At the same time I think that is a person who if you provided some insight, a different way of understanding, they would not resist that. Then there are organized hate groups. I mean you could put that book on their table, they would burn it. You are not going to change their minds, that would require a sort of 
spiritual transformation. But most people are somewhere in between. And we have all relied on stereotypes to operate. There is a lot of research on stereotypes and why they exist. They are a quick way to relate and to understand each other. The problem is that more often than not stereotypes are harmful and actually do not help us relate to each other. Instead they keep us from being able to relate to each other. (S. H., Interview, June 08, 2016)

As explained the above excerpt, S. H. perceived this book as a tool that could help people relate to the students. More specifically and as previously discussed, the students wanted their book to influence and expand dominant society's perception of them by offering an alternate way of knowing them and to counter the dominant narrative that predominantly labels them using negative stereotypes. The students, school personnel, and members of the community also hoped that, by providing an alternate way of knowing the students, the book would help:

[society in general] have a better understanding of the kids involved with the book and community as well. They are all great kids, they are loving kids and they are caring kids. Some of their backgrounds are a little, they have had some pretty big hardships in their life. So for me being here every day with the kids is just trying to love them every day and for the outside communities to be thoughtful and just being kinder to the kids when they are off community. (T. L., Interview, June 12, 2016)

It was beyond the scope of this research study to examine if and to what extent this book or previous books had influenced broader society's perception of the students.

Irrespective of this limitation, below I discuss how the students' and their book were perceived as an agent of social change for themselves and their community by reclaiming education as a space where they can reconnect with and develop their $\mathrm{C} \Delta$ ל० (Nehiyaw/Cree) identity.

As previously discussed during the March 24, 2016 Photography Class, students used markers to write words on their arm or hand as one way to express who they are. After writing these words on their arm or hand, each of the students went outside and 
took photos of themselves standing in-front of the exterior of their school which happened to be brick (Field note, March 24, 2016). During the book launch, the photos of the students and their arms or hands with words written on them were displayed around the room. Figure 2 and Figure 3 provide a sample of the photos that were on display. Figure 2 provides a picture of a section of the brick wall of the Lebret Residential School, that was part of the Lebret Residential Petroglyphs exhibit, and captures where Residential School students had etched their names into the brick as a way to document that they had existed. For example, I have highlighted one of the etchings by inserting a box around the name Richard in the bottom right corner of the image. In contrast, below in Figure 3 is of a sampling of the photos of the students' arms or hands as they stood in front of their brick school as a way to name themselves and document who they are.

Figure 2: Lebret Residential Petroglyphs Exhibit

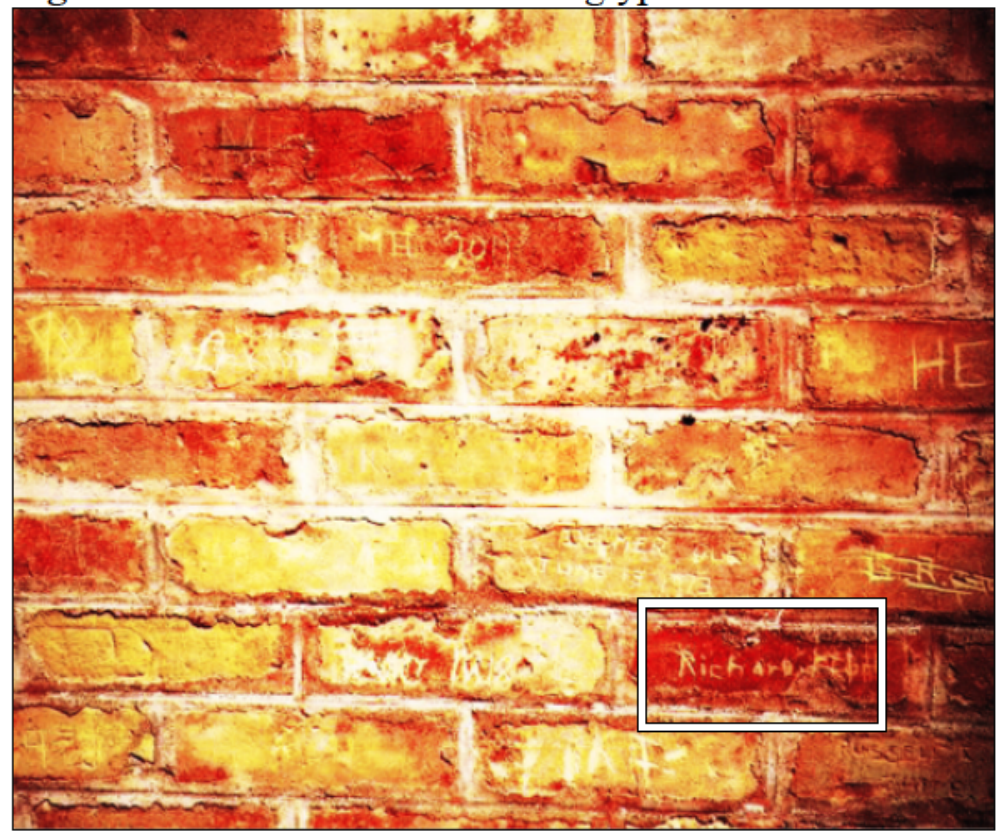




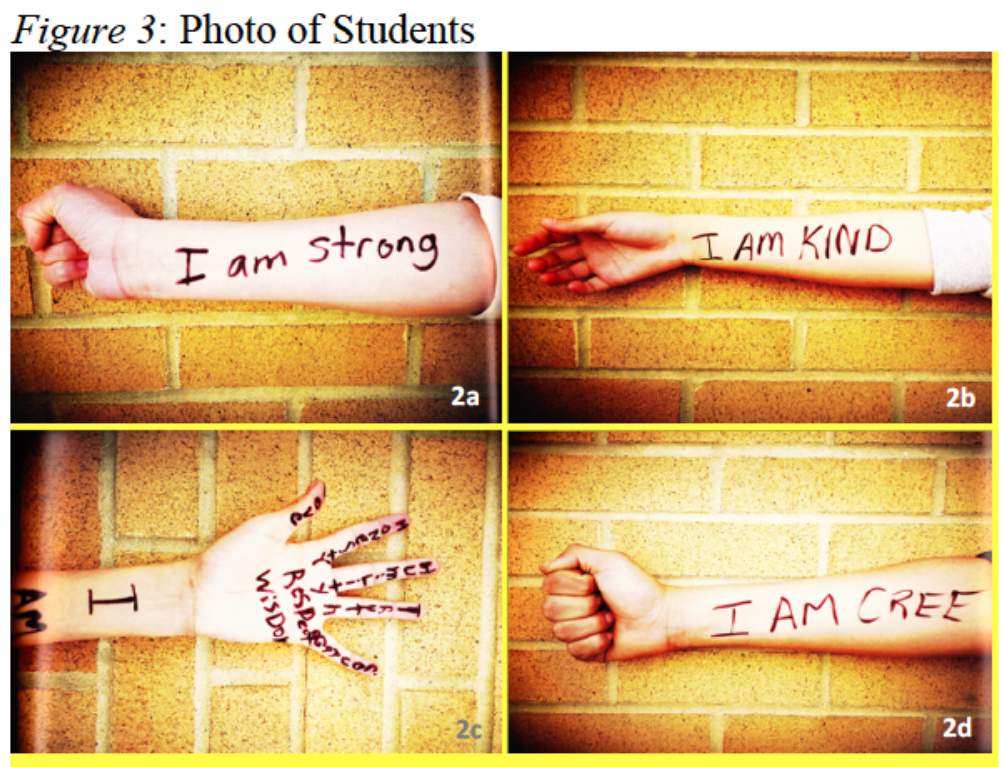

The photos on display had a significant impact on the book launch attendees.

This impact is best captured in the following quote where T. L. describes his experience as he walked into the photo exhibit and saw the students' photos:

As soon as I walked into the gallery, the pictures popped out right away. The pictures with their arms against the bricks . . . My mom grew up in Residential School and ... when you see the bricks like that it kind of brings you back to when your parents were in Residential Schools ... Then you start to kind of think about how your parents grew up. And at the same time the kids are kind of remembering that their parents were in Residential School. But at the same time they are putting messages [about who they are] on their arms . . . so that was powerful. (T. L., Interview, June 12, 2016)

As illustrated in the above quote and as discussed throughout this thesis, the Residential Schools were identified as the main tool that was used to introduce racism and a practice of hate to the students' community. In this way, the photos that were placed on display at the book launch represented a particular point of tension between the community's past and the students' present. Below is an excerpt from an interview with D. C., where he explained this tension:

Interviewer: So when you look at this picture [of Fort Qu'Appelle Indian Residential School] and what it represents with the kids having etched their names 
onto the school as proof that they existed. And then you standing in front of your school and taking photos. What does this mean to you?

Interviewee: It means a lot because in that time my Kokum[/grandma], she went to Residential School, and she said pretty bad over there and they treated pretty badly. Just wanted that to change and it felt pretty good to actually open up about stuff like that, people are actually recognizing that what happened to our people, while everybody just lived all right while our people lived in these schools. They had to go through hard things and harsh things, just messes up their culture mostly because they made us lose most of our culture, but they couldn't kill the culture because our culture lasts forever. (D. C., Interview, May 25, 2016)

As D. C. noted, the bricks in the photos represented the past (Residential Schools) as well as the youth honouring what their family and community has and continues to endure due to an educational system that attempted to assimilate them to "white man ways" to "kill the Indian in the child". In contrast, I argue that the words that were written on the students' arms or hands represented the students reclaiming and taking back the very apparatus that was used to harm their families and communities, the education system. For example, the photos illustrated the students reclaiming their school, as a space where they can learn about, express, and celebrate who they are as part

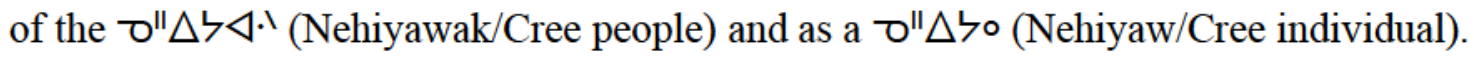
This reclaiming of their school as a space where they can connect with, and learn about, who they transforms the physical and symbolic site of assimilation and denigration (i.e., a school building) through a process of empowerment whereby the students take back their culture, their pride and their sense of self as Indigenous. It is this visual representation of 'taking back' that T. L. found so powerful about these photos.

Beyond the students and their community, the students' book was also understood as having implications for future generations. In an interview with Elder E. B., he stated that the students' book is an archive for the community and future generations designed 
to remind them of their $\mathrm{C}^{\|} \Delta$ ל० (Nehiyaw/Cree) teachings and practices (Field note, June 1, 2016). He explained that the book is not a substitute for the teachings such as the ones provided to the students during phase one and two. However, the book contains visual and textual reminders of the $\nearrow^{\prime \prime} \Delta ל \circ$ (Nehiyaw/Cree) teachings and practices that when viewed by future generations will remind and awaken in them their \" $\Delta$ ל० (Nehiyaw/Cree) identity. Once reminded, they can then go seek-out and learn from Elders. This finding demonstrates how, in making their book, students were not just learning about who they are for themselves but were also documenting ד $\triangle$ ל० (Nehiyaw/Cree) practices and teachings for future generations to learn and understand (Memo, December 17, 2016). As C. C. shared during her interview:

Twenty years from now, when I am looking at the book ... I can see my grandchildren looking at it, because I have all the books over the years that they did the books, and I can proudly show them to my grandkids and tell them this is what we did. (C. C., Interview, May 25, 2016)

In consequence, the students' book not only affected the students and their community, it will also serve their community into the foreseeable future as an archive that will connect past and future generations.

To summarize, in this section I unpacked the three impacts that the process of

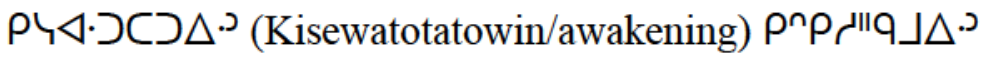

(Kiskisohkemowin/reminding) had on students. These impacts ranged from an intrapersonal level as exemplified by the effect of self-expression and sense of well-being to an interpersonal level as evidence by the effects of agents of social change. Arguably, the most significant effect is how the students, as agents of social change, reclaimed their school and hence the education system, in the context of the Photography Class, as a 
place to reconnect with and develop their identity as part of the $\mathrm{O}^{\prime \prime} \Delta ৬ \triangleleft \triangleleft$.

(Nehiyawak/Cree people) and as a $\bigsqcup^{\prime \prime} \Delta ל \circ$ (Nehiyaw/Cree individual). Having discussed the documented impacts of the Photography Class, the following section describes how I use Smith's $(1999,2012)$ theoretical lens of decolonization to take a step back and ask what this study's findings mean within the landscape of Canada's colonial legacy.

\section{Decolonization}

It is critical to situate and discuss this study's main finding within the larger context that the Photography Class was taking place within, Canada's colonial legacy. In this section I use Smith's theoretical lens of decolonization to examine the practice of

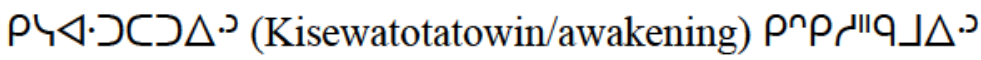

(Kiskisohkemowin/reminding). I utilize Smith's $(1999,2012)$ lens of decolonization because it provides one way to produce decolonizing knowledges.

As previously discussed, Smith (2012) argues that a decolonization of knowledge is accomplished through the application of two intersecting lines of inquiry that ask: (1) what do the findings illustrate about Indigenous authenticity prior to colonial contact and (2) how has colonialism impacted this aspect of Indigenous authenticity and how does this inform the research participant's immediate past, present, and future. In this section, I demonstrate how the application of Smith's lens of decolonization resonates with the

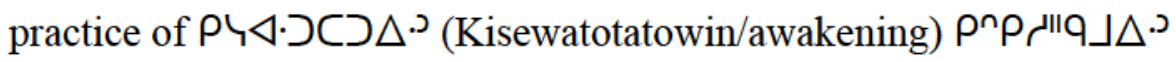
(Kiskisohkemowin/reminding) and illustrates a specific process of decolonization. Below I will illustrate how the practice documented in this study illustrates a process of decolonization that represents one way of mediating the colonial legacy of racism by 
renewing the community's practice of $\left\langle\rho^{\|} \Delta \supset \Delta^{\supset}\right.$ (Sakihitowin/love and kindness) and reclaiming education as space and place where students could authentically develop their ত" $\triangle$ ל० (Nehiyaw/Cree) identity.

Indigenous authenticity. Smith's (2012) first line of inquiry directs the researcher to ask what the research findings reveal about Indigenous authenticity prior to colonial contact. In assessing a decolonizing education program, I am asking did the program address the issue of authenticity. Guided by this question, I note that the and the findings from the first phase, $\triangleleft \Delta \cdot \mathrm{Q} P$ ל (Awina Niya/who I am, of the Photography Class clearly addressed this issue. The Elders spoke to the students about what their communities were like, prior to colonial contact which spoke to Indigenous authenticity. The content was culturally/locally specified and included a focus on the practice of $\left\llcorner{ }^{\prime \prime} \Delta \supset \Delta^{\supset}\right.$ (Sakihitowin/love and kindness). The Elders taught that, since time immemorial, the practice of $\left\langle\rho^{\|} \Delta \supset \Delta \cdot \supset\right.$ (Sakihitowin/love and kindness) was passed from one generation to the next through the renewal ceremony of storytelling. They also taught the students that prior to the Residential Schools the students' community experienced conflicts; however, these conflicts were different from contemporary conflicts because they were not grounded in racist ideology and because racism was not part of their language, customary law, teachings, or practices that informed their community's epistemology, values, and norms.

Impact in immediate past, present and future. Smith's (2012) second line of inquiry says that a decolonizing methodology should ask how colonialism has impacted Indigenous authenticity and, in turn, the research participants' immediate past, present, 
and future. Does the Photography Class examine this? The findings from the first phase $[\triangleleft \Delta \cdot \mathrm{Q} P$ ל (Awina Niya/who I am)] addressed how colonialism, through the Residential Schools, interrupted the community's Indigenous authenticity and harmed many of the people. They then linked these past practices to the current situations experienced by the students.

With respect to the interruption of Indigenous authenticity, the $\mathrm{C}^{\prime \prime} \Delta$ ל० (Nehiyaw/Cree) principles of teaching where severed when children were placed in Residential Schools and separated from their Elders and their knowledge holders. As a result, the children's access to the Elders teachings and the opportunity to put these teachings into practice and develop their identity as a that is part of the $\oslash^{\prime \prime} \Delta ל \triangleleft \cdot `$ (Nehiyawak/ Cree people) were disrupted. Further, the Residential Schools replaced the community's practice of $\left\langle\rho " \Delta \supset \Delta^{\prime} \cdot\right.$ (Sakihitowin/love and kindness) with a practice of hate that was based upon a racist ideology. This led to a number of harms such as drug and alcohol abuse. It also led to people being 'named' by others and negatively and oppressively labelled.

For the purpose of this study, this interruption meant that colonialism had significantly limited the students' access to $\mathrm{Z}^{\prime \prime} \Delta$ ל० (Nehiyaw/Cree) teachings and practices and in particular the practice of $\nmid \rho^{\prime \prime} \Delta \supset \Delta^{\cdot} \cdot$ (Sakihitowin/love and kindness). Further, if not redressed before the community's current Elders pass away, this situation would be exasperated because Elders would take their knowledge with them when they leave this world. If this occurs, it would significantly limit the students' and future generations ability to access and learn about their community's $\mathbf{O}^{\prime \prime} \Delta$ ל० (Nehiyaw/Cree) 
teachings and practices such as the teachings of $\left\langle\rho " \Delta \supset \Delta^{\cdot} \cdot\right.$ (Sakihitowin/love and kindness) and their ability to develop this aspect of their \" $\Delta$ ל० (Nehiyaw/Cree) identity.

A local process of decolonization. The application of Smith's theoretical lens of decolonization illustrates how the process of $P \backslash \triangleleft \cdot כ C \triangle^{\top} \Delta^{J}$

(Kisewatotatowin/awakening) $\left.\rho^{n} \rho \Gamma^{\text {III }}\right\lrcorner \Delta^{\cdot} \cdot$ (Kiskisohkemowin/reminding) responded to colonial impact on the students' immediate past by taking steps to mitigate the potential for present and future impacts on this aspect of the students' Indigenous authenticity, $\left\llcorner\rho " \Delta \supset \Delta^{\supset}\right.$ (Sakihitowin/love and kindness). For example, the first $[\triangleleft \Delta \cdot \mathrm{Q} \rho$ ל (Awina Niya/who I am)], and second [( (") $\Delta \triangleleft \triangleleft \cdot `$ (Nehiyawak/who I am as part of the Cree people)] phases sequentially laid a foundation of knowledge about the past and present and interwove what had been fragmented by the Residential Schools. Then phases three

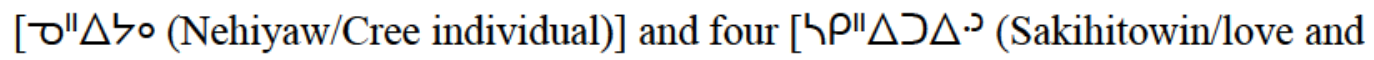
kindness)] fostered opportunities for the students to put the teaching of $\nmid \rho " \Delta \supset \Delta^{\prime} \mathrm{J}$ (Sakihitowin/love and kindness) into practice with the assistance of a practice of Courage. This resulted in the students authoring a book that provided a more complete and positive narrative about their Indigenous authenticity and represents the students literally "writ[ing] back ... from the margins" (Smith, 2012, p. 63) to "decolonize our minds, to recover ourselves, to claim a space in which to develop a sense of authentic humanity" (Smith, 2012, p. 63). In this manner, the first, second, and third phase 
represent a process of decolonization and self-determination that was based upon $\nearrow^{\prime \prime} \Delta$ ל० (Nehiyaw/Cree) theories of knowledge and identity development.

The fourth phase [ $һ P \| \Delta \supset \Delta^{\cdot}$ (Sakihitowin/love and kindness)] represented a renewal of the practice of $\left\langle\rho " \Delta \supset \Delta^{\cdot}\right.$ (Sakihitowin/love and kindness) that was, again, supported by a practice of Courage. This entailed the students standing-up in a public setting and sharing their more complete and positive narrative about who they are as a ૪" $\Delta$ ל० (Nehiyaw/Cree individual) that is part of the ૪" $\Delta ৬ \triangleleft \cdot `$ (Nehiyawak/ Cree people). This aspect of the renewal process reflects an interweaving of an interpersonal and societal level of decolonization. For example, as the students shared their narrative in a public setting that narrative was entered into circulation in the public realm and fostered conceptual space for audience members to begin decolonizing how they perceived and understood the students. In this way, the fourth phase represents a process of decolonization that had primarily operated at an interpersonal level during phase one, two and three but then broadened its sphere of influence to encapsulate both an interpersonal and societal level. Specifically, the process of self-determination experienced by the students as they shared their more complete and positive narrative about who they are with the public raised social consciousness about how colonialism had impacted them, their families and their community. Again, to what extent this narrative affected the public was beyond the scope of this study. However, the students' public narrative is significant because that narrative demonstrates how "give[ing] testimony to and restore[ing] a spirit, to bring back into existence a world fragmented and dying [the practice of $\left\langle P^{\prime \prime} \Delta \Delta^{\circ}\right.$ ' (Sakihitowin/love and kindness)]" (Smith, 1999, p. 28) 
and hence engaging in a process of self-determination that was shared in and thereby made visible in the public sphere during the book launch can override, if only for an evening, racist images based on social prejudice. As such, the process of $P 4 \triangleleft \cdot \supset C \supset \Delta^{\circ}$

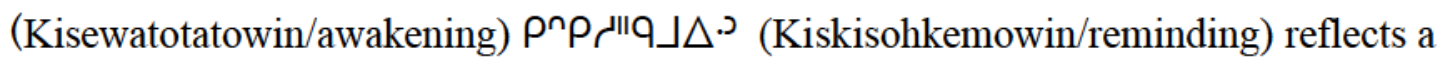
process of decolonization that illustrates one way of mediating the colonial legacy of racism by renewing the community's practice of $\left\lfloor\rho " \Delta \supset \Delta^{\cdot}\right.$ (Sakihitowin/love and kindness).

It is important to note that this process of self-determination not only impacted the students in terms of self-expression and sense of well-being (as previously discussed), but, also their educational environment. As evidenced in my analysis of the impact of agents of social change, this process of decolonization also had the effect of reclaiming power over the process of education. Within the context of the Photography Class, a space and place was created where students could authentically develop their $\mathrm{C} \Delta$ ל (Nehiyaw/Cree) identity and perceive self as a positive member of a vital and supportive ঠ" $\Delta$ ל० (Nehiyaw/Cree) community. Specifically, integration of traditional teachings by Elders highlights the power of the process of $P ৬ \triangleleft \cdot \supset C \supset \Delta^{\circ}$

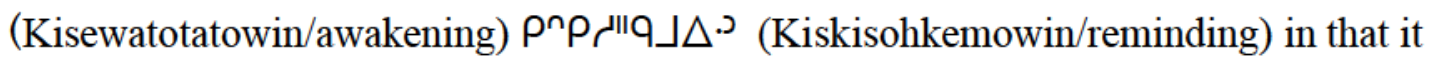
ultimately fostered an authentic space, grounded in and informed by local experience and knowledge. In-turn this authentic space fostered a environment that supported a pathway for the students' resurgence of an authentic identity (Taiaiake \& Corntassel, 2005; Simpson, 2015) that was characterized by diversity and positive self-identification that 
braided together intrapersonal and relational components of their "Creeness" (Brundige, 2004; Weber-Pillwax, 2001).

In this section I utilized Smith's $(1999,2012)$ theoretical lens of decolonization to illustrate how a process of decolonization was inherently embedded within the process of

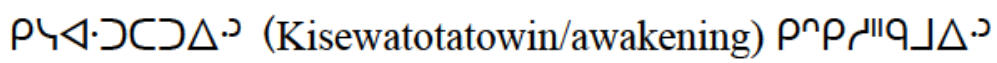

(Kiskisohkemowin/reminding) and its four phases. This process of decolonization was specific to the educational setting and was made visible through the impacts that were discussed earlier; self-expression, sense of well-being, and agents of social change. Collectively these impacts illustrate how the process of $P \zeta \triangleleft \cdot כ C \supset \Delta^{\cdot}$

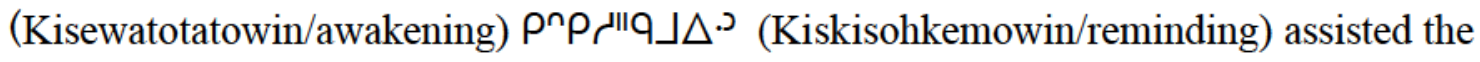
students by reclaiming education as a place and space to develop their $\mathrm{\nearrow} \Delta$ ל० (Nehiyaw/Cree) identity and iteratively moving towards an authentic identity. As a result, I argue that the process of $P \hookrightarrow \triangleleft \cdot \supset C \supset \Delta^{\supset}$ (Kisewatotatowin/awakening)

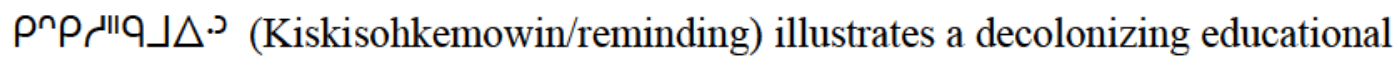
practice that specifically represents one way of redressing the colonial legacy of racism by weaving back together and reclaiming what had been fragmented, the community's practice of $\nmid \rho " \Delta \supset \Delta^{\cdot}$ (Sakihitowin/love and kindness), by the colonial practice of racism. In short, the process of $\rho 4 \triangleleft \cdot כ C \Delta^{\circ} \cdot$ (Kisewatotatowin/awakening)

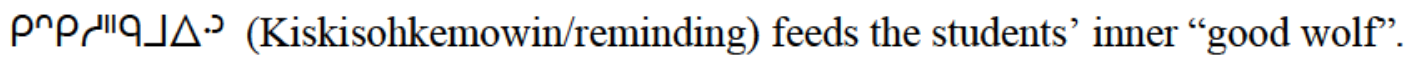
This chapter and the findings presented throughout it, like a process of decolonization, was not about arriving at a specific answer or destination. Rather it was about presenting the data in such a fashion that the process that underpinned the 
Photography Class was visible and legible and that the students' lived experience was articulated to the extent possible. Like the process documented in the research study, I began this chapter with the words of an Elder's teaching, the Cherokee Legend, and also like the process I end this chapter with the words of a student. The quote presented below, summarizes what one of students learned in the form of advice that he had for other First Nation youth who are struggling with the impacts of racism:

My advice to youth is this, you are valuable, don't let anyone make you believe differently. Just stay in school and do something good with your life. That's what I am trying to do. Don't let people call you down and make you feel bad about who you are. Find people to look up to. I have family to look up to but I didn't have a Dad to look up to. Be good to people, just treat them the way you want to be treated. If people are going to be racist or hateful just walk away and don't let them change how you feel about yourself . . . Always tell your family you love them. Just know there are people that love you. Always try and do our best and it will pay off. Just find and stay on the right path. Be proud of who you are and where you come from. When I was little I didn't think of my Culture, now I know it is important to listen to the Elders stories and teachings. I want to pick the right road in life. (J. C., Book, 2016, p. 62)

In this chapter, I took a descriptive narrative approach to identify and discuss how the students made their book to see and be seen and how the process of utilized storytelling and the four principles of $\mathrm{C}^{\|} \Delta$ ○० (Nehiyaw/Cree) teaching helped them articulate who they are as a $\mathrm{Z}^{\prime \prime} \Delta$ ל० (Nehiyaw/Cree individual) that is part of the ర" $\Delta ל \triangleleft \cdot `$ (Nehiyawak/ Cree people). I unpacked the four phases that were found to

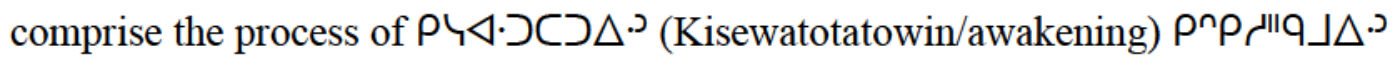
(Kiskisohkemowin/reminding) and the effects that this process had on the students. Delving deep into the findings and what they mean in the context of Canada colonial legacy I drew upon Smith's $(1999,2012)$ theoretical lens of decolonization to analyze how the Photography Class and creation of a book represent a locally informed process 
of educational decolonization and hence a process of self-determination. In the next chapter I review this study's key findings and their unique contributions to the study of prejudice, the limitations of shoes findings, and their implications for further research. 


\section{Chapter 5 - Conclusion}

Reflecting upon this research study's findings and the current state of the body of knowledge that currently informs the study of prejudice, this chapter reviews the main findings of my study and its unique contributions to this field. Further, I discuss in the chapter what the findings illustrate about racism as it is mediated by a ד $\triangle$ " $\Delta \circ$ (Nehiyaw/Cree) worldview and lived experience and how this process is similar to, and move beyond, Western theories of knowledge on the mediation of racial prejudice. I conclude by discussing my study limitations and implications for future research, especially for First Nations communities that have had similar experiences with Residential School, and for Canada as it looks to reconcile its colonial legacy.

\section{Summary of Findings}

From inception to dissemination this research study was designed to unfold in an iterative and multi-pronged manner and strategically interwove specific methods (participant observation and interviewing), methodologies (Indigenous, GTM, and reflexivity), analysis (GTM and narrative), and a theoretical framework (decolonization) to centre the research participants' lived experiences and ๑" $\Delta$ ४० (Nehiyaw/Cree) theories of knowledge. The study's main finding lies in its description and documentation of the process of $P \hookrightarrow \triangleleft \cdot כ C \Delta^{\cdot}$ (Kisewatotatowin/awakening) $\left.\rho^{n} \rho \Gamma^{\text {III }}\right\lrcorner \Delta^{\partial}$ (Kiskisohkemowin/reminding) and its analysis of a meditation process that is grounded in and informed by $\mathrm{C}^{\|} \Delta$ ל० (Nehiyaw/Cree) theories of knowledge and lived experience. 


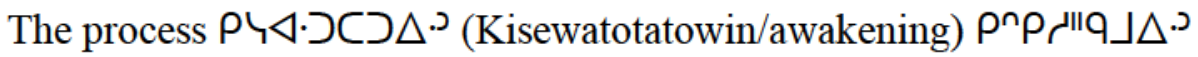

(Kiskisohkemowin/reminding) was identified as being comprised of four phases:

(1) $\triangleleft \Delta \cdot \mathrm{Q} P$ S (Awina Niya/who I am);

(2) $\nearrow^{\prime \prime} \Delta ৬ \triangleleft \cdot$ (Nehiyawak/Cree people);

(3) $\nearrow^{\prime \prime} \triangle$ ४० (Nehiyaw/Cree individual); and

(4) $\nmid \rho " \Delta \supset \Delta^{\cdot}$ (Sakihitowin/love and kindness).

Collectively these steps were found to be $P \hookrightarrow \triangleleft \cdot \supset C \supset \Delta^{\supset}$ (Kisewatotatowin/awakening) $\left.\rho^{n} \rho \Gamma^{\text {III }}\right\lrcorner \Delta^{\nu}$ (Kiskisohkemowin/reminding) the students of a specific aspect of identity,

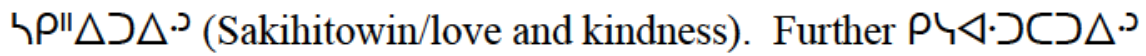
(Kisewatotatowin/awakening) $\rho^{n} \rho \overbrace{}^{\| l} \mathrm{q}\lrcorner \Delta^{\nu}$ (Kiskisohkemowin/reminding) was a response to the colonial disruption of the community's teaching and practice of $\left\llcorner\rho " \Delta \supset \Delta^{\cdot}\right.$ (Sakihitowin/love and kindness). This process illustrates one way to mitigate the colonial legacy of Residential Schools and its racist practices by interrupting the colonial praxis of hate through a reclaiming of $\left\lfloor\rho " \Delta \supset \Delta^{\cdot}\right.$ (Sakihitowin/love and kindness).

Moving beyond the constraints of Western-based theories of racism and its mediation, this process expands the theoretical and conceptual study of racial prejudice in two significant ways. First, as previously discussed in the thesis, the study of prejudice has been dominated by Western theories of knowledge and lived experience; an approach that excludes the identification and examination of mitigation strategies for minority groups that are targets of, and impacted by, racial prejudice. Taking a different tactic, this study examined a particular target group's approach to addressing racism, ত (Nehiyawak/Cree people) with a particular focus on youth. It documented the process 
used by $\nearrow^{\prime \prime} \Delta ৬ \triangleleft \cdot$ (Nehiyawak/Cree people to mitigate the impact of racial prejudice on

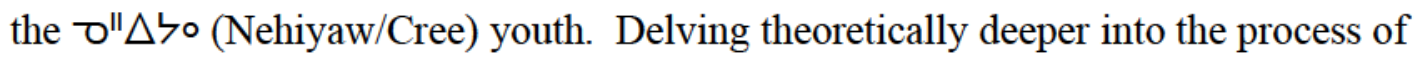

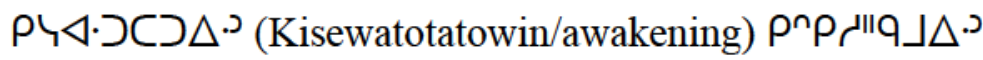

(Kiskisohkemowin/reminding), I applied Smith's $(1999,2012)$ theoretical lens of decolonization and examined how this process created a method of decolonization where the students came to understand and embrace $\mathrm{O}^{\prime \prime} \Delta$ ל० (Nehiyaw/Cree) knowledge and practices passed to them during the Photography class to "writ[e] back ... from the margins" (2012, p. 63) to "decolonize our minds, to recover ourselves, to claim a space in which to develop a sense of authentic humanity" (2012, p. 63). Specifically, the data in my study illustrate one way to mediate the colonial legacy of racism by renewing the community's practice of $น P \| \Delta \supset \Delta^{\supset}$ (Sakihitowin/love and kindness) and reclaiming education as space and place where students can authentically develop their (Nehiyaw/Cree) identity.

This process of decolonization had three major and positive impacts on participating students' (1) self-expression, (2) well-being, and (3) sense of self as agents of social change. Of particular importance, is how the students, in their role as agents of social change, reclaimed their school as a space where they could connect with Elders to learn about and develop their $\mathrm{C}^{\|} \Delta$ ל० (Nehiyaw/Cree) identity. By fostering an environment for them to become more active in their education, the Photography class provided the students with a space where they could learn about, and renew what was disrupted by the Residential Schools, the $\nmid \rho \| \Delta \Delta^{\prime} \cdot$ (Sakihitowin/love and kindness) aspect of their $\mathrm{C}^{\|} \Delta$ ל (Nehiyaw/Cree) identity. These findings illustrate that, not only 
did this process of decolonization foster space for the students to develop a more complete and positive narrative about who they are, it also positively impacted their sense of self. Specifically, the findings presented in this study highlight the effectiveness and, hence, the importance of utilizing Indigenous theories of knowledge and process to mitigate the impact of racism on Indigenous youth.

This study also found that racism as a concept and practice was not, and is not currently a part, of the $\mathrm{C}^{\prime \prime} \Delta \mathrm{\zeta}$ (Nehiyaw/Cree) language, customary law, scared teachings, or worldview. Racism had been introduced to this community through colonization and the Residential Schools. The schools mobilized racist ideology and practices that were experienced by First Nation children as a praxis of hate. A critical component of this praxis of hate was its implementation through the intentional and systemic separation of children from their family and community through Residential Schools. The assimilation process in the Residential Schools sought to "kill the Indian in

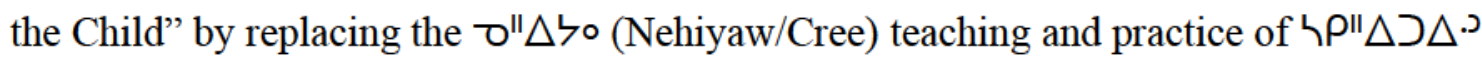
(Sakihitowin/love and kindness) with a praxis of hate that disrupted the renewal ceremony of storytelling that passed $\nearrow^{\prime \prime} \Delta ל \circ$ (Nehiyaw/Cree) teachings and practices such as $\nmid P \| \Delta \supset \Delta^{\supset}$ (Sakihitowin/love and kindness) from one generation to the next. In consequence, contemporary children and students, to differing degrees, are still

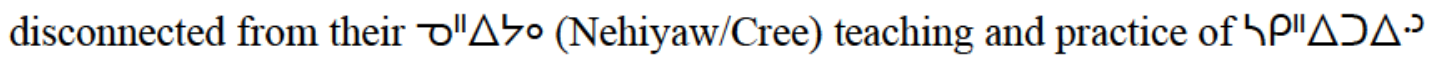
(Sakihitowin/love and kindness) and the processes they offer in forming a strong ד (Nehiyaw/Cree) identity. 
The colonial praxis as mobilized through the Residential Schools was a

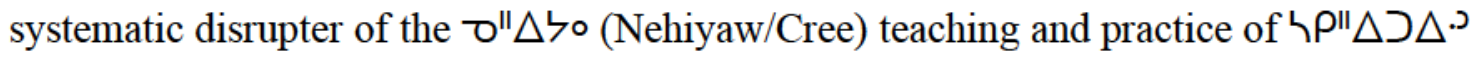
(Sakihitowin/love and kindness) and introduction of a praxis of hate is what this study identified as racism. This understanding of racism makes a significant contribution to the study of prejudice through its understanding racism that is based on what was and continues to be the experiences of and the understandings/definitions of a specific target group, ד $\Delta$ \০ (Nehiyaw/Cree) youth. Further, this understanding of racism does not accept racism as an inevitable aspect of the human condition. Rather the O" $\Delta$ ל० (Nehiyaw/Cree) understanding is that racism is part of a learning process that was and continues to be influenced by the stories that are told/circulated and that in-turn foster epistemological conditions that can support (depending on the stories that are told/narrative resources that are made accessible) a praxis of hate or a praxis of $\left\lfloor P \| \Delta \supset \Delta^{\cdot} \cdot\right.$ (Sakihitowin/love and kindness). The renewal of the community's practice of

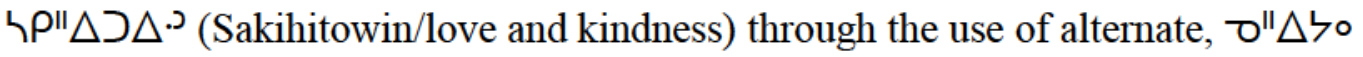
(Nehiyaw/Cree)/self-created narratives constituted the mitigation of racism which was facilitated through the process of $P \hookrightarrow \triangleleft \cdot \supset C \supset \Delta^{\cdot}$ (Kisewatotatowin/awakening) $\left.\rho^{n} \rho{ }^{\| l} \mathrm{q}\right\lrcorner \Delta^{\partial}$ (Kiskisohkemowin/reminding). Taken together, these findings underscore the importance of examining the lived experience of target groups with racism to identify methods of redress thereby moving the study of prejudice beyond Western theories of knowledge and lived experience that conceptually limits our re-imagining of ways to mitigate racism and its impact on a target groups. Next I discuss how these findings align with and move beyond Western theories of knowledge on racism and its mediation. 
As previously discussed, Allport (1954) drew upon Western theories of knowledge and argued that prejudice is acquired at an early age through observation and as such is not inevitable; but, once it developed it becomes inflexible. Further, he hypothesized that in-group members simultaneously hold positive and negative prejudice towards out-groups. Which prejudice (negative or positive) is expressed or acted upon depends on the social context surrounding an individual including social norms and social demands. There are some similarities and some differences in the understanding based on the Indigenous knowledges found in this study. For example, the underlying moral of the Cherokee Legend (see Chapter 4) that was grounded in Indigenous theories of knowledge holds that everyone has an inner "good wolf"/positive prejudice and an inner "evil wolf"/negative prejudice. But, the process of change depends on the choices, the on-going choices, that an individual makes when they metaphorically feed their inner "evil wolf" or feed their inner "good wolf". This process takes place within a social context. This study found that prior to colonial contact, racism had been prevented through the community's $\mathrm{O}^{\prime \prime} \Delta \mathrm{S}$ (Nehiyaw/Cree) language, customary laws, and scared teachings in ways that fostered an environment where the social norms and demands fed members' inner "good" wolf. Thereby preventing the formation of negative prejudice.

The dominant Western line of inquiry into prejudice and racism [that built upon Allport's Intergroup Contact theory (1954)] focuses on intervening with negative prejudice by targeting majority groups predominantly using methods that aim to enhance in-group members' knowledge about the other, reduce in-group members' anxiety, and increase in-group members' empathy/perspective taking and giving (Aboud et al., 2012; Bigler, 2012; Bruneau \& Saxe, 2012; Kteily et al., 2013; Turner \& Crisp, 2010; Turner et 
al., 2008; West \& Dovidio, 2013). This study has demonstrated the importance of mitigation strategies created by and for the groups that are impacted by racial prejudice. It focused on a particular target group's experience with racism, a ד" $\Delta$ ל० (Nehiyaw/Cree) community, and documented a process that mitigated the impact of racial prejudice on a cohort of $\mathrm{C}^{\prime \prime} \Delta \mathrm{\zeta O}$ (Nehiyaw/Cree) youth. This is how this study's findings compliment and move beyond the current body of knowledge by filling in the gap by documenting a process that was designed to renew the \" $\Delta$ ל० (Nehiyaw/Cree) practice of $\backslash \rho " \Delta \supset \Delta^{\cdot}$ (Sakihitowin/love and kindness). What is important to note is that this method of mitigation represents an intervention strategy that fostered an environment where the social norms and demands were guided by $\nmid \rho " \Delta \supset \Delta^{\prime} \cdot$ (Sakihitowin/love and kindness). In contrast to the strategies emerging from Allport's Intergroup Contact theory (1954), this approach reduced the impact of racism by fostering a practice of $\left\llcorner\rho " \Delta \supset \Delta^{\cdot}\right.$ (Sakihitowin/love and kindness) to renew the social norms and values that feed the students' inner "good wolf".

It is also important to note that from an Indigenous perspective the individual and the wider social group/context both matter. ర" $\Delta$ ל० (Nehiyaw/Cree) theories of knowledge assume that all beings (human and non-human) are interdependent and no being is of more or less value than the other. This perspective is essential to understanding change as a process of redressing racism. As this research study's findings demonstrate the Photography Class provided a relevant, effective, and inclusive process of mediation for Indigenous peoples where youth were provided space to explore their own identities within a context of the $\mathrm{O}^{\prime \prime} \Delta ל \triangleleft \cdot `$ (Nehiyawak/Cree people) and sacred 
teachings. They were encouraged to understand this as a journey that each person travels and where they are each at different places and moments. Due to the conceptual constraints that Western theories of knowledge impose on research conducted with First Nation communities these types of approaches have not been employed. Not only do they fail to integrate Indigenous knowledge/methods/teaching but they are typically not culturally relevant. This approach, I would argue, has wider implications. If Canada was to undertake a serious effort to foster social norms and demands the approach documented in this study could be used to foster opportunities of not just mitigating racial prejudice but the need to mitigate it in the first place. However, until this time arrives, it is critical for Indigenous students to have relevant, effective and culturally appropriate strategies to mediate the impacts of racism such as the renewal process documented in

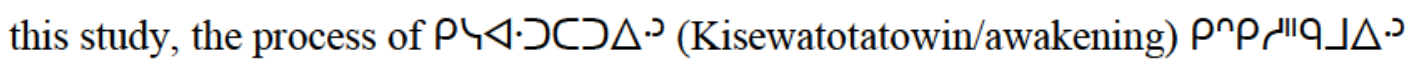
(Kiskisohkemowin/reminding).

\section{Study Limitations}

At various points throughout this thesis I have addressed different limitations related to this research study and its design. For example, I discussed methodological limitations and problematics related to participant and parent/caregiver consent, semistructured interviews, participant observation, language, power, insider outsider status, representation, units of analysis and what I did to mitigate, to the extent possible, their potential impacts on this research study. Below I expand upon two relational limitations that were of particular concern for me and what I did to, to the extent possible, to give back to research participants and their community and to address my use of English to communicate ૪" $\Delta$ ל० (Nehiyaw/Cree) concepts and theories of knowledge. 
One of the relational limitations that fostered certain tensions within this research study is the continued and justified distrust between Indigenous peoples and researchers. This distrust is due to that fact that too often researchers have conducted studies with Indigenous peoples and communities with little to no benefit and sometimes to the detriment of the Indigenous community. Using Indigenous methodologies and in particular Kirkness and Barnhardt's (1991) principle of reciprocity, I looked for, and acted upon, different ways that I could give back to the research participants and their community. For example, each time I travelled to community to attend a session of the Photography Class I brought with me a coffee or tea for each of the school Elders and the Coordinator. While I was conducting theoretical sampling, I brought lunch for the Elders and participating school personnel. Although small, these were ways that I could give back and show my appreciation for the opportunity to be part of the program and say thank you for their time and contributions to this research study. Further, when Elders were giving their respective Seven Sacred Teachings during the Photography Class, and with their prior and verbal consent, I digitally recorded their teachings. All but one of the Elders agreed to being recorded. As a way to give back to the students and with the consent of the recoded Elders I copied their teachings on to CDs (one for each student) and gave them to the Coordinator to give to the students so that each of them had a copy for themselves and their future children and grandchildren. In addition, I gave a copy to the school and Band and Council for their own archives.

As previously discussed, I held a focus group to validate this research study's findings and to ensure that the findings accurately reflected their understandings and experiences. Following this focus group, I had a local company cater a thank you lunch 
for the students, school personnel, and the school Elders. Further to acknowledging the critical role that Elders had in this research study, one of my Elders outside of the Photography Class, P. P., made Star Blankets for me to give to each of the school Elders to say thank you for their guidance and support throughout the research study. Finally, once I complete this research study I have committed to compiling a report that will summarize the findings of this research study to be included with future funding applications by the community. I acknowledge that each of these gestures are small. Nonetheless, it was my hope that collectively these actions of giving back would demonstrate a way of doing research that is more mutually meaningful and beneficial for both research participants and researchers.

Another relational limitation was related to language and the fact that I used English throughout this thesis to communicate concepts and processes that are based

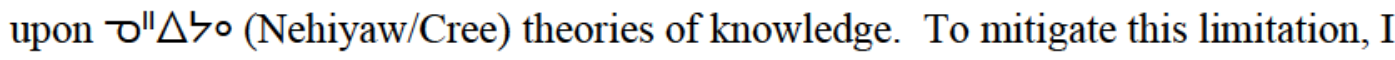
intentionally used \" $\Delta$ ל (Nehiyaw/Cree) Cree syllabics, Roman orthography when discussing key concepts to center, respect, and bridge these unique ways of understanding. However, there are certain concepts that cannot be translated or communicated in English. Further, as a monolingual English speaker, I was limited in my capacity to understand $\nearrow^{\prime \prime} \Delta ל \circ$ (Nehiyaw/Cree) theories of knowledge. I attempted to mitigate the influence of this situation and its potential impact on this study by working closely with the school Elders who are knowledge holders and fluent speakers of \" $\Delta$ ל० (Nehiyaw/Cree) and English. It cannot be over stressed how critical these relationships were to the success of this research study; without the Elders and their guidance this 
study would not have been able to document the renewal process of the ס $\Delta$ "ל०

(Nehiyaw/Cree) practice of $\left\lfloor\rho^{\prime \prime} \Delta \supset \Delta^{\supset} \cdot\right.$ (Sakihitowin/love and kindness).

\section{Where Do We Go From Here?}

The study of racial prejudice continues to be informed by Western theories of knowledge at both the theoretical and conceptual exclusion of different theories of knowledge such as Indigenous. Further, with a few exceptions (Vorauer \& Sasaki, 2009, 2012) this field predominantly focuses on majority group experiences with racism and how to reduce their racist attitudes, emotions, and behaviours. However, the social phenomenon of racial prejudice involves at least two actors (majority and minority) who respectively have a different relationship to, and experience with, racism (perpetrator and target).

As demonstrated in this study when the minority group's experience was centered and their theories of knowledge utilized, the mitigation strategy did not provide a predetermined structure and steps designed to attain a specific outcome of reduced racism. Rather, it outlined a process that was informed by a self-directed and life-long practice of $\left\langle\rho " \Delta \supset \Delta^{\supset}\right.$ (Sakihitowin/love and kindness). Building upon these findings, future research should begin to expand its theoretical and conceptual lens beyond Western theories of knowledge to include minority groups' theories of knowledge, experience with racism, and mitigation processes and strategies. Such an approach could more accurately examine and understand non-dominant groups experience with racism and therefore identify more appropriate, effective, and meaningful mitigation strategies to redress the impact of racism. 
Another line of inquiry that would be fruitful and should be taken-up in future research is a critical examination of the relationship between social factors (e.g., social norms and demands, values, and narratives) and the development of positive or negative prejudice for both dominant and non-dominant group members. This area of study should work to identify and develop strategies to foster social environments that prevent the development of racial prejudice in the first place. The process of $P 4 \triangleleft \cdot \supset C \supset \Delta^{\supset}$

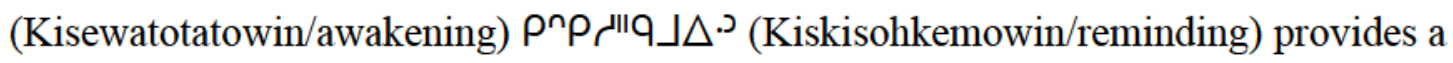
starting point and a framework of analysis for this line of inquiry. Given that Canada continues to struggle with its colonial legacy, including racism, this line of inquiry is if particular importance for various Indigenous communities that have had similar experiences with Canada's Residential Schools and racism and offer one way to begin mitigating the impact of historical (e.g., Residential Schools) and contemporary (e.g., media narratives) praxis of racism. The community with whom I conducted this research study used a school program, the Photography Class, to implement a locally informed process of decolonization to mitigate the impact of racism on students. However, other communities could implement a similar process inside or outside of the educational setting and it could take a different form. Reflecting upon this research study, the critical piece would be the inclusion of Elders to ensure that local theories of knowledge, principles of teaching and learning, and experience with racism are accounted for to provide a more effective and appropriate mitigation process.

Overall, by expanding the study of prejudice by identifying and examining prevention processes and strategies for racism and appropriate and effective processes for mitigating the impact of racism on non-dominant groups, such as Indigenous peoples, 
Canada will be in a better position to begin redressing its colonial legacy of racism. However, if the study of prejudice continues to be dominated by Western theories of knowledge and intervention strategies that target dominant group members, Canada will be unable to understand and redress its colonial legacy of racism. Beyond academia, federal and provincial governments, including Alberta, have committed to implementing the Truth and Reconciliation Commission's recommendations and the United Nations Declaration to the Rights of Indigenous Peoples. A core tenet of both documents is the mitigation of racism. If these governing bodies are going to attain this goal they will need to develop policies and funding programs that provide the necessary resources to adequately support Indigenous communities to do the work that only they can do to mitigate and decolonize the intergenerational impact of Canada's colonial legacy of racism for current and future generations. It should not be lost that there is also a time limit on such endeavors, once the current Elders are gone so too is the knowledge and teachings that provide the backbone for mitigation processes such as the one documented in this study. 


\section{References}

Abbot, P. (2002). Story, plot and narration. In D. Herman (Ed.), The Cambridge introduction to narrative (pp. 39-51). Cambridge, UK: Cambridge University Press.

Aboud, F. (1988). Children and prejudice. Cambridge, MA: Blackwell.

Aboud, F., Tredoux, C., Tropp, L., Brown, C., Niens, U., \& Noor, N. (2012). Interventions to reduce prejudice and enhance inclusion and respect for ethnic differences in early childhood: A systematic review. Developmental Review, 32(4), 307-336.

Alfred, T., \& Corntassel, J. (2005). Being Indigenous: Resurgence against contemporary colonialism. Government \& Opposition, 40(4), 597-614.

Ali, S. (2005). Aboriginal perspectives into the teaching and learning of science education: Beginning the conversations in Southern Saskatchewan. Retrieved from http://ourspace.uregina.ca/bitstream/handle/10294/1142/Aboriginal_Perspectives. pdf;sequence $=1$

Allport, G. (1954). The nature of prejudice. Reading, MA: Addison-Wesley.

Bainbridge, R., Whiteside, M., \& McCalman, J. (2012). Being, knowing, and doing: A phronetic approach to constructing grounded theory with Aboriginal Australian partners. Qualitative Health Research 23(2), 275-288.

Ball, J. (2004). As if Indigenous knowledge and communities mattered: Transformative education in First Nations communities in Canada. The American Indian Quarterly, 28(3\&4), 454-479. 
Battiste, M. (2005). Indigenous knowledge: Foundations for First Nations. Retrieved from

http://142.25.103.249/integratedplanning/documents/IndegenousKnowledgePaper byMarieBattistecopy.pdf

Battiste, M., \& Henderson, J. (2009). Naturalizing Indigenous knowledge in Eurocentric education. Canadian Journal of Native Education, 32(1), 5-20.

Bhabba, H. (1994). The location of culture. New York, NY: Routledge.

Bigler, R., \& Liben, L. (1992). Cognitive mechanisms in children's gender stereotyping: Theoretical and educational implications of a cognitive-based intervention. Child Development, 63(6), 1351-1363.

Bond, J., \& Bond, S. (1986). Sociology and health care. Edinburgh, UK: Churchill Livingstone.

Bourassa, C., McKay-McNabb, K., \& Hampton, M. (2004). Racism, sexism, and colonialism: The impact on the health of Aboriginal women in Canada. Canadian Woman Studies, 24(1), 23-29.

Brittain, M., \& Blackstock, C. 2015. First Nations child poverty: A literature and analysis. First Nations Children's Action Research and Education Service.

Retrieved from https://fncaringsociety.com/sites/default/files/First\%20Nations\%20Child\%20Pove rty\%20-\%20A\%20Literature\%20Review\%20and\%20Analysis\%202015_3.pdf

Brown, R., \& Hewstone, M. (2005). An integrative theory of intergroup contact. In M. Zanna (Ed.), Advances in experimental social psychology (Vol. 37, pp. 255-343). San Diego, CA: Academic Press. 
Brundige, L. (2004). Tanisi Isinisitohtamahk Kitaskino: Cree philosophy. Akwa Kayaskiacimowin (Unpublished doctoral dissertation). University of Oregon, Eugene.

Bruneau, E., \& Saxe, R. (2012). The power of being heard: The benefits of 'perspectivegiving' in the context of intergroup conflict. Journal of Experimental Social Psychology, 48(4), 855-866.

Cameron, L., Rutland, B., \& Brown, R. (2007). Promoting children's positive intergroup attitudes towards stigmatized groups: Extended contact and multiple classification skills training. International Journal of Behavioral Development, 31(5), 454-466.

Cameron, L., Rutland, A., Brown, R., \& Douch, R. (2006). Changing children's intergroup attitudes toward refugees: Testing different models of extended contact. Child Development, 77(5), 1208-1219.

Canadian Human Rights Tribunal. (2016). First Nations child and family caring society of Canada versus Indian and Northern Affairs of Canada. Retrieved from https://fncaringsociety.com/sites/default/files/2016\%20CHRT\%20Ruling\%20on $\% 20 \mathrm{FN} \% 20$ child $\% 20$ welfare $\% 20$ case.pdf

Charmaz, K. (1991). Good days, bad days: The self in chronic illness and time. New Brunswick, NJ: Rutgers University Press.

Charmaz, K. (2003). Grounded theory: Objectivist and constructivist methods. In N. Denizin \& Y. Lincoln (Eds.) Strategies of qualitative inquiry (pp. 249-291), Thousand Oaks, CA: Sage.

Charmaz, K. (2006). Constructing grounded theory: A practical guide through qualitative analysis. Thousand Oaks, CA: Sage Publications. 
Charmaz, K. (2010). Disclosing illness and disability in the workplace. Journal of International Education in Business, 3(1), 6-9.

Charmaz, K. (2014). Constructing grounded theory ( $2^{\text {nd }}$ ed.). Thousand Oaks, CA: Sage Publications.

Charmaz, K., \& Belgrave, L. (2012). Qualitative interviewing and grounded theory analysis. In J. Gubrium, J. Holstein, A. Marvasti, \& K. McKinney (2 ${ }^{\text {nd }}$ ed.), Handbook of interview research: The complexity of the craft (pp. 381-396). Thousand Oaks, CA: Sage Publications.

Community and Family Services (2000). Policy and Procedures Manual: Cree Customary Law Section. Unpublished Document. Nehiyaw/Cree Community: $\mathrm{AB}$.

Coombes, B. (2013). Indigenism, public intellectuals, and the forever opposed-or, the making of a "Hori Academic". In D. Mertens, F. Cram, \& B. Chilisa (Eds.), Indigenous pathways into social research: Voices of a new generation (pp. 7188). Walnut Creek, CA: Left Coast Press.

Corbin-Dwyer, S. \& Buckle, J. (2009). The space between: On being an insider-outsider in qualitative research. International Journal of Qualitative Methods, 8(1), 54-63.

Corntassel, J. (2012). Re-visioning resurgence: Indigenous pathways to decolonization and sustainable self-determination. Decolonization: Indigeneity, Education \& Society, 1(1), 86-101.

Corntassel, J., Chaw-win-is, T'lakwadzi. (2009). The politics of Indigenous truth- telling: Challenges for the Canadian Truth and Reconciliation Commission. English Studies in Canada, 35(1), 135-159. 
Crisp, R., Husnu, S., Meleady, R. Stathi, S., \& Turner, R. (2010). From imagery to intention: A dual route model of imagined contact effects. European Review of Social Psychology, 21(1), 188-236.

Crisp, R., Stathi, S., Turner, R., \& Husnu, S. (2008). Imagined intergroup contact: Theory, paradigm and practice. Social and Personality Psychology Compass, $3(1), 1-18$.

Crisp, R., \& Turner, R. (2009). Can imagined interactions produce positive perceptions? Reducing prejudice through simulated social contact. American Psychologist, 64(4), 231-240.

Daly, E., \& Sarkin, J. (2007). Reconciliation in divided societies: Finding common ground. Philadelphia: PA. University of Pennsylvania Press.

Daveson, B., O'Callaghan, C., \& Grocke, D. (2008). Indigenous music therapy theory building through grounded theory research: The developing Indigenous theory framework. The Arts in Psychotherapy, 35(2008), 280-286.

Denzin, N. (2010). Grounded theories and the politics of pragmatism. Sociological Inquiry, 80(2), 296-312.

DeVault, M. (1990). Talking and listening from women's standpoint: Feminist strategies for interviewing and analysis. Social Problems, 37(1), 96-116.

DeWalt, K., DeWalt, B., \& Wayland, C. (1998). Participant observation. In H. Bernard (Ed.), Handbook of methods in cultural anthropology (pp. 259-299). Walnut Creek, CA: AltaMira Press.

Downey, B., \& Sweetwater, I. (2003). International network of Indigenous health knowledge and development. The Aboriginal Nurse, 18(2), 8-10. 
Fanon, F. (1963). The wretched of the earth. New York: NY. Vintage.

Fetterman, D. (1998). Ethnography step by step ( ${ }^{\text {nd }}$ ed.). Thousand Oaks, CA: Sage Publications.

Finlay, L. (2012). Five lenses for the reflexive interviewer. In J. Gubrium, J. Holstein, A. Marvasti, \& K. McKinney (Eds.), Handbook of interview research: The complexity of the craft ( $2^{\text {nd }}$ ed.) (pp. 317-332). Thousand Oaks, CA: Sage Publications.

Floersch, J., Longhofer, J., Kranke, D., \& Townsend, L. (2010). Integrating thematic, grounded theory and narrative analysis: A case study of adolescent psychotropic treatment. Qualitative Social Work, 9(3), 407-425.

Four Directions Teachings. (2006). Cree (Nehiyawak) teaching Elder: Mary Lee. Retrieved from http://www.fourdirectionsteachings.com/transcripts/cree.html Frank, A. (1995). The wounded storyteller: Body, illness, and ethics. Chicago, IL: The University Chicago Press.

Frank, A. (1997). Blurred inscriptions of health and illness. Body \& Society, 3, 103-113.

Frank, A. (1998). Just listening: Narrative and deep illness. Families, Systems \& Health, $16,197-212$.

Frank, A. (2000). Illness and the interactionist vocation. Symbolic Interaction, 23(4), $321-332$.

Frank, A. (2002). Why study people's stories? The dialogical ethics of narrative analysis. International Journal of Qualitative Methods, 1(1), 109-117.

Frey, J., \& Oishi, S. (1995). How to conduct interviews by telephone and in person. London, UK: Sage Publications. 
Gair, S. (2012). Feeling their stories: Contemplating empathy, insider/outsider positionings, and enriching qualitative research. Qualitative Health Research, 22(1), 134-143.

Gilroy. P. (2000). Against race imagining political culture beyond the colour line. Cambridge, MA: Harvard University Press.

Glaser, B. (1978). Theoretical sensitivity. Mill Valley, CA: Sociology Press.

Goff, P., Steele, C., \& Davies, P. (2008). The space between us: Stereotype threat and distance in interracial contexts. Journal of Personality and Social Psychology, 94(1), 91-107.

Government of Alberta. (2017). Alberta Indigenous relations. Retrieved from http://indigenous.alberta.ca/InteractiveMap.cfm

Government of Canada. (2005). Canada's action plan against racism: A Canada for all. Retrieved from http://publications.gc.ca/collections/Collection/CH34-72005E.pdf

Government of Canada. (2011). Evaluation of Canada's action plan against racism. Retrieved from http://www.cic.gc.ca/english/resources/evaluation/CAPAR/summary.asp

Grant, A. (1996). No end to grief: Indian residential schools in Canada. Winnipeg, MB: Pemican Publications.

Hall, S. (1996). Who needs 'identity’? In S. Hall \& P. Du Gay (Eds.), Question of Cultural Identity (pp. 1-17). London, UK: Sage Publications Inc.

Haslam, S., Turner, J., Oakes, P., McGarty, C., \& Hayes, B. (1992). Context dependent variation in social stereotyping 1 : The effects of intergroup relations as mediated 
by social change and frame of reference. European Journal of Social Psychology, 22(1), 3-20.

Hayfield, N., \& Huxley, C. (2015). Insider and outsider perspectives: Reflections on researcher identities in research with lesbian and bisexual women. Qualitative Research in Psychology, 12(2), 91-106.

Heath, H., \& Cowley, S. (2003). Developing a grounded theory approach: A comparison of Glaser and Strauss. International Journal of Nursing Studies, 41(2004), 141150.

Henderson, J. (2002). Postcolonial Indigenous legal consciousness. Indigenous Law Journal, 1(1), 1-52.

Husnu, S., \& Crisp, R. (2010). Imagined intergroup contact: A new technique for encouraging greater inter-ethnic contact in Cyprus. Peace \& Conflict: Journal of Peace Psychology, 16(1), 97-108.

Islam, M., \& Hewstone, M. (1993). Dimensions of contact as predictors of intergroup anxiety, perceived out-group variability, and out-group attitude: An integrative model. Personality and Social Psychology Bulletin, 19(6), 700-710.

Jennings, G., Kensbock, S., Junek, O., Radel, K., \& Kachel, U. (2010). Lived experience of early career researchers: Learning about and doing grounded theory. Journal of Hospitality and Tourism Management, 17(1), 21-33.

Johnson, D., Jasper, D., Griffin, S., \& Huffman, B. (2013). Reading narrative fiction reduces Arab-Muslim prejudice and offers a safe haven from intergroup anxiety. Social Cognition, 31(5), 578-598. 
Jones, A., \& Jenkins, K. (2008). Rethinking collaboration: Working the indigenecolonizer hyphen. In N. Denzin, Y. Lincoln, \& L. Smith (Eds.), Handbook of critical and indigenous methodologies (pp. 471-486). Thousand Oaks, CA: Sage.

Katz, I. (1991). Gordon Allport's: Nature of prejudice. International Society of Political Psychology, 12(1), 125-157.

Kim, A., \& Dionne, L. (2014). Traditional ecological knowledge in science education and its integration in grades 7 and 8 Canadian science curriculum documents. Canadian Journal of Science, Mathematics and Technology Education, 14(4), $311-329$.

King, M., \& Gracey, M. (2009). Indigenous health part 1: Determinants and disease patterns. The Lancet, 374(9683), 65-75.

King, M., Smith, A., \& Gracey, M. (2009). Indigenous health part 2: The underlying causes of the health gap. Lancet, 374(9683), 76-85.

Kirkness, V., \& Barnhardt, R. (1991). First Nations higher education: The four R's respect, relevance, reciprocity, responsibility. Journal of American Indian Education, 30(3), 1-17.

Kovach, M. (2009). Indigenous methodologies: Characteristics, conversations, and contexts. Toronto, ON: University of Toronto Press.

Kteily, N., Saguy, T., Sidanius, J., \& Taylor, D. (2013). Negotiating power: Agenda ordering and the willingness to negotiate in asymmetric intergroup conflicts. Journal of Personality and Social Psychology, 105(6), 978-995.

Laenui, P. (2000). Processes of decolonization. In M. Battiste (Ed.), Reclaiming Indigenous voice and vision (pp. 150-160). Vancouver, BC: UBC Press. 
Lather, P. (1991). Getting smart: Feminist research and pedagogy with/in the postmodern. New York, NY: Routledge.

Lawrence, M. (2004). "Real" Indians and others: Mixed-blood urban native peoples and indigenous nationhood. Vancouver, BC: UBC Press.

Lempert, L. (2007). Asking questions of the data: Memo writing in the grounded theory tradition. In A. Bryant \& K. Charmaz (Eds.), The Sage handbook of grounded theory (pp. 245-264). Thousand Oaks, CA: SAGE Publications Ltd.

Library of Parliament. (1883). Journals of the House of Commons of the Dominion of Canada. Retrieved from http://parl.canadiana.ca/view/oocihm.9_07171_17/4?r=0\&s=1

Liebkind, K., \& McAllister, A. (1999). Extended contact through peer modeling to promote tolerance in Finland. European Journal of Social Psychology, 29(5-6), $765-780$.

Liebow, E. (1967). Tally's corner: A study of Negro streetcorner men. Boston, MA: Little, Brown.

Little Bear, L. (2000). Jagged worldviews colliding. In M. Battiste (Ed), Reclaiming Indigenous voice and vision (pp. 77-85). Vancouver, BC: UBC Press.

Livesley, W., \& Bromley, D. (1973). Person perception in childhood and adolescence. New York, NY: John Wiley \& Sons, Inc.

Lowell, A., Kildea, S., Liddle, M., Cox, B., \& Paterson, B. (2015). Supporting aboriginal knowledge and practice in health care: Lessons from a qualitative evaluation of the strong women, strong babies, strong culture program. BMC Pregnancy \& Childbirth, 15(1), 1-12. 
Lynch, C. (2008). Reflexivity in research on civil society: Constructivist perspectives. International Studies Review, 10(4), 708-721.

Mahonen, T., Jasinskaja-Lahti, I., \& Liebkind, K. (2011). The impact of perceived social norms, gender, and intergroup anxiety on the relationship between intergroup contact and ethnic attitudes of adolescents. Journal of Applied Social Psychology, 41(8), 1887-1899.

McCalman, J., Tsey, K., Bainbridge, R., Shakeshaft, A., Singleton, M., \& Doran, C. (2013). Tailoring a response to youth binge drinking in an Aboriginal Australian community: A grounded theory study. BMC Public Health, 13(726), 1-9.

McCracken, G. (1988). The long interview. London, UK: Sage Publications.

McGregor, D. (2004). Coming full circle: Indigenous knowledge, environment, and our future. American Indian Quarterly, 28(3\&4), 385-410.

Menzies, C., \& Butler, C. (2007). Returning to selective fishing through Indigenous fisheries knowledge: The example of K'moda, Gitxaala Territory. The American Indian Quarterly, 31(3), 441-464.

Meyer, M. (2003). Ho'Oulu: Our times of becoming: Hawaiian epistemology and early writings. Honolulu, HI: 'Ai Pohaku Press Native Books.

Milbur, M. (2004). Indigenous nutrition: Using traditional food knowledge to solve contemporary health problems. American Indian Quarterly, 28(3\&4), 411-434.

Miller, J. (1996). Shingwauk's vision: A history of Native residential schools. Toronto, ON: University of Toronto Press.

Mills, C. (1959). The social imagination. New York, NY: Grove Press. 
Oaker, G., \& Brown, R. (1986). Intergroup relations in a hospital Setting: A further test of social identity theory. Human Relations, 39(8), 767-778.

Paolini, S., Hewstone, M., Cairns, E., \& Voci, A. (2004). Effects of direct and indirect crossgroup friendships on judgments of Catholic and Protestants in Northern Ireland: The mediating role of an anxiety-reduction mechanism. Personality and Social Psychology Bulletin, 30(6), 770-786.

Payne, G., \& Payne, J. (2004). Key concepts in social research. London, UK: Sage.

Pettigrew, T., \& Tropp, L. (2008). How does intergroup contact reduce prejudice? Meta analytic tests of three mediators. European Journal of Social Psychology, 38(6), $922-934$.

Pettigrew, T., \& Tropp, L. (2006). A meta-analytic test of intergroup contact theory. Journal of Personality and Social Psychology, 90(5), 751-783.

Plant, E. (2004). Responses to interracial interactions over time. Personality and Social Psychology Bulletin, 30(11), 1458-1471.

Plant, E., \& Butz, D. (2006). The causes and consequences of an avoidance-focus for interracial interactions. Personality and Social Psychology Bulletin, 32(6), 833846.

Prus, R., Lorenz Dietz, M., \& Shaffir, W. (1997). Doing ethnographic research: Fieldwork as a practical accomplishment. In R. Prus (Ed.), Subcultural mosaics and intersubjective realities (pp. 191-251). New York, NY: State University of New York Press.

Red Road Healing Society. (2017). Retrieved from http://www.theredroad.ca/logicmodel-1.html 
Riessman, C. (1990). Strategic uses of narrative in the presentation of self and Illness. Social Science and Medicine, 30(11), 1195-1200.

Rountree, J., \& Smith, A. (2016). Strength-based well-being indicators for Indigenous children and families: A literature review of Indigenous communities' identified well-being indicators. American Indian \& Alaska Native Mental Health Research: The Journal of the National Center, 23(3), 206-220.

Rousell, D., \& Giles, A. (2012). Leadership, power and racism: Lifeguards' influences on Aboriginal people's experiences at a Northern Canadian aquatic facility. Leisure Studies, 31(4), 409-428.

Royal Commission on Aboriginal Peoples. (1996). The Royal Commission on Aboriginal peoples. Retrieved from http://www.collectionscanada.gc.ca/webarchives/20071115053257/ http://www.ainc-inac.gc.ca/ch/rcap/sg/sgmm_e.html

Rubin, H., \& Rubin, I. (2012). Qualitative interviewing: The art of hearing data $\left(3^{\text {rd }} \mathrm{ed}.\right)$. London, UK: Sage Publications.

Ryan, L., Kofman, E., \& Aaron, P. (2011). Insiders and outsiders: Working with peer researchers in researching Muslim communities. International Journal of Social Research Methodology, 14(1), 49-60.

Ryan, M. (2007). Toward a definition of narrative. In D. Herman (Ed.) The Cambridge companion to narrative (pp. 22-35). Cambridge, UK: Cambridge University Press. 
Ryen, A. (2002). Cross-cultural interviewing. In J. F. Gubrium \& J. Holstein (Eds.), Handbook of interview research: Context and method (pp. 334-355). Thousand Oaks, CA: Sage Publications.

Saguy, T., Dovidio, J., \& Pratto, F. (2008). Beyond contact: Intergroup contact in the context of power relations. Personality and Social Psychology Bulletin, 34(3), 432-445.

Saguy, T., \& Kteily, N. (2014). Power, negotiations, and the anticipation of intergroup encounters. European Review of Social Psychology, 25(1), 107-141.

Said, E. (1978). Orientalism: Western conceptions of the Orient. London, UK: Routledge and Kegan Paul Ltd.

Said, E. (1994). Representations of the intellectual. New York, NY: Pantheon.

Saloojee, A. (2003). Social inclusion, anti-racism and democratic society. Toronto, ON, Canada: The Laidlaw Foundation.

Sharing Circle. (2017). The 7 sacred teachings. Retrieved from http://www.thesharingcircle.com/sacred_teachings.html

Shelton, J., \& Richeson, J. (2005). Intergroup contact and pluralistic ignorance. Journal of Personality and Social Psychology, 88(1), 91-107.

Shnabel, N., \& Nadler, A. (2008). A needs-based model of reconciliation: Satisfying the differential emotional needs of victim and perpetrator as a key to promoting reconciliation. Journal of Personality and Social Psychology, 94(1), 116.

Shnabel, N., Nadler, A., Ullrich, J., Dovidio, J., \& Carmi, D. (2009). Promoting reconciliation through the satisfaction of the emotional needs of victimized and 
perpetrating group members: The needs-based model of reconciliation.

Personality and Social Psychology Bulletin, 35(8), 1021-1030.

Sinclair, R., Bruyere, G., \& Hart, M. (2009). Wicihitowin: Aboriginal social work in Canada. Black Point, NS: Fernwood Publishing.

Simpson, L. (2015). Anger, resentment and love: Fuelling resurgent struggle. Paper presented at the Native American and Indigenous Studies Association Conference, Washington, DC.

Smith, L. (1999). Decolonizing methodologies: Research and Indigenous peoples. London, UK: Zed Books.

Smith, L. (2012). Decolonizing methodologies: Research and Indigenous peoples ( $2^{\text {nd }}$ ed.). London, UK: Zed Books.

Spivak, G. (1988). Subaltern studies: Deconstructing historiography. In R. Guha \& G. Spivak (Eds.), In other worlds: Essays in cultural politics (pp. 197-221). Oxford, UK: University Press.

Stangeland, J., \& Walsh, C. (2013). Defining permanency for Aboriginal youth in care. First Peoples Child \& Family Review, 8(2), 24-39.

Stanton, K. (2011). Canada's Truth and Reconciliation Commission: Settling the past? The International Indigenous Policy Journal, 2(3), 1-18.

Star, S. (2007). Living grounded theory: Cognitive and emotional forms of pragmatism. In A. Bryant \& K. Charmaz (Eds.), Handbook of grounded theory (pp. 75-93) London: Sage Publications.

Stephan, W., \& Stephan, C. (2000). An integrated threat theory of prejudice. In S. Oskamp (Ed.), Reducing prejudice and discrimination (pp. 23-45). Mahwah, NJ: 
Lawrence Erlbaum Associates.

Stuckey, H. (2013). Three types of interviews: Qualitative research methods in social research. Methodological Issues in Social Health and Diabetes Research, 1(2), $56-59$.

Tajfel, H., \& Turner, J. (1986). The social identity theory of intergroup behaviour. In S. Worchel \& W. Austin (Eds.), Psychology of intergroup relations (pp. 7-24). Chicago, IL: Nelson-Hall.

Tang, D. (2007). The research pendulum: Multiple roles and responsibilities as a researcher. Journal of Lesbian Studies, 10(3-4), 11-27.

Tausch, N., Hewstone, M., Kenworthy, J., Cairns, E., \& Christ, O. (2007). Crosscommunity contact, perceived status differences, and intergroup attitudes in Northern Ireland: The mediating roles of individual-level versus group-level threats and the moderating role of social identification. Political Psychology, 28(1), 53-68.

Toronto Sun. (2011). Gang Members Plague Hobbema. Retrieved from, http://www.torontosun.com/2011/08/28/gangs-murders-plague-hobbema

Truth and Reconciliation Commission of Canada. (2015). Honouring the truth, reconciling for the future. Retrieved from http://www.trc.ca/websites/trcinstitution/index.php?p=890

Turner, R., Hewstone, M., \& Voci, A. (2007). Reducing explicit and implicit outgroup prejudice via direct and extended contact: The mediating role of self-disclosure and intergroup anxiety. Journal of Personality and Social Psychology, 93(3), 369-388. 
Turner, R., \& Crisp, R. (2010). Imagining intergroup contact reduces implicit prejudice. British Journal of Social Psychology, 49(1), 129-142.

Turner, R., Crisp, R., \& Lambert, E. (2007). Imagining intergroup contact can improve intergroup attitudes. Group Processes \& Intergroup Relations, 10(4), 427-441.

Turner, R. N., Hewstone, M., Voci, A., \& Vonofakou, C. (2008). A test of the extended intergroup contact hypothesis: The mediating role of intergroup anxiety, perceived ingroup and outgroup norms, and inclusion of the outgroup in the self. Journal of Personality and Social Psychology, 95(4), 843-860.

Van Dick, R., Wagner, U., Pettigrew, T., Christ, O., Wolf, C., Petzel, T., Castro, V., \& Jackson, J. (2004). Role of perceived importance in intergroup contact. Journal of Personality and Social Psychology, 87(2), 211-227.

VandenBos, G. (Ed.). (2015). American Psychological Association dictionary of psychology (2 $2^{\text {nd }}$ Ed.). Washington, DC: American Psychological Association.

Villegas, M., Neugebauer, S., \& Venegas, K. (2008). Indigenous knowledge and education: Sites of struggle, strength, and survivance. Cambridge, MA: Harvard Education Review.

Voci, A., \& Pagotto, L. (2010). Mediated moderation in the relation between contact and prejudice reduction: The role of intergroup anxiety and prototypicality. Testing Psychometrics, Methodology, 17(1), 37-49.

Vorauer, J., Main, K., \& O'Connell, G. (1998). How do individuals expect to be viewed by members of lower status groups? Content and implications of metastereotypes. Journal of Personality and Social Psychology, 75(4), 917-937. 
Vorauer, J., \& Sasaki, S. (2009). Helpful only in the abstract? Ironic effects of empathy in intergroup interaction. Psychological Science, 20(2), 191-197.

Vorauer, J., \& Sasaki, S. (2012). The pitfalls of empathy as a default intergroup interaction strategy: Distinct effects of trying to empathize with a lower status outgroup member who does versus does not express distress. Journal of Experimental Social Psychology, 48(2), 519-524.

Wagner, U., Christ, O., \& Pettigrew, T. (2008). Prejudice and group-related behavior in Germany. Journal of Social Issues, 64(2), 403-416.

Wagner, U., Christ, O., Pettigrew, T., Stellmacher, J., \& Wolf, C. (2006). Prejudice and minority proportion: Contact instead of threat effects. Social Psychology Quarterly, 69(4), 380-390.

Weber-Pilwax, C. (2001). What is Indigenous research? Canadian Journal of native Education, 25(2), 166-174.

Wesley-Esquimaux, C., \& Smolewski, M. 2004. Historic trauma and Aboriginal healing. Retrieved from http://www.ahf.ca/publications/research-series

West, T., \& Dovidio, J. (2013). Intergroup contact across time: Beyond initial contact. In G. Hodson \& M. Hewstone (Eds.), Advances in intergroup contact (p. 152-175). New York, NY: Psychology Press.

Wilson, S. (2008). Research is ceremony: Indigenous research methods. Black Point, NS: Fernwood Publishing.

Young, N., Wabano, M., Usuba, K., Pangowish, B., Trottier, M., Jacko, D., Burke, T., Corbiere, R. (2015). Validity of the Aboriginal children's health and well-being measure: Aaiish Naa Gegii. Health and Quality of Life Outcomes, 13(148), 1-7. 


\section{Appendix A}

\section{STUDENT INFORMATION LETTER \& WRITTEN ASSENT}

Title of Research Project: Photography Class: Using Photography to Make Sense of Individual and Social Identity in Relation to Racist Practices ${ }^{27}$

Date of ethics clearance: November 2015

Date of expiration for the project: August 31, 2016

*Information under the following headings will be described verbally to potential participants.

Invitation to Participate: You are invited to take part in a research study called Photography Class: Using Photography to Make Sense of Individual and Social Identity in Relation to Racist Practices, that is being led by Davina Rousell, a doctoral student at Carleton University with the Department of Sociology and Anthropology under the supervision of Dr. Katharine Kelly who is cross appointed between Pauline Jewett Institute of Women's and Gender Studies Cross and the Department of Sociology and Anthropology.

Who is taking part

In order to take part in this study you need to be First Nations, a grade 7, 8, or 9 student attending Community School and taking part in the Photography Class.

Goal of the Study

This year the Photography Class is going to explore the topic of racism. The goal of this study is to learn about your ideas and experience with the Photography Class and with racism. For example, you will be asked about your experience with the Photography Class and about your experience with racism. What you share will be used to strengthen the Photography Class and learn how to address racism.

What will you be asked to do?

If you agree to take part in the study you will be asked to take part in two activities, (1) participant observation and (2) an interview. You do not have to take part in this study. If you do not agree to take part in this study you can still take part in the Photography Class.

Participant Observation

\footnotetext{
${ }^{27}$ As the study unfolder the title of the research project changed to reflect what was happening in the data and what this study was about. As such this research study's title was revised to Indigenous Theories of Knowledge of Racism and its Mediation.
} 
You will be asked to take part in an activity called participant observation. This means that I will take part in the Photography Class with you so that I can see what is going on. If you agree, after each class is over I will write down what I saw during class so that I can learn more about the Photography Class, your experience with the Club and your experience with racism.

Interview

You will also be asked to take part in an interview. If you agree, this activity will take 30 to 45 minutes and you will be asked to share your ideas and experience with the Photography Class and with racism. The interview will take place at your school and will be audio recorded. If you do not want to be recorded I will take notes of what you share with me during the interview.

You might be asked to take part in a second interview. If you agree, this second interview will take 15 to 30 minutes so that I can learn more about your ideas and experience with the Photography Class and with racism. The interview will take place at your school and will be audio recorded. If you do not want to be recorded I will only take notes of what you share with me.

Possible Benefits

By taking part in this research study, your ideas and experience will help to strengthen the Photography Class and learn how to address racism.

Possible Risks

I do not anticipate any risks involved with taking part in this study. But you might talk about issues/problems that upset you. If this happens I will give you a sheet of paper that has a list of people that you can contact that can help you. If you share with me that you are at risk of being hurt or at risk of hurting someone else I need to share this information to the appropriate authority.

Confidentiality

Participant Observation

All participant observations will take place at the school during Photography Class classes. I will not take notes during class. I will only write down what I saw after each class has ended and when I am alone. My notes will not include any information that can be used to identify you or your participation in the BookMaker. You will not have access to the notes nor will any other participant or parents/caregivers have access to the notes.

\section{Interview}

Interviews will be audio recorded. The recordings will be written out word for word and saved as an electronic document. This document will be given back to you two weeks after the interview so that you can read it and make sure that it is correct. I will not tell anyone that you took part in an interview and I will not share any of the information that you shared with me during the interview. No other participants or your parents/caregivers will have access to your transcript. 
Use of Information

Your name will be replaced with a pretend name so that nobody, other than me, can tell what you said or shared. Your name will not be used in any presentations, reports or papers about this study. The information collected will remain in a password protected storage box in my office located in my private home in Edmonton indefinitely. Only I (Davina Rousell) and my supervisor (Dr. Katharine Kelly) will have access to the information. The information will only be looked at again and used in the future for the goals shared in this sheet. If I would like to look at this information for a different reason I will contact you to ask if you agree to this.

Can you quit?

Yes, you can change your mind and stop taking part in this study at any time. After the study ends in August 2016 you have one month to remove yourself from the study. If you decide to remove yourself from the study I will destroy any information that you shared with me, including any notes on your participation in the Photography Class.

Your signature

If you want to take part in this study I will ask you to sign the consent form to show that you agree to take part in the research study. Your parent or caregiver will be asked if they agree for you to take part in this study. Even if your parent or caregiver agrees that you can take part in this study the final decision is yours to make.

Contact Names and Telephone Numbers:

This research project was reviewed and received ethics clearance by the Carleton University Research Ethics Board. If you have any concerns or questions about your involvement in the study please contact the chairs of Research Ethics Board. The chairs names and contact information are as follows:

Professor Louise Heslop, Chair

Professor Andy Alder, Vice-Chair

Research Ethics Board

Carleton University Research Office

Carleton University

511 Tory, 1125 Colonel By Drive

Ottawa, Ontario K1S 5B6

Tel: 613-520-2517 E-mail: ethics@carleton.ca

Do you have more questions?

If you have any questions or would like more information, you can ask me, Davina. My contact information as well as my supervisors' is below.

Thank you!

Davina Rousell, doctoral student

Carleton University

Department of Sociology and Anthropology

B750 Loeb Building, 1125 Colonel By Drive 
Ottawa, ON, K1S 5B6

Phone: 780-862-0353

Email: davina.rousell@carleton.ca

Dr. Katharine Kelly, Supervisor

Carleton University

Pauline Jewett Institute of Women's and Gender Studies

1424 Dunton Tower, 125 Colonel By Drive

Ottawa, ON, K1S 5B6

Phone: 613-520-2622

Email: katharine_kelly@carleton.ca

Thank you! 


\section{Appendix B}

\section{STUDENT ASSENT FORM}

Title of Program: Photography Class: Using Photography to Make Sense of Individual and Social Identity in Relation to Racist Practices

Please check each box to show what activities you agree to take part in.

\section{Information and Assent Form:}

I have read the information sheet about the research...................... please check)

\section{Research Activities:}

I agree to take part in participant observation.......................... please check)

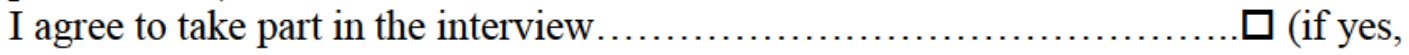
please check)

I agree to take part in a second interview........................... please check)

\section{Use of Information:}

I agree to have notes recorded and examined...................... (if yes, please check)

I agree to have interviews recorded and examined.................... $\square$ (if yes, please check)

Please print and sign your name to show that you agree to take part in the Research Activities and the Uses of Information that are checked above:

I

$$
\text { (First, Last) }
$$

agree to

take part in the checked research activities.

Signature of participant:

Date:

Below please write your phone number and email address or mailing address so that I can contact you to review your interview document and the study's findings.

Phone Number:

Email or Mailing Address: 
Two copies of the consent form are provided: one to be signed and returned to me for my own records and one for you to keep for your own records.

\section{Demographic Information}

Please answer the following questions:

1. What gender do you identify with?

2. What is your current age?

3. What grade are you in?

Thank you for taking the time to complete the above questions! 


\section{Appendix C}

\section{STUDENT INFORMATION LETTER \& ASSENT SCRIPT}

Title of Research Project: Photography Class: Using Photography to Make Sense of Individual and Social Identity in Relation to Racist Practices

Date of ethics clearance: November 2015

Date of expiration for the project: August 31, 2016

*Information under the following headings will be described verbally to potential participants.

Invitation to Participate: You are invited to take part in a research study called Photography Class: Using Photography to Make Sense of Individual and Social Identity in Relation to Racist Practices, that is being led by Davina Rousell, a doctoral student at Carleton University with the Department of Sociology and Anthropology under the supervision of Dr. Katharine Kelly who is cross appointed between Pauline Jewett Institute of Women's and Gender Studies Cross and the Department of Sociology and Anthropology.

Who is taking part

In order to take part in this study you need to be First Nations, a grade 7, 8, or 9 student attending Community School and taking part in the Photography Class.

Goal of the Study

This year the Photography Class is going to explore the topic of racism. The goal of this study is to learn about your ideas and experience with the Photography Class and with racism. For example, you will be asked about your experience with the Photography Class and about your experience with racism. What you share will be used to strengthen the Photography Class and learn how to address racism.

What will you be asked to do?

If you agree to take part in the study you will be asked to take part in two activities, (1) participant observation and (2) an interview. You do not have to take part in this study. If you do not agree to take part in this study you can still take part in the Photography Class.

Participant Observation

You will be asked to take part in an activity called participant observation. This means that I will take part in the Photography Class with you so that I can see what is going on. If you agree, after each class is over I will write down what I saw during class so that I can learn more about the Photography Class, your experience with the Club and your experience with racism. 
Interview

You will also be asked to take part in an interview. If you agree, this activity will take 30 to 45 minutes and you will be asked to share your ideas and experience with the Photography Class and with racism. The interview will take place at your school and will be audio recorded. If you do not want to be recorded I will take notes of what you share with me during the interview.

You might be asked to take part in a second interview. If you agree, this second interview will take 15 to 30 minutes so that I can learn more about your ideas and experience with the Photography Class and with racism. The interview will take place at your school and will be audio recorded. If you do not want to be recorded I will only take notes of what you share with me.

Possible Benefits

By taking part in this research study, your ideas and experience will help to strengthen the Photography Class and learn how to address racism.

Possible Risks

I do not anticipate any risks involved with taking part in this study. But you might talk about issues/problems that upset you. If this happens I will give you a sheet of paper that has a list of people that you can contact that can help you. If you share with me that you are at risk of being hurt or at risk of hurting someone else I need to share this information to the appropriate authority.

Confidentiality

Participant Observation

All participant observations will take place at the school during Photography Class classes. I will not take notes during class. I will only write down what I saw after each class has ended and when I am alone. My notes will not include any information that can be used to identify you or your participation in the Photography Class. You will not have access to the notes nor will any other participant or parents/caregivers have access to the notes.

Interview

Interviews will be audio recorded. The recordings will be written out word for word and saved as an electronic document. This document will be given back to you two weeks after the interview so that you can read it and make sure that it is correct. I will not tell anyone that you took part in an interview and I will not share any of the information that you shared with me during the interview. No other participants or your parents/caregivers will have access to your transcript.

Use of Information

Your name will be replaced with a pretend name so that nobody, other than me, can tell what you said or shared. Your name will not be used in any presentations, reports or papers about this study. The information collected will remain in a password protected 
storage box in my office located in my private home in Edmonton indefinitely. Only I (Davina Rousell) and my supervisor (Dr. Katharine Kelly) will have access to the information. The information will only be looked at again and used in the future for the goals shared in this sheet. If I would like to look at this information for a different reason I will contact you to ask if you agree to this.

Can you quit?

Yes, you can change your mind and stop taking part in this study at any time. After the study ends in August 2016 you have one month to remove yourself from the study. If you decide to remove yourself from the study I will destroy any information that you shared with me, including any notes on your participation in the Photography Class.

Your Verbal Permission:

If you want to take part in this study I will ask you to say out loud that you agree and want to take part in the research study and we will fill-out this consent form together. Your parent or caregiver will be asked if they agree for you to take part in this study. Even if your parent or caregiver agrees that you can take part in this study the final decision is yours to make.

Contact Names and Telephone Numbers:

This research project was reviewed and received ethics clearance by the Carleton University Research Ethics Board. If you have any concerns or questions about your involvement in the study please contact the chairs of Research Ethics Board. The chairs names and contact information are as follows:

Professor Louise Heslop, Chair

Professor Andy Alder, Vice-Chair

Research Ethics Board

Carleton University Research Office

Carleton University

511 Tory, 1125 Colonel By Drive

Ottawa, Ontario K1S 5B6

Tel: 613-520-2517 E-mail: ethics@carleton.ca

Do you have more questions?

If you have any questions or would like more information, you can ask me, Davina. My contact information as well as my supervisors' is below.

Davina Rousell, doctoral student

Carleton University

Department of Sociology and Anthropology

B750 Loeb Building, 1125 Colonel By Drive

Ottawa, ON, K1S 5B6

Phone: 780-862-0353, Email: davina.rousell@carleton.ca

Thank you!

Dr. Katharine Kelly, Supervisor 
Carleton University

Pauline Jewett Institute of Women's and Gender Studies

1424 Dunton Tower, 125 Colonel By Drive

Ottawa, ON, K1S 5B6

Phone: 613-520-2622, Email: katharine_kelly@carleton.ca 


\section{Appendix D}

\section{STUDENT ASSENT FORM}

Title of Program: Photography Class: Using Photography to Make Sense of Individual and Social Identity in Relation to Racist Practices

As I read the different questions please let me know what boxes to check to show what activities you agree to take part in.

Information and Assent Form:

I have read you the information sheet about the research study ................ (if yes, please check)

\section{Research Activities:}

I agree to take part in participant observation............................ please check)

I agree to take part in the interview.

(if yes, please check)

I agree to take part in a second interview .............................. please check)

Use of Information:

I agree to have notes recorded and examined......................... (if yes, please check)

I agree to have interviews recorded and examined..................... $\square$ (if yes, please check)

Say yes to let me know that you agree to take part in the Research Activities and the Uses of Information that are checked above:

I have completed this assent form on behalf of (Researcher's first and last name)

(Research participant's first and last name) agrees to take part in the checked research activities.

Signature of researcher: Date:

Location:

Please share a phone number and email address or mailing address so that I can contact you to review your interview document and the study's findings.

Phone Number:

Email or Mailing Address: 
Two copies of the assent form are provided: one signed for my own records and one for you to keep for your own records.

Demographic Information

Please answer the following questions:

1. What gender do you identify with?

2. What is your current age?

3. What grade are you in?

Thank you for taking the time to complete the above questions! 


\section{Appendix E}

\section{PARENT/CAREGIVER INFORMATION \& WRITTEN CONSENT FORM}

Title of Research Project: Photography Class: Using Photography to Make Sense of Individual and Social Identity in Relation to Racist Practices

Date of ethics clearance: November 2015

Date of expiration for the project: August 31, 2016

Invitation to Participate: Your child is invited to participate in the research study called Photography Class: Using Photography to Make Sense of Individual and Social Identity in Relation to Racist Practices, that is being led by Davina Rousell, a doctoral student at Carleton University with the Department of Sociology and Anthropology under the supervision of Dr. Katharine Kelly who is cross appointed between Pauline Jewett Institute of Women's and Gender Studies Cross and the Department of Sociology and Anthropology.

Who is taking part

In order to take part in this study your child needs to be First Nations, a grade 7,8 , or 9 student attending Community School and taking part in the Photography Class.

Goal of the Study

This year the Photography Class is going to explore the topic of racism. The goal of this study is to learn about your child's ideas and experience with the Photography Class and with racism. For example, your child will be asked about their experience with the Photography Class and about their experience with racism. What they share will be used to strengthen the Photography Class and learn how to address racism.

What will you be asked to do?

If you and your child agree to take part in the study your child will be asked to take part in two activities, (1) participant observation and (2) an interview. They do not have to take part in this study. If you and your child do not agree to take part in this study they can still take part in the Photography Class.

Participant Observation

Your child will be asked to take part in an activity called participant observation. This means that I will take part in the Photography Class so that I can see what is going on. If you and your child agree, after each class is over I will write down what I saw during class so that I can learn more about the Photography Class, their experience with the Club and their experience with racism.

Interview

Your child will also be asked to take part in an interview. If you and your child agree, this activity will take 30 to 45 minutes and they will be asked to share their ideas and 
experience with the Photography Class and with racism. The interview will take place at their school and will be audio recorded. If your child does not want to be recorded I will take notes on what they share with me during the interview.

Your child might be asked to take part in a second interview. If you and your child agree, this second interview will take 15 to 30 minutes so that I can learn more about their ideas and experience with the Photography Class and with racism. The interview will take place at their school and will be audio recorded. If they do not want to be recorded I will only take notes on what they share with me.

Possible Benefits

By taking part in this research study, your child's ideas and experience will help to strengthen the Photography Class and learn how to address racism.

Possible Risks

I do not anticipate any risks involved with taking part in this study. But your child might talk about issues/problems that upset them. If this happens I will give you a sheet of paper that has a list of people that they can contact that can help them. If your child shares with me that they are at risk of being hurt or at risk of hurting someone else I need to share this information with the appropriate authority.

Confidentiality

Participant Observation

All participant observations will take place at the school during Photography Class classes. I will not take notes during class. I will only write down what I saw after each class has ended and when I am alone. My notes will not include any information that can be used to identify your child or their participation in the Photography Class. You will not have access to the notes nor will any other parents/caregivers or participants have access to the notes.

Interview

Interviews will be audio recorded. The recordings will be written out word for word and saved as an electronic document. This document will be given back to your child two weeks after the interview so that they can read it and make sure that it is correct. I will not tell anyone that your child took part in an interview and I will not share any of the information that your child shared with me during the interview. No other parents/caregivers of participants will have access to your child's transcript.

Use of Information

Your child's name will be replaced with a pretend name so that nobody, other than me, can tell what your child said or shared. Your child's name will not be used in any presentations, reports or papers about this study. The information collected will remain in a password protected storage box in my office located in my private home in Edmonton indefinitely. Only I (Davina Rousell) and my supervisor (Dr. Katharine Kelly) will have access to the information. The information will only be looked at again and used in the 
future for the goals shared in this sheet. If I would like to look at this information for a different reason I will contact you and your child to ask if both of you agree.

Can you quit?

Yes, you and your child can change your mind and your child can stop taking part in the study at any time. After the study ends in August 2016 you and your child have one month to remove your child from the study. If you or your child decide to remove your child from the study I will destroy any information that they shared with me, including any notes on their participation in the Photography Class.

Your signature

If you agree to let your child to take part in this study I will ask you to sign the consent form to show that you agree to have your child take part in the research study. Your child will be asked to sign another form to show that they agree to take part in this study. Even if you agree that your child can take part in this study the final decision is your child's to make.

Contact Names and Telephone Numbers:

This research project was reviewed and received ethics clearance by the Carleton University Research Ethics Board. If you have any concerns or questions about your involvement in the study please contact the chairs of Research Ethics Board. The chairs names and contact information are as follows:

Professor Louise Heslop, Chair

Professor Andy Alder, Vice-Chair

Research Ethics Board

Carleton University Research Office

Carleton University

511 Tory, 1125 Colonel By Drive

Ottawa, Ontario K1S 5B6

Tel: 613-520-2517 E-mail: ethics@carleton.ca

Do you have more questions?

If you have any questions or would like more information, you can ask me, Davina. My contact information as well as my supervisors' is below.

Thank you!

Davina Rousell, doctoral student

Carleton University

Department of Sociology and Anthropology

B750 Loeb Building, 1125 Colonel By Drive

Ottawa, ON, K1S 5B6

Phone: 780-862-0353, Email: davina.rousell@carleton.ca

Dr. Katharine Kelly, Supervisor

Carleton University 
Pauline Jewett Institute of Women's and Gender Studies 1424 Dunton Tower, 125 Colonel By Drive

Ottawa, ON, K1S 5B6

Phone: 613-520-2622, Email: katharine_kelly@carleton.ca 


\section{Appendix F}

\section{PARENT/CAREGIVER CONSENT FORM}

Title of Program: Photography Class: Using Photography to Make Sense of Individual and Social Identity in Relation to Racist Practices

Please check each box to show what activities you are willing and consent to have your child take part in.

\section{Information and Consent Form:}

I have read the information sheet about the research....................... (if yes, please check)

\section{Research Activities:}

I agree to have my child participate in the interview......................... please check)

I agree to have my child participate in a follow-up interview................... (if yes, please check)

I agree to have my child participate in participatory observation.................. (if yes, please check)

Use of Information:

I agree to have my child's interviews digitally recorded and examined........... $\square$ (if yes, please check)

I agree to have my child's participation digitally recorded and examined......... (if yes, please check)

Please print and sign your name to show that you agree to have your child take part in the Research Activities and the Uses of Information that have been checked:

I consent to (First, Last)

have my child join in the above activities of the research project that have been checked.

Signature of child's parent/caregiver: Date:

Please provide a phone number and email or mailing address where you may be reached to be invited to a discussion on the study's findings.

Phone Number:

Email or Mailing Address:

Two copies of the consent form are provided: one to be signed and returned to me for my own records and one for you to keep for your own records. 


\section{Appendix G}

\section{PARENT/CAREGIVER INFORMATION \& WRITTEN CONSENT SCRIPT}

Title of Research Project: Photography Class: Using Photography to Make Sense of Individual and Social Identity in Relation to Racist Practices

Date of ethics clearance: November 2015

Date of expiration for the project: August 31, 2016

Invitation to Participate: Your child is invited to participate in the research study called Photography Class: Using Photography to Make Sense of Individual and Social Identity in Relation to Racist Practices, that is being led by Davina Rousell, a doctoral student at Carleton University with the Department of Sociology and Anthropology under the supervision of Dr. Katharine Kelly who is cross appointed between Pauline Jewett Institute of Women's and Gender Studies Cross and the Department of Sociology and Anthropology.

Who is taking part

In order to take part in this study your child needs to be First Nations, a grade 7, 8, or 9 student attending Community School and taking part in the Photography Class.

Goal of the Study

This year the Photography Class is going to explore the topic of racism. The goal of this study is to learn about your child's ideas and experience with the Photography Class and with racism. For example, your child will be asked about their experience with the Photography Class and about their experience with racism. What they share will be used to strengthen the Photography Class and learn how to address racism.

What will you be asked to do?

If you and your child agree to take part in the study your child will be asked to take part in two activities, (1) participant observation and (2) an interview. They do not have to take part in this study. If you and your child do not agree to take part in this study they can still take part in the Photography Class.

Participant Observation

Your child will be asked to take part in an activity called participant observation. This means that I will take part in the Photography Class so that I can see what is going on. If you and your child agree, after each class is over I will write down what I saw during class so that I can learn more about the Photography Class, their experience with the Club and their experience with racism.

Interview

Your child will also be asked to take part in an interview. If you and your child agree, this activity will take 30 to 45 minutes and they will be asked to share their ideas and 
experience with the Photography Class and with racism. The interview will take place at their school and will be audio recorded. If your child does not want to be recorded I will take notes on what they share with me during the interview.

Your child might be asked to take part in a second interview. If you and your child agree, this second interview will take 15 to 30 minutes so that I can learn more about their ideas and experience with the Photography Class and with racism. The interview will take place at their school and will be audio recorded. If they do not want to be recorded I will only take notes on what they share with me.

Possible Benefits

By taking part in this research study, your child's ideas and experience will help to strengthen the Photography Class and learn how to address racism.

Possible Risks

I do not anticipate any risks involved with taking part in this study. But your child might talk about issues/problems that upset them. If this happens I will give you a sheet of paper that has a list of people that they can contact that can help them. If your child shares with me that they are at risk of being hurt or at risk of hurting someone else I need to share this information with the appropriate authority.

Confidentiality

Participant Observation

All participant observations will take place at the school during Photography Class classes. I will not take notes during class. I will only write down what I saw after each class has ended and when I am alone. My notes will not include any information that can be used to identify your child or their participation in the BookMaker. You will not have access to the notes nor will any other parents/caregivers or participants have access to the notes.

\section{Interview}

Interviews will be audio recorded. The recordings will be written out word for word and saved as an electronic document. This document will be given back to your child two weeks after the interview so that they can read it and make sure that it is correct. I will not tell anyone that your child took part in an interview and I will not share any of the information that your child shared with me during the interview. No other parents/caregivers of participants will have access to your child's transcript.

Use of Information

Your child's name will be replaced with a pretend name so that nobody, other than me, can tell what your child said or shared. Your child's name will not be used in any presentations, reports or papers about this study. The information collected will remain in a password protected storage box in my office located in my private home in Edmonton indefinitely. Only I (Davina Rousell) and my supervisor (Dr. Katharine Kelly) will have access to the information. The information will only be looked at again and used in the 
future for the goals shared in this sheet. If I would like to look at this information for a different reason I will contact you and your child to ask if both of you agree.

Can you quit?

Yes, you and your child can change your mind and your child can stop taking part in the study at any time. After the study ends in August 2016 you and your child have one month to remove your child from the study. If you or your child decide to remove your child from the study I will destroy any information that they shared with me, including any notes on their participation in the Photography Class.

Your Verbal Permission:

If you are willing to let your child take part in this study I will ask you to say out loud that you agree and we will fill-out the rest of this consent form together. Your child will be asked if they want to take part in this study. Even if you agree that your child can take part in this study the final decision is your child's to make.

Contact Names and Telephone Numbers:

This research project was reviewed and received ethics clearance by the Carleton University Research Ethics Board. If you have any concerns or questions about your involvement in the study please contact the chairs of Research Ethics Board. The chairs names and contact information are as follows:

Professor Louise Heslop, Chair

Professor Andy Alder, Vice-Chair

Research Ethics Board

Carleton University Research Office

Carleton University

511 Tory, 1125 Colonel By Drive

Ottawa, Ontario K1S 5B6

Tel: 613-520-2517 E-mail: ethics@carleton.ca

Do you have more questions?

If you have any questions or would like more information, you can ask me, Davina. My contact information as well as my supervisors' is below.

Thank you!

Davina Rousell, doctoral student

Carleton University

Department of Sociology and Anthropology

B750 Loeb Building, 1125 Colonel By Drive

Ottawa, ON, K1S 5B6

Phone: 780-862-0353

Email: davina.rousell@carleton.ca

Dr. Katharine Kelly, Supervisor

Carleton University 
Pauline Jewett Institute of Women's and Gender Studies 1424 Dunton Tower, 125 Colonel By Drive

Ottawa, ON, K1S 5B6

Phone: 613-520-2622

Email: katharine_kelly@carleton.ca 


\section{Appendix H}

\section{PARENT/CAREGIVER CONSENT FORM}

Title of Program: Photography Class: Using Photography to Make Sense of Individual and Social Identity in Relation to Racist Practices

As I read the different questions please let me know what boxes to check to identify the different activities you are willing and give permission for your child to take part in.

\section{Information and Consent Form:}

I have read the information sheet about the research....................... please check)

\section{Research Activities:}

I agree to have my child participate in the interview......................... please check)

I agree to have my child participate in a follow-up interview................... (if yes, please check)

I agree to have my child participate in participatory observation.................. (if yes, please check)

Use of Information:

I agree to have my child's interviews digitally recorded and examined........... $\square$ (if yes, please check)

I agree to have my child's participation digitally recorded and examined........ $\square$ (if yes, please check)

Please let me know, by saying yes, that you are willingness to allow your child to participate in the Research Activities and the Uses of Information that are checked above:

I have completed this consent form

on behalf of (Researcher's first and last name)

(Research participant's parent/caregiver first and last name)

who agrees to allow their child to

take part in the activities that are checked above.

Signature of researcher:

Date:

Location:

Please provide a phone number and email or mailing address where you may be reached to be invited to a discussion on the study's findings.

Phone Number: 
Email or Mailing Address:

Two copies of the consent form are provided: one to be signed and returned to me for my own records and one for you to keep for your own records. 


\section{Appendix I}

\section{SCHOOL STAFF INFORMATION LETTER \& WRITTEN CONSENT}

Title of Research Project: Photography Class: Using Photography to Make Sense of Individual and Social Identity in Relation to Racist Practices

Date of ethics clearance: November 2015

Date of expiration for the project: August 31, 2016

*Information under the following headings will be described verbally to potential participants.

Invitation to Participate: You are invited to take part in a research study called Photography Class: Using Photography to Make Sense of Individual and Social Identity in Relation to Racist Practices, that is being led by Davina Rousell, a doctoral student at Carleton University with the Department of Sociology and Anthropology under the supervision of Dr. Katharine Kelly who is cross appointed between Pauline Jewett Institute of Women's and Gender Studies Cross and the Department of Sociology and Anthropology.

Who is taking part In order to take part in this study you need to be a school personnel that is involved with Community School's Photography Class.

Goal of the Study

This year the Photography Class is going to explore the topic of racism. The goal of this study is to learn about your ideas and thoughts about the students experience with the Photography Class. For example, you will be asked about your role with the Photography Class and your observations about the students experience with the Club and learning about racism. What you share will be used to strengthen the Photography Class and/or learn how to address racism.

What will you be asked to do?

If you agree to take part in the study you will be asked to take part in an interview. You do not have to take part in this study.

Interview

You will also be asked to take part in an interview. If you agree, this activity will take 30 to 45 minutes and you will be asked to share your ideas and thoughts about the students experience with the Photography Class and learning about racism. The interview will take place at your school and will be audio recorded. If you do not want to be recorded I will take notes of what you share with me during the interview. 
You might be asked to take part in a second interview. If you agree, this second interview will take 15 to 30 minutes so that I can learn more about your ideas and thoughts about the students experience with the Photography Class and learning about racism. The interview will take place at the school and will be audio recorded. If you do not want to be recorded I will only take notes of what you share with me.

Possible Benefits

By taking part in this research study, your ideas and experience will help to strengthen the Photography Class and/or learn how to address racism.

\section{Possible Risks}

I do not anticipate any risks involved with taking part in this study. But you might talk about issues/problems that upset you. If this happens I will give you a sheet of paper that has a list of people that you can contact that can help you. If you share with me that you are at risk of being hurt or at risk of hurting someone else I need to share this information to the appropriate authority.

\section{Confidentiality}

Interview

Interviews will be audio recorded. The recordings will be written out word for word and saved as an electronic document. This document will be given back to you two weeks after the interview so that you can read it and make sure that it is correct. I will not tell anyone that you took part in an interview and I will not share any of the information that you shared with me during the interview. No other participants will have access to your transcript.

Use of Information

Your name will be replaced with a pretend name so that nobody, other than me, can tell what you said or shared. Your name will not be used in any presentations, reports or papers about this study. The information collected will remain in a password protected storage box in my office located in my private home in Edmonton indefinitely. Only I (Davina Rousell) and my supervisor (Dr. Katharine Kelly) will have access to the information. The information will only be looked at again and used in the future for the goals shared in this sheet. If I would like to look at this information for a different reason I will contact you to ask if you agree to this.

Can you quit?

Yes, you can change your mind and stop taking part in this study at any time. After the study ends in September 2016 you have one month to remove yourself from the study. If you decide to remove yourself from the study I will destroy any information that you shared with me, including any notes on your participation in the Photography Class.

Your signature

If you want to take part in this study I will ask you to sign the consent form to show that you agree to take part in the research study. 
Contact Names and Telephone Numbers:

This research project was reviewed and received ethics clearance by the Carleton University Research Ethics Board. If you have any concerns or questions about your involvement in the study please contact the chairs of Research Ethics Board. The chairs names and contact information are as follows:

Professor Louise Heslop, Chair

Professor Andy Alder, Vice-Chair

Research Ethics Board

Carleton University Research Office

Carleton University

511 Tory, 1125 Colonel By Drive

Ottawa, Ontario K1S 5B6

Tel: 613-520-2517 E-mail: ethics@carleton.ca

Do you have more questions?

If you have any questions or would like more information, you can ask me, Davina. My contact information as well as my supervisors' is below.

Thank you!

Davina Rousell, doctoral student

Carleton University

Department of Sociology and Anthropology

B750 Loeb Building, 1125 Colonel By Drive

Ottawa, ON, K1S 5B6

Phone: $780-862-0353$

Email: davina.rousell@carleton.ca

Dr. Katharine Kelly, Supervisor

Carleton University

Pauline Jewett Institute of Women's and Gender Studies

1424 Dunton Tower, 125 Colonel By Drive

Ottawa, ON, K1S 5B6

Phone: 613-520-2622

Email: katharine_kelly@carleton.ca

Thank you! 


\section{Appendix J}

\section{SCHOOL STAFF WRITTEN CONSENT FORM}

Title of Program: Photography Class: Using Photography to Make Sense of Individual and Social Identity in Relation to Racist Practices

Please check each box to show what activities you agree to take part in.

Information and Assent Form:

I have read the information sheet about the research....................... please check)

Research Activities:

I agree to take part in the interview................................... $\square$ (if yes, please check)

I agree to take part in a second interview............................... $\square$ (if yes, please check)

Use of Information:

I agree to have interviews recorded and examined..................... (if yes, please check)

Please print and sign your name to show that you agree to take part in the Research Activities and the Uses of Information that are checked above:

I agree to

(First, Last)

take part in the checked research activities.

Signature of participant:

Date:

Below please write your phone number and email address or mailing address so that I can contact you to review your interview document and the study's findings.

Phone Number:

Email or Mailing Address:

Two copies of the consent form are provided: one to be signed and returned to me for my own records and one for you to keep for your own records. 


\section{Appendix K}

\section{SCHOOL STAFF INFORMATION LETTER \& VERBAL CONSENT}

Title of Research Project: Photography Class: Using Photography to Make Sense of Individual and Social Identity in Relation to Racist Practices

Date of ethics clearance: November 2015

Date of expiration for the project: August 31, 2016

*Information under the following headings will be described verbally to potential participants.

Invitation to Participate: You are invited to take part in a research study called Photography Class: Using Photography to Make Sense of Individual and Social Identity in Relation to Racist Practices, that is being led by Davina Rousell, a doctoral student at Carleton University with the Department of Sociology and Anthropology under the supervision of Dr. Katharine Kelly who is cross appointed between Pauline Jewett Institute of Women's and Gender Studies Cross and the Department of Sociology and Anthropology.

Who is taking part In order to take part in this study you need to be a school personnel that is involved with Community School's Photography Class.

Goal of the Study

This year the Photography Class is going to explore the topic of racism. The goal of this study is to learn about your ideas and thoughts about the students experience with the Photography Class. For example, you will be asked about your role with the Photography Class and your observations about the students experience with the Club and learning about racism. What you share will be used to strengthen the Photography Class and/or learn how to address racism.

What will you be asked to do?

If you agree to take part in the study you will be asked to take part in an interview. You do not have to take part in this study.

Interview

You will also be asked to take part in an interview. If you agree, this activity will take 30 to 45 minutes and you will be asked to share your ideas and thoughts about the students experience with the Photography Class and learning about racism. The interview will take place at your school and will be audio recorded. If you do not want to be recorded I will take notes of what you share with me during the interview. 
You might be asked to take part in a second interview. If you agree, this second interview will take 15 to 30 minutes so that I can learn more about your ideas and thoughts about the students experience with the Photography Class and learning about racism. The interview will take place at the school and will be audio recorded. If you do not want to be recorded I will only take notes of what you share with me.

Possible Benefits

By taking part in this research study, your ideas and experience will help to strengthen the Photography Class and/or learn how to address racism.

\section{Possible Risks}

I do not anticipate any risks involved with taking part in this study. But you might talk about issues/problems that upset you. If this happens I will give you a sheet of paper that has a list of people that you can contact that can help you. If you share with me that you are at risk of being hurt or at risk of hurting someone else I need to share this information to the appropriate authority.

\section{Confidentiality}

Interview

Interviews will be audio recorded. The recordings will be written out word for word and saved as an electronic document. This document will be given back to you two weeks after the interview so that you can read it and make sure that it is correct. I will not tell anyone that you took part in an interview and I will not share any of the information that you shared with me during the interview. No other participants will have access to your transcript.

Use of Information

Your name will be replaced with a pretend name so that nobody, other than me, can tell what you said or shared. Your name will not be used in any presentations, reports or papers about this study. The information collected will remain in a password protected storage box in my office located in my private home in Edmonton indefinitely. Only I (Davina Rousell) and my supervisor (Dr. Katharine Kelly) will have access to the information. The information will only be looked at again and used in the future for the goals shared in this sheet. If I would like to look at this information for a different reason I will contact you to ask if you agree to this.

Can you quit?

Yes, you can change your mind and stop taking part in this study at any time. After the study ends in September 2016 you have one month to remove yourself from the study. If you decide to remove yourself from the study I will destroy any information that you shared with me, including any notes on your participation in the Photography Class.

Your Verbal Permission:

If you are willing to take part in this study I will ask you to say out loud that you agree and we will fill-out the rest of this consent form together. 
Contact Names and Telephone Numbers:

This research project was reviewed and received ethics clearance by the Carleton University Research Ethics Board. If you have any concerns or questions about your involvement in the study please contact the chairs of Research Ethics Board. The chairs names and contact information are as follows:

Professor Louise Heslop, Chair

Professor Andy Alder, Vice-Chair

Research Ethics Board

Carleton University Research Office

Carleton University

511 Tory, 1125 Colonel By Drive

Ottawa, Ontario K1S 5B6

Tel: 613-520-2517 E-mail: ethics@carleton.ca

Do you have more questions?

If you have any questions or would like more information, you can ask me, Davina. My contact information as well as my supervisors' is below.

Thank you!

Davina Rousell, doctoral student

Carleton University

Department of Sociology and Anthropology

B750 Loeb Building, 1125 Colonel By Drive

Ottawa, ON, K1S 5B6

Phone: $780-862-0353$

Email: davina.rousell@carleton.ca

Dr. Katharine Kelly, Supervisor

Carleton University

Pauline Jewett Institute of Women's and Gender Studies

1424 Dunton Tower, 125 Colonel By Drive

Ottawa, ON, K1S 5B6

Phone: 613-520-2622

Email: katharine_kelly@carleton.ca

Thank you! 


\section{Appendix L}

\section{SCHOOL STAFF VERBAL CONSENT FORM}

Title of Program: Photography Class: Using Photography to Make Sense of Individual and Social Identity in Relation to Racist Practices

As I read the different questions please let me know what boxes to check to identify the different activities you are willing to take part in.

Information and Consent Form:

I have read the information sheet about the research.................... please check)

Research Activities:

I agree to take part in the interview..................................... please check)

I agree to take part in a second interview............................. please check)

Use of Information:

I agree to have interviews recorded and examined.................... $\square$ (if yes, please check)

Please let me know, by saying yes, that you are willingness to take part in the Research Activities and the Uses of Information that are checked above:

I have completed this consent form on behalf of

(Research participant's first and last name) who agrees to take part in the

activities that are checked above.

Signature of researcher:

Date:

Location:

Please provide a phone number and email or mailing address where you may be reached to be invited to a discussion on the study's findings.

Phone Number:

Email or Mailing Address: 
Two copies of the consent form are provided: one to be signed and returned to me for my own records and one for you to keep for your own records. 


\section{Appendix M}

\section{Research Assistant and Confidentiality Agreement}

Title of Research Project: Photography Class: Using Photography to Make Sense of Individual and Social Identity in Relation to Racist Practices

This agreement is between Research Assistant and Researcher

The Research Assistant will be compensated for a total of $\$ 1500.00$ at the beginning of the study to assist with the following tasks as outlined in the Research Agreement.

- To assist with the consent gathering process by helping the researcher connect with parents/guardians and potential research participants (please note that the researcher is responsible for gathering consent).

- To assist with the interview process by helping the researcher reconnect with potential research participants (please note that the researcher is responsible for conducting interviews).

- To assist with the verification process and presentation of findings by helping the researcher reconnect with parents/guardians and research participants (please note that the researcher is responsible for the verification process and presentation of findings).

- To keep all the research information with regards to potential research participants and their guardian/caregiver confidential by NOT discussing or sharing who was contacted to participate in the research study with anyone other than the researcher (Davina Rousell).

Signatures indicate that the Research Assistant and the Researcher agree to this agreement as outlined above.

Research Assistant's (print name): Signature:

Researcher (print name):

Signature:

Date: 


\section{Appendix N}

\section{STUDENT INTERVIEW GUIDE}

Project Title: Photography Class: Using Photography to Make Sense of Individual and Social Identity in Relation to Racist Practices

Initial Open-ended Questions

1. How did you come to take part in the Photography Class?

2. Can you describe to me what happened when you first started to go to the Photography Class? For example, what did you do? What did you talk about? [N.B. Probe for how did you feel (excited and/or worried)]

3. Do you think that it became easier for you after attending for a while? [If yes] Why do you think it became easier? [If no] Why not? [N.B. Probe here for feelings about identity, discrimination].

4. What types of activities do you find the most interesting/fun? Can you explain why you like those the best?

5. What types of activities, do you dislike? Can you explain why you dislike them?

6. Could you describe the most important teaching that you learned while going to the Photography Class?

Intermediate/Follow-up Questions

1. What, if anything, did you know about racism before the Photography Class?

2. Tell me about your thoughts and feelings when you first learned about racism.

3. When, if at all, did you first experience racism [or see racism]?

a. [If so] Can you share what this experience was like for you? [N.B. Probe here for feelings about identity, discrimination].

4. Since taking part in the Photography Class how, if at all, have your thoughts and feelings about racism changed how you think about [yourself, your community, yourself in community] [N.B. Probe here for feelings about identity, discrimination]?

a. [If yes] Why do you think these changes happened? [If no] Why not?

5. How would you describe how you viewed yourself before taking part in the Photography Class?

a. How, if at all, has your view of yourself changed?

b. How, if at all, has your view of your community changed?

c. How, if at all, has your view of yourself in your community changed?

6. Tell me how you would describe the person you are now?

a. [If they have indicated a change] Tell me about what contributed to this change [its continuity]?

7. When you look back over your experience with the Photography Class, are there any event or experience that stand out in your mind?

a. [If so] Could you describe [each one] it? [If no] Why not?

b. [If so] How did this event impact what happened? 
c. [If so] How did you respond to [the event; the resulting situations]?

8. What changes, if any, have occurred in your life since taking part in the Photography Class?

9. Where do you see yourself in two years?

a. Describe the person you hope to be then.

b. How would you compare the person you hope to be and the person you see yourself as now?

c. What challenges might you face?

d. [If so] Tell me about the source of these challenges? [If no] Why not? [N.B. Probe here for feelings about identity, discrimination].

Closing Questions

1. Have you grown as a person since taking part in the Photography Class?

a. [If so] Tell me about your strengths that you discovered or developed through your involvement in the Photography Class. [If no] Why not?

b. What do you value most about yourself now?

c. What do others most value about you?

2. After having these experiences, what advice would you give to someone who has just heard about the Photography Class and is thinking about taking part?

3. Is there anything else you think I should know to understand your experience with the Photography Class better?

4. Is there anything you would like to ask me?

*Questions have been adapted from Kathy Charmaz's (2006; 2014) work.

\section{References}

Charmaz, K. (2006). Constructing grounded theory: A practical guide through qualitative analysis. Thousand Oaks, CA: Sage Publications.

Charmaz, K. (2014). Constructing grounded theory $\left(2^{\text {nd }}\right.$ ed.). Thousand Oaks, CA: Sage Publications. 


\section{Appendix 0}

\section{SCHOOL STAFF INTERVIEW GUIDE}

\section{Project Title: Photography Class: Using Photography to Make Sense of Individual and}

Social Identity in Relation to Racist Practices

\section{Initial Open-ended Questions}

1. How did you come to take part in the Photography Class?

2. Can you describe to me what happened when you first started to be involved with the Photography Class? For example, what was your role? What did you talk about? [N.B. Probe for how did you feel (excited and/or worried)]

3. Do you think that it became easier for the students after attending the program for a while? [If yes] Why do you think it became easier? [If no] Why not? [N.B. Probe here for feelings about identity, discrimination].

4. What types of activities do you think the students enjoyed the most or found the most interesting/fun? Can you explain why you think they like these activities best?

5. What types of activities, do you find that the students disliked? Can you explain why you think they disliked these activities?

6. Could you describe what teaching you think was the most important that students learned while going to the Photography Class?

Intermediate/Follow-up Questions

1. What, if anything, do you think the students knew about racism before the Photography Class?

2. Since taking part in the Photography Class how, if at all, do you think that the students' thoughts and feelings about racism changed how they think about [themselves, their community, themselves in community] [N.B. Probe here for feelings about identity, discrimination]?

a. [If yes] Why do you think these changes happened? [If no] Why not?

3. How would you describe how the students viewed themselves before taking part in the Photography Class?

a. How, if at all, has their view of themselves changed?

b. How, if at all, has their view of their community changed?

c. How, if at all, has their view of themselves in your community changed?

4. When you look back over the students experience with the Photography Class, are there any event or experience that stand out in your mind?

a. [If so] Could you describe [each one] it? [If no] Why not?

b. [If so] How did this event impact what happened?

c. [If so] How did you respond to [the event; the resulting situations]?

5. What changes, if any, have you seen occur in the students' lives since taking part in the Photography Class?

Closing Questions 
1. Have you seen the students grown as individuals since taking part in the Photography Class?

a. [If so] Tell me about the strengths that you observed developed through their involvement in the Photography Class. [If no] Why not?

2. After having been part of the Photography Class, what advice would you give to someone who has just heard about this program and is thinking about taking part?

3. Is there anything else you think I should know to understand the students' experience with the Photography Class better?

4. Is there anything you would like to ask me?

*Questions have been adapted from Kathy Charmaz's (2006; 2014) work.

\section{References}

Charmaz, K. (2006). Constructing grounded theory: A practical guide through qualitative analysis. Thousand Oaks, CA: Sage Publications.

Charmaz, K. (2014). Constructing grounded theory ( $2^{\text {nd }}$ ed.). Thousand Oaks, CA: Sage Publications. 


\title{
Appendix P
}

\section{RESEARCH AGREEMENT}

\author{
between \\ Davina Rousell with Carleton University, \\ Community School \\ and \\ Chief and Council
}

This research agreement, effective the 1st ${ }^{\text {th }}$ day of October, 2015 and ending the 31st day of October, 2016 is between Davina Rousell, Community School and Nehiyaw/Cree First Nation Community Chief and Council.

\section{A. General}

With this research agreement Davina Rousell, a doctoral student at Carleton University with the Department of Sociology and Anthropology under the supervision of Dr.

Katharine Kelly who is cross appointed between Pauline Jewett Institute of Women's and Gender Studies Cross and the Department of Sociology and Anthropology is formally seeking permission to conduct the research study outlined in Section $\mathrm{C}$ of this agreement in partnership with the Community School with the permission of Nehiyaw/Cree First Nation Community Chief and Council. In addition, Davina Rousell agrees to deliver all of the deliverables outlined in Section B of this agreement.

\section{B. Responsibilities and Deliverables}

The researcher is responsible for designing and conducting a research study of the Photography Class program at Community School in an ethical, transparent, respectful and safe manner. In particular, Davina Rousell is responsible for designing the research study as well as the ethical and traditional protocol. Elder E. B. and S. H. will review the research design, the ethics and traditional protocols to ensure they are appropriate and meaningful for research participants, the Community School and the Nehiyaw/Cree First Nation Community Chief and Council. Davina Rousell will make all revisions requested by Elder E. B. and S. H. at any time during the research study provided these revisions do not compromise Carleton University ethical research practices. Once data has been collected Davina Rousell is responsible for the data preparation, conducting analysis, verifying data with research participants as well as the preliminary and final findings, writing the final reports, and presenting the research results to the research participants, Community School and Chief and Council.

The researcher will report to S. H. and Elder E. B. on behalf of Community School and Chief and Council. In collaboration with Elder E. B., S. H. and her thesis supervisor, Dr. Katharine Kelly, the researcher will be responsible for making timely decisions regarding the overall research plan and its components. S. H. will assist the researcher in connecting with potential participants and, as much as is possible, assist the researcher in resolving logistical barriers that may be encountered while conducting the research study. 
The researcher, Davina Rousell will be responsible for obtaining free and informed consent from all participants and their parents/caregivers, for collecting and analyzing data as well as writing the final reports and providing presentations. The researcher, from beginning to end will be held to highest of ethical standards and will be conducted in accordance with ethical standards set-out in the Tri-Council Policy Statement and follow the principles of Community Based Research (e.g., research to be conducted for, by, with community and is mutually beneficial to community and the researcher).

The researcher is responsible for and will deliver the following deliverables:

1. Copy of approved Research Ethics Application (Completed by October 2015)

2. Copy of Research Proposal (Completed by October 2015)

3. Potential participants identified and free and informed consent from parents/caregivers and their child/participant (Completed by October 2015)

4. Data collection (Completed by June 2016)

5. Preliminary data analysis (Completed by August 2016)

6. Verification of preliminary findings (Completed by June 2016)

7. Copy of Research Report tailored to community interests and needs (e.g., documents and discusses the benefits and challenges related to the Photography Class and recommendations for strengthening the current program (Completed by October 2016)

8. Copy of Dissertation (Completed by October 2016)

A deliverable will not be considered satisfactorily completed until it is approved/accepted by Chief and Council and the thesis supervisor, Dr. Katharine Kelly. If a deliverable is not approved/accepted by Chief and Council and the thesis supervisor, specific reasons for its disapproval/rejection must be provided to the evaluator within two weeks of the deliverable's receipt so that the evaluator can address any and all concerns in a timely fashion.

C. Overview of Proposed Research Study

The Photography Class is a class offered at Nehiyaw/Cree First Nation's Community School since 2010 that uses photography to help youth explore their individual and social identity in relation to different social phenomena. This year the Photography Class is exploring the social phenomenon of racist practices. The research study seeks to ask how First Nations youth use photography to make sense of their individual and social identity in relation to such practices.

Purpose of the Study: The purpose of this study is to learn about the students' ideas and experience with the Photography Class and racism. For example, students will be asked about their experience with the Photography Class and their experience with racism. What students share will be used to strengthen the Photography Class and learn how to address racism between non-First Nations and First Nations peoples. 
Who will be Asked to Participate: Grade 7, 8 and 9 students taking part in the Photography Class will be asked to take part in the study.

What will Participants be Asked to Do? If participants agree to take part in the study, they will be asked to take part in two activities, (1) participant observation and (2) an interview.

Participant Observation: This activity will require the participant's willingness to allow me to observe them as part of the group of students who are participating in the Photography Class. If students agree, I will take part in each class in order to observe and learn about the Photography Class and how it impacts the students' use photography to make sense of their individual and social identity in relation to racist practices.

Interview: This activity will require 30-45 minutes of the participant's time. During the interview the participants will be asked to share their ideas and experience with the Photography Class. The interview will be held at Community School or a safe place chosen by the interviewee.

Possible Benefits for Research Participants: This study may or may not have any direct benefits for participants. However, it is hoped that the participants will benefit from the opportunity to discuss, share and reflect on their experiences with the Photography Class. It is also hoped that the participants' knowledge and experience will lead to the development of a model that fundamentally reflects First Nations youths' experience with racist practices thereby providing First Nations, researchers, policy-makers and governing bodies a framework to better understand and address these negative practices between Canada's First Nations and non-First Nations peoples. It is also hoped that participants will benefit from the research findings being used to strengthen the current Photography Class.

Possible Benefits for the School and Chief and Council: This study may or may not have any direct benefits for Community School or Chief and Council of First Nation Community. However, it is hoped that the school and Chief and Council will benefit from having the opportunity learn about and more fully understand the impacts, benefits and challenges related to the Photography Class and from having the opportunity to use the study's findings to strengthen the current program and share the findings with different stakeholders.

Possible Risks for Research Participants: I do not anticipate any risks involved with taking part in this research study. However, there is a chance that during an interview a participant might talk about issue/problem in their life that they find upsetting. If this happens, I will share a resource leaflet with the participant that has contact information for people that can help them, which includes S. H. and School Elders. If a participant shares that they are at risk of being harmed or at risk of harming others I will share this information with the appropriate authorities (e.g. S. H.) who are familiar with the School's policies and procedures for these types of situations. 
Use of Information \& Confidentiality: In all of the information that is collected, participants' names will be replaced with a fake name so that nobody, other than myself, can tell what a participant said or shared. Participants' real names will never be used in any presentations, reports or papers about this study. All of the information collected will remain in a password protected storage box in my office located in my private home in Edmonton indefinitely. Only I (Davina Rousell) and my supervisor (Dr. Katharine Kelly) will have access to collected information. The collected information will only be looked at again and used in the future for the purpose and topic described in this agreement. If in the future I would like to use the data for a purpose that is different from what is described in this document, I will contact each participant to ask for their permission.

Can participants quit? Yes, parents/caregivers and/or their child (the participants) can change their mind and stop taking part in this research study or any part of the study (participant observation or interview) at any time and up until the research project has ended in August 2016 parents/caregivers and participants have one month to withdraw from the study. Should the parent/caregiver or participant decide to withdraw from the study the information that the participant shared will be destroyed.

Consent: If a parent/caregiver is willing to allow their child to take part in this study I will ask them to sign a consent form or to provide verbal permission to indicate that they agree to have their child take part in the research study and the two different activities (participant observation and interview).

If a student is willing to participate in this study I will ask them to sign an assent form or to provide verbal permission to show that they agree to take part in the research study and the two different activities (participant observation and interview).

\section{Termination}

This agreement can be terminated by either party (i.e., Chief, Principal, Researcher) with 15-day written notice.

\section{E. Statement of Work}

The researcher agrees to perform the activities outlined in this agreement and partners agree to their named activities within this project and the deliverables outlined in Section $\mathrm{B}$ of this agreement.

As duly authorized representatives of this research partnership, the signatures below indicate agreement with the aforementioned roles, responsibilities and deliverables.

\section{PARTNERS}

CHIEF, on behalf of First Nation Community, 
Signature:

Date:

Name:

PRINCIPAL on behalf of the Community School,

Signature:

Date:

Name:

RESEARCHER, on behalf of Carleton University, Davina Rousell:

Signature:

Date:

Name: 